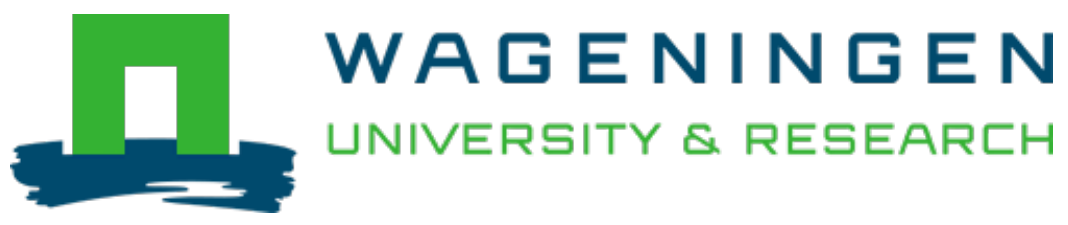

\title{
Meteorological aspects of heavy precipitation in relation to floods - An overview
}

Earth-Science Reviews

Breugem, A.J.; Wesseling, J.G.; Oostindie, K.; Ritsema, C.J.

https://doi.org/10.1016/j.earscirev.2020.103171

This publication is made publicly available in the institutional repository of Wageningen University and Research, under the terms of article $25 \mathrm{fa}$ of the Dutch Copyright Act, also known as the Amendment Taverne. This has been done with explicit consent by the author.

Article $25 \mathrm{fa}$ states that the author of a short scientific work funded either wholly or partially by Dutch public funds is entitled to make that work publicly available for no consideration following a reasonable period of time after the work was first published, provided that clear reference is made to the source of the first publication of the work.

This publication is distributed under The Association of Universities in the Netherlands (VSNU) 'Article $25 \mathrm{fa}$ implementation' project. In this project research outputs of researchers employed by Dutch Universities that comply with the legal requirements of Article $25 \mathrm{fa}$ of the Dutch Copyright Act are distributed online and free of cost or other barriers in institutional repositories. Research outputs are distributed six months after their first online publication in the original published version and with proper attribution to the source of the original publication.

You are permitted to download and use the publication for personal purposes. All rights remain with the author(s) and / or copyright owner(s) of this work. Any use of the publication or parts of it other than authorised under article $25 \mathrm{fa}$ of the Dutch Copyright act is prohibited. Wageningen University \& Research and the author(s) of this publication shall not be held responsible or liable for any damages resulting from your (re)use of this publication.

For questions regarding the public availability of this publication please contact openscience.library@,wur.nl 


\title{
Meteorological aspects of heavy precipitation in relation to floods - An overview
}

\author{
A.J. Breugem*, J.G. Wesseling, K. Oostindie, C.J. Ritsema \\ Wageningen University and Research Centre, Department of Soil Physics and Land Management, Droevendaalsesteeg 3, P.O. Box 47, 6700 AA Wageningen, The \\ Netherlands
}

\section{A R T I C L E I N F O}

\section{Keywords:}

Heavy precipitation

Characteristics

Ingredients

Classification

Storm types

Climate change

\begin{abstract}
A B S T R A C T
Floods do have multiple aspects: they are integral phenomena by nature. In this paper we deal with the meteorological aspects, which need to be adequately understood in order to understand the occurrence and development of floods. This holds the more as different meteorological environments and accompanying mechanisms can result in different types of heavy precipitation and so in different flood responses. In this paper, the meteorological aspects of floods are described from the perspective of a precipitation event. The characteristics, the categorisations and the ingredients of the storm systems are presented. The influences of global warming on heavy precipitation events will be discussed as well. The sequence of these aspects reads as a logical succession of the distinct topics of the meteorological aspects of a heavy precipitation event. Since floods commonly have a profound impact on environment and society, the understanding of the meteorological aspects is a first and necessary step in a challenge of dealing with floods. The ultimate goal of this step is to diminish the harmful consequences of floods as adequately as possible.
\end{abstract}

\section{Introduction}

Flooding can have a strict meteorological cause: usually precipitation is (directly or indirectly) responsible for flooding. Consequently, to understand flooding as a phenomenon it is necessary to understand its meteorological causes. The understanding of the meteorology entails the unravelling of the responsible storm systems and the accompanying production of rain, as well as the relationship between the storm system and the production of rain.

It is important to make a hydrometeorological analysis of the storm system responsible for heavy precipitation events. This analysis, which is based upon observations, delivers the characteristics of a storm system (system structure, motion and evolution). As heavy precipitation events manifest themselves at small scales and with high spatiotemporal variability, high resolution monitoring by ground-based sensors or satellites is required to improve their characterisation (Rios Gaona et al., 2018). The analysis of these characteristics determines the mechanisms of the production of rain (e.g. orographic and frontal rainfall) with which the meteorological processes and factors responsible for the heavy precipitation (e.g. convergence and warm air advection) can be assessed. The analysis of these processes and factors finally provides insights in the ingredients of heavy precipitation events (e.g. moisture content and instability). This is helpful to better understand hydrometeorological controls of a flood (e.g. intensity and duration). Distinguished characteristics of a heavy precipitation event can have specific meteorological causes and hydrological consequences. The relationships between these characteristics and meteorological causes or hydrological impacts can be unravelled through such analysis. The hydrometeorological analysis provides the necessary insights into the causes of floods. If the causes of a flood are understood, next the flood itself (both its generation and development), as well as the hydrologic response of catchments to precipitation events, can be better explained. This understanding will assist in the prevention of serious floods and may prevent financial damages.

If a hydrometeorologist understands the meteorological environment and accompanying mechanisms and features conducive to the generation and development of heavy rainfall, the hydrometeorologist will be able to model the storm system and predict its associated characteristics. With these predictions the hydrometeorologist is capable to predict the resulting precipitation event to assess the heavy precipitation potential. The hydrometeorological modelling provides additional insights into the causes of floods. The better the understanding of the responsible meteorological mechanisms and features, the better the forecasting of precipitation events and the better the estimation of their intensity, frequency and duration. In this context the possibility to distinguish a heavy rainfall event from a normal one with

\footnotetext{
* Corresponding author.

E-mail address: arjan.breugem@wur.nl (A.J. Breugem).
} 
their precursor signals and anomalies in (thermo-)dynamic variables is of crucial importance (Lima et al., 2010; Milrad et al., 2009a; Milrad et al., 2014; Nugent and Rios-Berrios, 2018; Toreti et al., 2016) Due to their small space-time scales, prediction of both location and initiation time of heavy precipitation producing storms together with the amount or intensity appears to be a complex task (Ducrocq et al., 2014; Fiori et al., 2017; Iwai et al., 2018; Moore et al., 2003; Rios Gaona et al., 2018). This prediction is commonly called quantitative precipitation forecasting (Buzzi et al., 2014; Chen et al., 2010; Demirtaş (2016) and provides basic information for increasing the preparedness to heavy precipitation storms like tropical cyclones because of the vast amounts of rain they carry (Rios Gaona et al., 2018).

When this prediction happens timely, precipitation now-casts can be made and the flooding potential can be assessed qualitatively in advance. If, however, the precipitation predictions function as input of a hydrological model, the flooding potential can be predicted quantitatively and in advance. The better the forecasting of precipitation, the better the forecasting of flood events. In both cases, the prediction of a flooding potential is of great value because herewith timely and location specific alerts can be given and more directed flood protection measures can be developed. In this context the possibility to distinguish a flash flood from a non-flash flood is of crucial importance as flash floods commonly are highly disastrous (De Vries et al., 2016; Konrad, 1997; Terranova and Gariano, 2014). This way authorities and inhabitants timely can take their preparations by which harmful consequences of flooding can be diminished.

Another advantage of understanding the meteorological situations of flooding is the possibility to design and adapt a more- targeted monitoring network to accurately measure the adequate meteorological variables. In this way a much more accurate determination of the precipitation as physical input of a catchment can be made. If the precipitation can be determined more accurately both in time and space, the possibility of a severe flooding can be predicted in advance or the realised flooding can be better analysed afterwards. Therefor an accurate determination of this input is highly needed.

In this paper about the meteorological causes of floods the most important word is 'event'. We present a comprehensive overview of the meteorological aspects of a flood event. A compilation of the main meteorological aspects is presented, such as the characteristics of a precipitation event, the criteria of a heavy precipitation event, the ingredients (or pre-conditions) of the meteorological processes and factors responsible for the development of a heavy precipitation event and the storm systems that deliver these processes. Finally, we describe how global warming might influence the meteorological processes that are relevant for heavy precipitation.

We use the words 'rainfall' and 'precipitation' interchangeably, though in our opinion 'rainfall' is the physical processes of rain formation and 'precipitation' the liquid water as monitored by a measuring apparatus. To increase the readability of the text, we have chosen to use acronyms as little as possible.

In this paper we discuss the physical aspects of a heavy rain event and the papers concerning these aspects. The layout of the paper is presented in Fig. 1. Numerical models and modelling techniques are not presented here on purpose as we think that subject is worth a separate study.

\section{Characteristics of a single (heavy) precipitation event}

Severe flooding is often caused by due to one or (generally) multiple heavy rainfall events. But what is meant by heavy rainfall? In literature several classification systems for the heaviness or severity of rainfall events can be found. The severity of those events depends on several characteristics of a rainfall event. Therefore, before discussing classification systems, we first have to discuss some characteristics. In hydrology and related earth sciences, the main characteristics (also called properties or descriptors) of a single rainfall event used at a site are total rainfall depth, duration, peak rainfall intensity and average rainfall rate (see e.g. Dunkerley, 2008a; Gaál et al., 2014; Hanel and Máca, 2014). These characteristics will be described below. The related classification systems will be discussed in the next section.

Rainfall is commonly reported as falling in events. But how is a rain event identified or defined? Many criteria exist to identify individual rain events (Dunkerley, 2008a, 2008b, 2015; Dunkerley, 2010; Gaál et al., 2014; Hanel and Máca, 2014). The most commonly used criterion is the minimum inter-event time (MIT, in h) criterion. With this criterion, an individual rain event is identified as a period of rainfall whose beginning and end are defined by rainless intervals of at least a minimum inter-event time. The minimum inter-event time specifies an essentially arbitrary rainless period with a wide range of values, often 6 - 8h (Dunkerley, 2010). As both type and scale of a study area are relevant in view of the hydrological response, these area characteristics have also to be taken into consideration when dealing with the minimum inter-event time. Usually, this minimum inter-event time criterion is combined with supplementary event criteria like minimum event depth and minimum event rate, to compound rain event criteria. The actual length of time between events is the inter-event time (IET, in h)(Dunkerley, 2008b).The statistical distribution of the inter-event time is strongly positively skewed (Acreman, 1990; Dunkerley, 2008b; Guo et al., 2006). Acreman (1990) defined the temporal distribution of rain intensity within an event as the event profile that is controlled by the mechanism of rainfall in particular cases (Dunkerley, 2008a). An overview of the main characteristics of a rainfall event as used in this section is given in Table 1 .

A consequence of using a fixed minimum inter-event time is that intra-event rainless periods are included within a rain event and therefore rainfall events mostly are intermittent events. The rain event characteristic intra-event rainfall intermittency (IERI, -) refers to the time fraction (in percentage of event duration) of no-rain periods (according to a no-rain criterion) during an event and logically depends on the value of the minimum inter-event time (Dunkerley, 2015). Intraevent rainfall intermittency results from precipitation mechanisms that operate over timescales from seconds to hours (Dunkerley, 2015). This minimum inter-event time value does not say anything about the presence or nature of intense bursts within a defined event (Dunkerley, 2010). Intra-event rainfall intermittency depends on rain characteristics of the enclosing rainfall event: it tends to decline with increasing rainfall depth, rainfall rate and rainfall duration. Contiguous no-rain periods of a rain event occupy about $14 \%-50 \%$ of the mean event duration (Dunkerley, 2015).

The value of minimum inter-event time substantially influences the number and characteristics of identified rainfall events (Fig. 2). A larger minimum inter-event time permits longer intra-event rainless periods that lengthens defined rainfall events and therefore decreases the number of events. Consequently, it increases the intraevent variability in rain rates and lowers the event mean rain rate (Dunkerley, 2008b, 2015; Dunkerley, 2010; Hanel and Máca, 2014). Large values of minimum inter-event time sometimes are chosen on purpose to seek independence among the events (Dunkerley, 2008b; Dunkerley, 2010).

The total amount of rain fallen in a rain event is called the rainfall depth (also called event depth) and commonly denoted as rainfall amount $\left(D_{e}\right.$, in mm). It is a characteristic that is not systematically considered in literature, presumably because of its straightness and easiness. That doesn't mean depth is an unimportant characteristic: rainfall depth is frequently mentioned in literature, often on a daily basis and not on an event basis. This is in agreement with Dunkerley (2008a) who remarks that rain events are often classified in terms of depth of rain delivered in 24 hours. In these terms, there are many accounts of very large daily rainfall depths that are often sustained over several days (Dunkerley, 2008a). In this respect, Dunkerley (2008b) mentions daily rainfall totals of $400-600 \mathrm{~mm}$. These data are often obtained from studies dealing with cyclonic or other intense rains. 


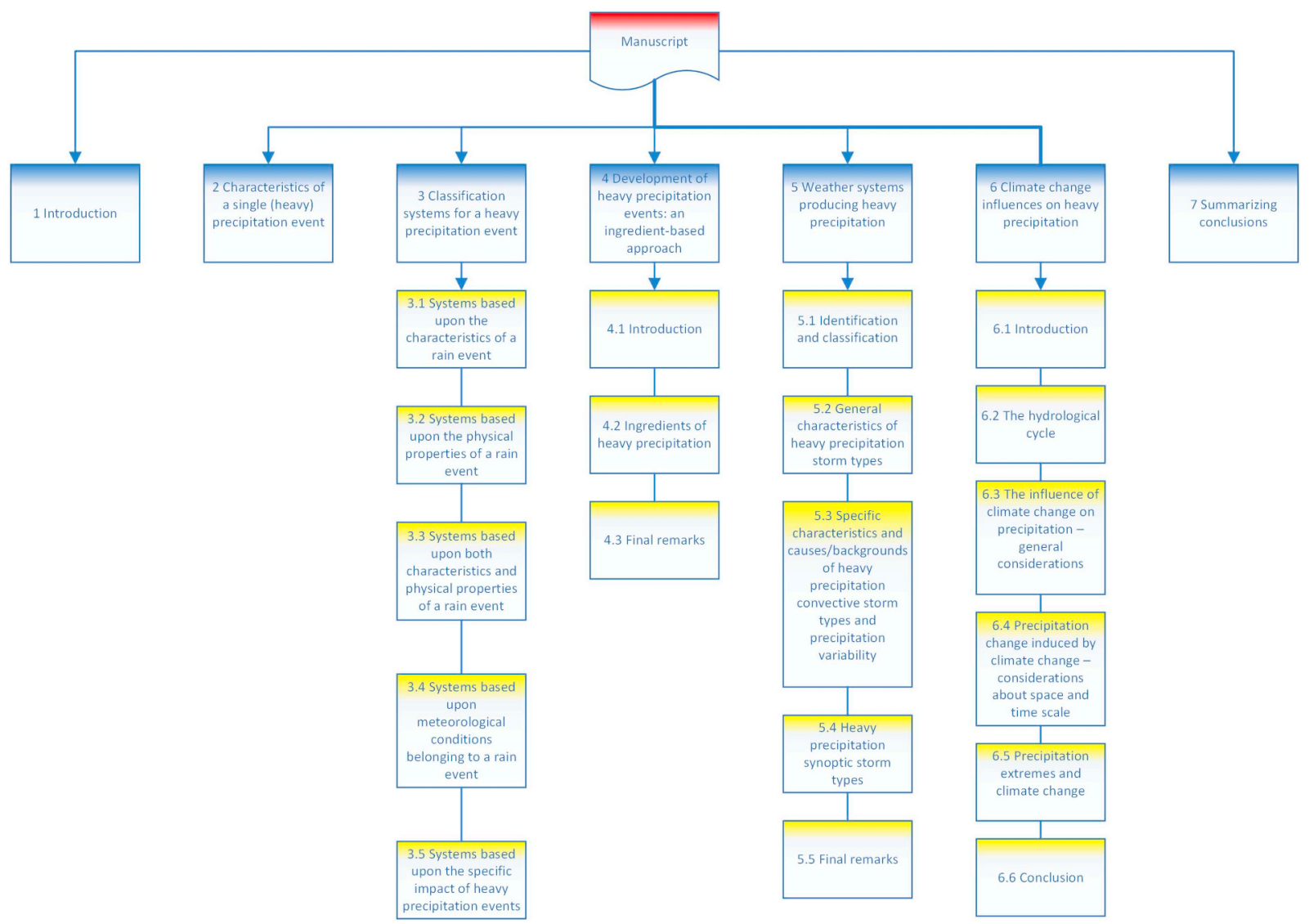

Fig. 1. The structure of the paper.

Table 1

The main characteristics of a precipitation event.

\begin{tabular}{ll}
\hline Characteristic & Unit \\
\hline Minimum intervention time & $\mathrm{h}$ \\
Inter-event time & $\mathrm{h}$ \\
Intra-event rainfall intermittency & - \\
Duration & $\mathrm{h}$ \\
Amount & $\mathrm{mm}$ \\
Rain rate & $\mathrm{mm} \mathrm{h}^{-1}$ \\
Rain intensity & $\mathrm{mm} \mathrm{h}^{-1}$ \\
Maximum rain intensity & $\mathrm{mm} \mathrm{h}^{-1}$ \\
Area or Spatial extent & $\mathrm{km}^{2}$ \\
\hline
\end{tabular}

Statistically seen, it has been established that the distribution of event depth is strongly positively skewed (Acreman, 1990; Dunkerley, 2008b; Guo et al., 2006), just like the distribution of daily event depth is
(Gochis et al., 2006). This skewness is generally due to the fact that light-event rain depths are much more frequently observed than moderate- or heavy-event rain depths. Besides the integration of the rainfall amount over time, this amount also can be integrated over the area where rain falls (Schumacher et al., 2011).

Besides rain intensity, rain duration is one of the major factors that control floods (Liu, 2011). Rain duration ( $T_{e}$, usually presented in hours), is the length of a single event. According to Dunkerley (2008a), there is a considerable variability in event durations. Some events last longer than a day, while many last less than an hour. In their study of 10278 rain events, Vilar and Burgueño (1995) found the average duration of a rainfall event to be about 30 minutes. The statistical distribution of event duration is (also) strongly positively skewed (Acreman, 1990; Dunkerley, 2008b; Guo et al., 2006). The most common duration is the one with event durations ranging from about

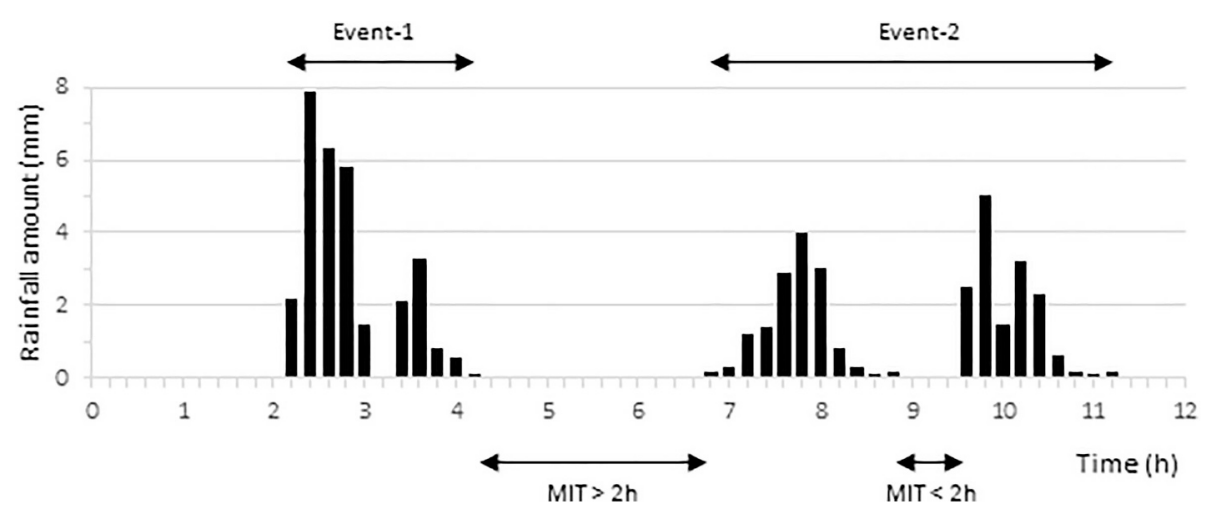

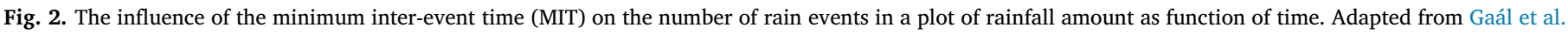
(2014). Only if the inter-event time between two events is above a certain minimum, the associated events are considered as two separate events. 
10 to 15 minutes. This duration refers to more intense rain events that last for only a small fraction of total rain time (Dunkerley, 2008a). Rainfall duration depends on the motion of both individual rain cells and the precipitation system as a whole (Curtis, 2017).

A distinction can be made between short-duration, long-duration and persistent precipitation events. Short-duration events last 1 hour (convective precipitation) to 4-6 hours (stratiform precipitation), longduration events last one day and persistent events last longer than one day (Brommer et al., 2007; Budikova et al., 2010; Lenderink and Van Meijgaard, 2010; Liu and Wu, 2016). Tang et al. (2006) describe persistent events by several characteristics as high intensity (no day below $25 \mathrm{~mm} \mathrm{~d}^{-1}$ ), broad extent and persistent (more than 4 days) and stable existence (relatively stable rain band). Besides the large impact of shortduration events, long-duration (as caused by a tropical cyclone) and persistent events (as caused by a wet spell during a monsoon) also can have a profound impact on a region through a greater potential for (more prolonged and extensive) flooding because of saturated soil conditions.

Rain rate can be considered as the most used rain event characteristic (though rain rate is commonly denoted as rain intensity in literature). Most classification systems (as will be seen later) are based upon this characteristic. Within a rainfall event considerable variations in rain rate occur, even when rain is continuous (Dunkerley, 2008b). Dunkerley (2008a) distinguishes two types of rain rates: the average or event rain rate $\left(R_{e}\right.$, in $\left.\mathrm{mm} \mathrm{h}^{-1}\right)$, which is based upon the duration of an entire rain event, and the interval rain rate $\left(R_{t}\right.$, in $\left.\mathrm{mm} \mathrm{h}^{-1}\right)$, which is based upon a prescribed interval such as $6 \mathrm{~min}, 30 \mathrm{~min}, 1 \mathrm{~h}, 24 \mathrm{~h}$ etc. Statistically seen, the distribution of event rain rate is strongly positively skewed (Acreman, 1990; Dunkerley, 2008b; Guo et al., 2006). The majority of rain events therefore has an event rain rate well below the mean event rain rate that is based upon the event rain rates of all events considered. The mean rain rate of a rain event often lies in the range $0.5-5 \mathrm{~mm} \mathrm{~h}^{-1}$ (Dunkerley, 2008a).

Besides the use of event rain rate (or interval rain rate) also rain intensity (or instantaneous rain rate) is commonly used. Rain intensity (I, in $\mathrm{mm} \mathrm{h}^{-1}$ ), is effectively an instantaneous rain rate, i.e. with integration times of $10 \mathrm{~s}$ or less (Dunkerley, 2008a). With respect to rain intensity, Dunkerley (2008a) and Dunkerley (2010) distinguished the frequently mentioned largest instantaneous rate $\left(I_{\max }\right.$ or $I_{P}$ ) encountered in the rain event and rain intensity from relatively short intra-event durations $\left(\mathrm{I}_{30}\right.$, or intra-event rain rate. Differences between intra-event rain rates and the mean rain rate of an event indicate there are short bursts of rain that may occur within longer rainfall events (Dunkerley, 2010). It underpins the intra-event variability in rain rates.

It is important to be aware of the distinctions made in the definitions of rain rate. Rain rates associated with a long integration time are essentially means, while those associated with short integration times can approach instantaneous or peak rain rates (Pelletier et al., 2009). According to Dunkerley (2008a) it is widely recognized that the meaning or the significance of measured rainfall rates varies with the integration or the aggregation time used to define the rate (hour, day, event, etc.). The distinction between the largest instantaneous rate and the average rain rate is important because of the widespread finding that large portions of the total rainfall in an event are received within a small fraction of the event time, regardless of the event duration (Dunkerley, 2008a). Finally, the accurate reader can derive from the above that the meaning of the $30 \mathrm{~min}$ interval rain rate equals that of intra-event rain rate.

The spatial extent (or spatial scale) of a precipitation event (A, in $\mathrm{km}^{2}$ ) is the area on which a rainfall producing system delivers its precipitation. Because of the probable motion of a rainfall system, this area isn't necessarily the same as the area preoccupied by the system itself. Konrad (2001) distinguished local-, medium- and large-scale events with sizes of $2500,10.000$ and $500.000 \mathrm{~km}^{2}$ respectively. In addition, Smith et al. (1994b) made a distinction between isolated heavy precipitation events affecting less than $1000 \mathrm{~km}^{2}$ and large-area affecting areas larger than $10.000 \mathrm{~km}^{2}$. The size or scale of a heavy precipitation event is an important characteristic because it affects the scale of the flooding potential (Boers et al., 2016).

The characteristics of natural rain events are discussed independently. However, interdependencies between characteristics do exist. In addition, these characteristics as well as their interdependences are dependent on the definition of a rain event and on the value of minimal inter-event time (Bracken et al., 2008; Dunkerley, 2008a; Dunkerley, 2010; Haile et al., 2011; Hand et al., 2004). Event depth is positively correlated with event duration. The mean event rain rate shows a negative correlation with event duration. Between rain depth and average rain rate both negative and positive correlations exist (Dunkerley, 2008a; Haile et al., 2011; Hanel and Máca, 2014). Gaál et al. (2014) show that intense warm season events - usually associated with convection - have practically no correlation between peak intensity and event duration (while when all storms are considered including stratiform rain this correlation was significantly positive), peak intensity is less strongly correlated to total rainfall depth, and average rain intensity is more strongly negatively correlated with duration in the intense event set than for all events that include events of a stratiform nature. The positive correlation between peak rain rate and rain duration (as mentioned by Gaál et al. (2014)) also holds for other intraevent rain rates, i.e. intra-event rain rate of several short durations (Dunkerley, 2010). Finally, longer (and hence generally less intense) events actually contain periods of higher intra-event rain rate of short durations. Intra-event rainfall intermittency is negatively correlated with depth, duration and mean rain rate of the enclosing rain event (Dunkerley, 2015).

From the literature on common rainfall event characteristics of which the above is a brief summary, it has become clear that rainfall events can be described with several characteristics that are correlated with each other. In fact, this correlation is an indication of a certain meteorological origin of an event, as can be reasoned by the results of Acreman (1990) and Gaál et al. (2014). These characteristics are essential ingredients in both the classification and the understanding of the nature and effects of (extreme) rain events, or as stated by Dunkerley (2008a): "Only by focusing more attention on rain events and their properties will we be able to develop a fuller understanding of how rain events should be identified to yield the most explanatory power in studies of streamflow generation, soil erosion, and other processes."

Strictly speaking, location also can be indicated as a characteristic of heavy precipitation. Recently, the location of heavy precipitation has received research interest in view of the ability and accuracy of its prediction (Li et al., 2017). Because of the strong interaction between the land surface and the location of heavy precipitation, it is crucial to know its location.

In this section so far no explicit attention has been paid to snowfall. Nevertheless, it is important to distinguish between rain and snow. In cold climates and at high elevations (mountainous areas) precipitation particularly can occur as snowfall (instead of rain). Later on this snowfall will melt at a much different intensity; snowmelt as water input intensity can even surpass the intensity of heavy rainfall (Fassnacht and Recrods, 2015; Harpold and Kohler, 2017).

\section{Classification systems for a heavy precipitation event}

Categorisation or classification of the severity of rainstorms or precipitation events is very useful for several purposes: identification and communication of extreme meteorological conditions in warning and disaster prevention operations, assessment of impacts, design of engineering solutions, and benchmarking and comparison of precipitation events (Wu et al., 2015b). A central question in this respect is: when can a certain rainfall event be identified and classified as a heavy one?

Though many different classification systems exist in literature, five 
main groups of systems can be distinguished based on i) rain event characteristics; ii) rain event physical properties; iii) both rain event characteristics and rain event physical properties; iv) meteorological conditions and v) specific impacts of heavy precipitation events. These classification systems will be discussed successively in the following sections.

\subsection{Systems based upon the characteristics of a rain event}

A widely-used classification of rain event durations does not exist, but events are often classified by the depth of rain delivered in 24 hours (Dunkerley, 2008a). One example of such a classification system is presented by Gochis et al. (2006), who define rain events as 'light' if 24h depths are less than $10.0 \mathrm{~mm}$, 'moderate' if depths are between $10.0 \mathrm{~mm}$ and $50.8 \mathrm{~mm}$ (or $2 \mathrm{in}$.), and 'heavy' if the depth exceeds 50.8 $\mathrm{mm}$. The Spanish National Meteorological Institute characterises depths of more than $15 \mathrm{~mm}$ as heavy (Gaál et al., 2014), while the WMO (2008) characterises depths between 10 and $50 \mathrm{~mm}$ as heavy and those exceeding $50 \mathrm{~mm}$ as violent. Chen et al. (2004) however define rainfall events as heavy if depths exceed $100 \mathrm{~mm}$ over at least three stations. Easterling et al. (2000) present a list of thresholds (ranging between 20 and $100 \mathrm{~mm}$ ) that define heavy rain events for a number of countries in the world. In China, heavy precipitation is defined as two rain intensities $\left(20 \mathrm{~mm} \mathrm{~h}^{-1}\right.$ or $100 \mathrm{~mm} \mathrm{~d}^{-1}$ ) (Luo and Chen, 2015). In Korea, the definition of heavy precipitation is based on both precipitation intensities, precipitation duration and areal coverage (Jeong et al., 2014b). These examples show that the depth for the classification of an event as heavy can differ considerably from one region to another based on the local climate, duration and areal coverage. That the number of considered stations can be relevant in the classification of an event.

Several classifications of rain rate exist (Dunkerley, 2008a). The representative classification of Tokay and Short (1996) introduced six different categories, as shown in Table 2. Pawlina (2002) and Dairaku et al. (2004) define rain rates smaller than $5 \mathrm{~mm} \mathrm{~h}^{-1}$ as weak and rates larger than $5 \mathrm{~mm} \mathrm{~h}^{-1}$ as strong. Vilar and Burgueño (1995) classify a rain rate larger than $10 \mathrm{~mm} \mathrm{~h}^{-1}$ as heavy. These few examples show the variation in the categories used and in the ranges they represent. Huff (1967) expanded previous classifications dividing a rain event into quartiles and classifying the event depending on the quartile in which the highest rain rate occurred. The concept of Huff has been applied manifold and worldwide (Al-Rawas and Valeo, 2009; Terranova and Gariano, 2014). Gaál et al. (2014) note that the severity of events not only depends on the event depth and the temporal resolution of rain data, but also on event duration and (peak) rainfall intensity. The statistical properties of rainfall events and their interdependencies both are of fundamental importance for practical and scientific purposes.

Compared to the preceding classification systems, much more complicated classification systems have been developed as well. These systems consider one rain event variable with different duration or aggregation times (Casas et al., 2004) or consider two or more rain event variables simultaneously with (Pinto et al., 2013) or without (Molini et al., 2009; Wu et al., 2015a) aggregation times. Casas et al. (2004); Casas et al. (2010) developed an intensity index (IP) that is a measure of the severity and complexity of the rain event. It is based

Table 2

Rain rate classification according to Tokay and Short (1996) taken from Dunkerley, 2008b.

\begin{tabular}{ll}
\hline Descriptive rain rate category & Rain rate $\mathrm{R}\left(\mathrm{mm} \mathrm{h}^{-1}\right)$ \\
\hline Very light & $<1$ \\
Light & $1 \leq \mathrm{R}<2$ \\
Moderate & $2 \leq \mathrm{R}<5$ \\
Heavy & $5 \leq \mathrm{R}<10$ \\
Very heavy & $10 \leq \mathrm{R}<20$ \\
Extreme & $\geq 20$
\end{tabular}

upon the maximum intensities registered for every event in four characteristic durations ( $5 \mathrm{~min}, 1,2$ and $24 \mathrm{~h}$ ). These intensities represent the contribution of local, small and large meso- and synoptic scale processes respectively in the origin of an event. The intensity index can be used to classify extreme rainfall events (with return periods equal to or larger than 5 years) into four clearly differentiated groups that respectively represent local rainfall events (with clear seasonality and daily cycle), very active fronts moving slowly (with mesoscale convective complexes and clear seasonality), synoptic rainfall events and events showing high rainfall rate for large range of durations associated to both mid and synoptic scale processes (mesoscale structures embedded into synoptic systems). The classification of Pinto et al. (2013) can be considered as a spatial extension of that of Casas et al. (2004, 2010). They combined the intensities with the affected area of every event in five specific durations. According to Pinto et al. (2013) "both the spatial and temporal distribution of rainfall intensities and extension of the events must be considered in order to interpret the integral effects of precipitation in terms of flooding". Molini et al. $(2009,2010)$ introduced a hydro-meteorological classification system for extreme rain events (at which at least one gauge receives $50 \mathrm{~mm}$ in $1 \mathrm{~h}$ ) in which these events were divided in two classes, long-lived and spatially distributed class 1 events and short-lived and smaller class 2 events. It is presumed that differences exist in the meteorology of them that is of importance in the production of timely hydrological estimates. Wu et al. (2015b) developed the severity index (SI) to quantify the severity and magnitude of a rain event (having daily depths larger than $50 \mathrm{~mm}$ ) with the aid of its peak intensity, peak amount, outer and inner area. Due to quantification of storm severity with respect to historical rainstorms in a certain region, severity index is applicable to places of different climate regimes.

\subsection{Systems based upon the physical properties of a rain event}

In literature we found two physically-based classification systems: Llasat's system dealing with the convection process itself and Harat's system dealing with the consequences of this process. Llasat (2001) developed a classification system of rainfall events based upon their convective character, quantified by the convectivity index $(\beta *)$. Rain events with a convectivity index equal to 0 are classified as non-convective and events with a convectivity index between 0.75 and 1.0 as very convective. In addition, she discovered that very convective events (I $>40 \mathrm{~mm} \mathrm{~h}^{-1}$ ) last less long than $1 \mathrm{~h}$, while the slightly convective ones $\left(\mathrm{I}<10 \mathrm{~mm} \mathrm{~h}^{-1}\right)$ last longer than $5 \mathrm{~h}$. The moderate convective events have an intermediate duration which is seasonally dependent. The very and moderately convective events broadly correspond to unior multi convective cells and highly organised convective systems respectively. Other convective characteristics are Convective Available Potential Energy (CAPE), the $\mathrm{K}$ index and the bulk wind shear (Funatsu et al., 2008; Milrad et al., 2015). Harats et al. (2010) developed the Modified K-Index (MKI) and the Rain Dynamic Index (RDI) with which the potential for heavy rainfall can be assessed. The Modified K-Index, a lightning index, is used to evaluate the lightning activity or instability in thunderstorms and the Rain Dynamic Index, the vertically integrated upward moisture flux within the free troposphere, is used to evaluate the rain rate. Values of 25 and 20 are presented as critical values for Modified K-Index and Rain Dynamic Index respectively. As far as torrential rain is concerned, the location and timing of extreme values of both indices agree. The Rain Dynamic Index can be derived for different spatial scales giving the opportunity to determine scale-dependent factors responsible for the heavy rainfall event.

\subsection{Systems based upon both characteristics and physical properties of a rain event}

The classification systems found differ in the use of the physical properties. In the system of Gaál et al. (2014) the presence of lightning 
(which is a meteorological property) is used as an indicator for convection while the adjustment time scale of the system of Molini et al. (2011) is used as the indicator for synoptic influence on convection. Gaál et al. (2014) developed a system to classify intense warm season rainfall events where convection is present. They used the $10 \mathrm{~min}$ peak in rainfall intensity $\left(\mathrm{I}_{\mathrm{P}}\right)$ to characterize these events and $\mathrm{I}^{*}$ as the threshold value in their classification. $I^{*}$ is estimated with the aid of lighting data as external variable that indicate the convective character of these events. The classification system of Molini et al. (2011) is a supplement to that of Molini et al. (2009). This supplement entails the incorporation of the convective adjustment time scale to assess the adjustment time of (local) convection to changes in the synoptic environment. Short convective adjustment times (smaller than 6h) imply a rapid response of local convection to changes in the synoptic environment. This means that the synoptic factors dominate the local ones and the large-scale production of CAPE (a physical measurement of the instability; see Tudurí and Ramis (1997)) and of Helicity (H, an approximate measurement of type and strength of warmth advection, Tudurí and Ramis (1997)) is balanced by its convective consumption. Long times indicate that local factors dominate over the synoptic factors implying that large-scale production of CAPE over longer time scales is superior due to the local-scale inhibition of convection. The value of this dynamical classification, is to discover the differences in meteorological environments in which the two event types of Molini et al. (2009) occur.

\subsection{Systems based upon meteorological conditions belonging to a rain event}

Large-scale heavy rainfall events have been related to extreme largescale (synoptic) meteorological conditions. According to Müller et al. (2009) the synoptic situation of a heavy rainfall event can be characterized by the extremeness of certain dynamic and thermodynamic meteorological variables, and these variables are distinctly correlated with the extremity of rainfall events. A composite extremeness (EM) index based on these variables has been developed to evaluate the variables as a whole because only opportune coincidence makes the synoptic situation dangerous. Days with minimal extremeness index values regularly correspond to heavy rainfall events in the region. Analogously to the extremeness index, (Kašpar and Müller, 2014) developed the Circulation Extremity Index (CEI). In this case, the meteorological circulations producing heavy large-scale rainfall can be characterized by combinations of large-scale meteorological field anomalies, expressed as extremeness of certain meteorological variables. A combination of these variables results in the Circulation Extremity Index; high values of Circulation Extremity Index regularly correspond to heavy rainfall events in the region. These events are usually associated with frontal boundaries and cyclones (Kašpar and Muiller, 2014). Another large-scale example is the Asia-India summer monsoon circulation index of Ranade and Singh (2014). This index is correlated with the rain depth of the main monsoon wet spell rain depth and can be used to estimate the rain depth from the large-scale monsoon intensity.

Loriaux et al. (2016) statistically investigated the atmospheric conditions and large-scale forcing of heavy precipitation events (with increasing precipitation intensity) in the mid-latitudes to understand their relationships and to assess potential indicators for these events. They observed that stronger events are characterised by an increasing instability and moisture content and by a stronger large-scale convergence or vertical velocity. As positive relations between these variables and precipitation intensity are weak, no one single indicator for heavy precipitation can be derived, unlike the tropics, where strong relations exist between large-scale convergence or vertical velocity and precipitation intensity (Davies et al., 2013). In addition, these investigators observed that stronger events react with a stronger temporal signal of these variables with respect to the time of the peak intensity. In a follow-up study, Loriaux et al. (2017) corroborated the results of
Loriaux et al. (2016) with a simulation experiment: an increase of heavy convective precipitation is the result of an increase of the factors caused by large-scale convergence, instability and relative humidity. This increase of heavy precipitation is manifested by an effect upon precipitation area (due to large-scale convergence) and precipitation intensity (due to instability and relative humidity).

\subsection{Systems based upon the specific impact of heavy precipitation events}

The heaviness (or severity) of a heavy rainfall event can also be described in terms of specific impacts the rainfall event leads to. Wu et al. (2015b) mention the Landslide Potential Index (LPI), which describes the relative heaviness of a rainfall event (in comparison with the heaviest one) with respect to the number of landslides caused in Hong Kong. Another example is the Universal Soil Loss Equation in which the event-based soil loss is related to the ' $\mathrm{R}$ ' factor that describes rainfall erosivity as an expression of the rain event characteristics $\mathrm{E}$ (rainfall kinetic energy) and $\mathrm{I}_{30}$ (Dunkerley, 2008b; Hanel and Máca, 2014). Dunkerley (2008a) also gives the index cumulative erosion potential of De Ploey et al. (1991). Hanel and Máca (2014) give indices of intra-event sediment pollution of McCarthy et al. (2012). A common characteristic of the indices given is that they directly relate rainfall event characteristics to a specific impact caused by that rainfall event.

\section{Development of heavy precipitation events: an ingredient- based approach}

\subsection{Introduction}

In the following sections we'll present a brief discussion of the meteorological causes of heavy precipitation. Chappell (1986) states that the heaviest precipitation occurs where the rainfall rate is the highest for the longest time. In fact, this statement may imply that precipitation (on a certain location on earth) is equal to the product of rainfall rate and duration of the rainfall. The rain intensity is assumed to be proportional to the vertical moisture flux, which is equal to the product of the ascent rate and the mixing ratio of the rising air. High rainfall rates are associated with large vertical moisture fluxes (i.e. rapid ascent of moist air). This means that rising air should have a substantial water vapour content and a rapid ascent rate if a high condensation rate and a high rainfall rate are to develop. The rain intensity is supposed to be equal to the product of the precipitation efficiency and the vertical moisture flux. The precipitation efficiency deals with the fact that not all water vapour that flows into a cloud, falls out as precipitation on earth. If at least one of the three ingredients for high rainfall (precipitation efficiency, ascent rate, mixing ratio of the rising air) is large (while the other ingredients are at least moderate) the potential for high rain intensities exists and this potential increases as precipitation efficiency, ascent rate, and/or mixing ratio of the rising air increase. Besides a high rain intensity, heavy precipitation is also determined by the duration of rainfall: a slow movement of the rainfallproducing system causes a long duration of high rain intensities (Doswell et al., 1996).

From a methodological or physical point of view, high rainfall rates, or simply said, large vertical moisture fluxes, require three basic ingredients: moisture, lifting and instability. The way by which heavy precipitation has been created can vary from case to case at different moments or locations on earth. However, these basic ingredients function as a common thread in the plethora of heavy precipitation events and form a methodological framework by which the physical base of their high rain intensities can be unravelled (Doswell et al., 1998). Large vertical fluxes are mostly -but not solely- related to deep, moist convection and non-convective high rain rates also fit in this framework (Doswell et al., 1996). Deep, moist convection occurs only if sufficient amounts of these ingredients are simultaneously present in the area, though a weaker value of one ingredient can be counterbalanced by a 
higher value of another (Doswell et al., 1996; Lin et al., 2001; Nuissier et al., 2008). A well-known quantity of the moisture content of the air is the precipitable water. It is a measure of the depth of liquid water in a column of air if it is completely condensed to the surface (Aylward and Dyer, 2010).

A combination of these ingredients, conducive for the generation of heavy precipitation, can be found in a wide variety of synoptic and mesoscale situations (both environments and processes) (e.g. Maddox et al. (1979)). Those situations can be associated with a wide variety of rainfall-producing systems or storm types (Doswell et al., 1996; Doswell et al., 1998; Lin et al., 2001; Moore et al., 2015). The ingredients of a heavy precipitation event together with their meteorological situations (conditions) are successively described in section 4.2 and the rainfallproducing systems in section 5.3 and 5.4 .

\subsection{Ingredients of heavy precipitation}

In this section the five ingredients that cause heavy precipitation will be discussed in more detail: moisture, lifting, instability, duration and precipitation efficiency.

\subsubsection{Moisture and its large-scale transport}

In order to obtain the formation of rainfall in a region, the transport of water vapour - moisture advection - is necessary. Only when there is a sufficiently large supply of water vapour a high rainfall rate can take place. Moisture advection is governed by certain synoptic-scale situations - also indicated as large-scale forcing (De Vries et al., 2016; Doswell, 1987; Doswell et al., 1996; Milrad et al., 2010a; Milrad et al., 2014; Moore et al., 2015; Nuissier et al., 2008; Roberge et al., 2009). These synoptic-scale situations are characterised by certain synoptic flow structures that generate certain transport mechanisms of moisture and heat. Synoptic flow structures appear as upper- and lower-level height or pressure anomalies and upper-level potential vorticity anomalies upstream (i.c. westward on northern hemisphere due to the westward flow of the upper-level flow or jet stream) of a heavy precipitation event (Funatsu et al., 2009; Konrad, 1997). These anomalies are associated with a certain synoptic configuration of troughs at the upper-level and their associated cyclones (low-pressure areas) or fronts of cyclones at the lowerlevel. These synoptic structures generate and intensify a southerly, lowlevel flow of moist and warm air (moisture advection and warm air advection respectively.) into the precipitation region if they flow over adjacent warm seas or warm and moist land surfaces and appear as low-level ridges very near the precipitation region (Konrad, 1997; Maddox et al., 1979). This low-level flow entails a cyclonic flow or a low-level jet in the warm sector preceding cold or slow-moving fronts, that focusses and feeds the precipitation system (Aylward and Dyer, 2010; Budikova et al., 2010; Delrieu et al., 2005; Doswell et al., 1998; Konrad, 2001; Kozaric and Ivančan-Picek, 2006; Lin et al., 2001; Moore et al., 2015; Nuissier et al., 2008; Ramis et al., 1997; Warner and Mass Jr., 2012). In this respect Lin et al. (2001), Nuissier et al. (2008), Ducrocq et al. (2008) and Dayan et al. (2015) deliberately speak about transport of moist, conditionally or convectionally unstable air. Conditionally unstable air is air that can rise if it becomes saturated and convectionally unstable air is air that is able to rise after certain forced convection has taken place. in both cases the air has become lighter than its environment. This common southerly low-level flow (on northern hemisphere) can be combined with northern upper-level cold air flowing into the region of precipitation and contribute both to the instability of the air (Nuissier et al., 2008; Ivančan-Picek et al., 2003). Warm areas appear as positive temperature anomalies and moist areas as positive water vapour anomalies on weather maps. Anomalously high water vapour values alone are not sufficient to produce heavy precipitation. If the low-level flow is weak or displaced by a weakened or displaced jet stream (low moisture advection) the resulting upward velocities are too low for the release of sufficient (conditional or convective) instability and so for the formation of rain (Warner and Mass Jr., 2012).

Many heavy precipitation events (associated with a certain synoptic configuration) have a different or additional moisture meridional lowlevel transport being concentrated within shallow, narrow, elongated corridors from distant upwind sources of often tropical origin vapour into the precipitation region (Smith et al., 2000; Couto et al., 2012; Neiman et al., 2013; Mahoney et al., 2016). This transport of moisture is known as tropical plumes or atmospheric rivers and they can be characterised as distinct flows of moist air stretching from the (sub) tropics into the mid-latitudes (Catto and Pfahl, 2013; Dayan et al., 2015; Milrad et al., 2015; Moore et al., 2015; Warner and Mass Jr., 2012; Zhu and Newell, 1994; Zhu and Newell, 1998) and located in the lower troposphere with in the warm sector of extratropical cyclones and within areas of strong wind (Lavers et al., 2011). Low-level jets and atmospheric rivers are the two main low-level, large-scale meteorological structures that play an important role in the large-scale atmospheric moisture transport, the former in the (sub)tropical regions (primarily in warm season) and the latter in the extratropical regions (Gimeno et al., 2016). Atmospheric rivers and low-level jets occur in both coastal (after landfall) and inland regions (after inland penetration) (Gimeno et al., 2016; Neiman et al., 2013). Both migratory and stationary atmospheric rivers exist (Moore et al., 2012). Migratory atmospheric rivers are migratory rivers that develop over the ocean in connection with precold-frontal low-level jets associated with (extra) tropical cyclones and slow-moving subtropical lows (or depressions) (Moore et al., 2012) and have a seasonally variable impact on a region (Mahoney et al., 2016). These rivers are embedded within a broader region of generally poleward heat transport in the warm sector of these extratropical cyclones (usually referred to as the warm conveyor belt) that have a variable position (Neiman et al., 2013). These atmospheric rivers supply warm conveyor belts with moisture (Sodemann and Stohl, 2013) and are often associated with heavy precipitation (Ralph et al., 2006; Lavers et al., 2011) at the downwind end of atmospheric river conditions due to dynamical uplift in these belts (Gimeno et al., 2016). In contradiction, stationary atmospheric rivers are static rivers that develop in association with stationary synoptic-scale flow that maintained strong and persistent low-level jets (Moore et al., 2012). Besides eastward transport of mid-latitude upperlevel troughs (see before) also equatorward transport (intrusion) of mid-latitude upper-level troughs to low-latitudes occurs. This intrusion instigates tropical low-level transport of moisture into the precipitation region. This large moisture transport takes place in zones, tropical moisture exports, and is often conducted by atmospheric rivers towards cyclones and warm conveyor belts (Gimeno et al., 2016). The accompanying heavy precipitation events are an example of tropicalsubtropical interactions that often occur in semiarid and subtropical regions (De Vries et al., 2016).

Heavy precipitation events can also occur in synoptic configurations at which accompanying height anomalies are associated with certain ridges/anticyclones at upper-level and their associated high-pressure areas at low-level. In this case high-pressure disturbances coexist with troughs/cyclones and low-pressure systems. These upper-level highpressure ridges/low-level high-pressure systems are the cause of the blocking of the synoptic-scale flow and of the impediment of the propagation of convective situations responsible for heavy precipitation. As these synoptic-scale systems are quasi-stationary they play an important role in the persistence of the convective system which helps to produce long-lasting, persistent rainfall (Ramis et al., 1997; Lin et al., 2001; Nuissier et al., 2008; Lima et al., 2010; Mastrangelo et al., 2011; Dayan et al., 2015; Milrad et al., 2014, 2015; Sun et al., 2015; Yang et al., 2017b). In addition to blocking of anticyclones/ridges, Hellström (2005) and (Milrad et al., 2009b; Milrad et al., 2010b; Milrad et al., 2014; Milrad et al., 2015) remarked that these high-pressure systems also play an important role in moisture transport and air modification, while cyclones/troughs account for the majority of heavy precipitation events. According to Lin et al. (2001), also tropical cyclones or fronts can induce quasi-stationarity to the synoptic-scale flow and De Vries et al. (2016) reported about an quasi upper-level trough 
that together with persistent advection of moist air towards the precipitation area can result in a long-lasting precipitation period. You et al. (2010) observed that deep advection of warm air is related to a longer precipitation period and a higher precipitation rate. Large-scale tropical and monsoon related circulation systems (together with underlying lower boundary conditions) may also cause long-lasting precipitation periods (Lee et al., 2017a; Liu and Wu, 2016). Liu and Wu (2016) conclude that the duration of precipitation events depends on the duration of specific circulation phenomena.

The intensity of these upper-level structures can vary from strong and deep depressions to weak and shallow ones and even in some cases a cyclone is not present (Doswell et al., 1998; Ivančan-Picek et al., 2014; Nuissier et al., 2008). Also, when a cyclone-related low-level jet is absent, heavy precipitation can occur if quasi-geostrophic induced low-level flow impinges a mountain range (Massacand et al., 1998; Milrad et al., 2015; Wang et al., 2014b). A low-level jet is a low-level air stream caused by a large temperature gradient across the cold and warm sector of a cyclone. In addition, the presence of a cyclone or cold front doesn't always mean that a low-level jet occurs while a heavy precipitation event can develop as the study of Lima et al. (2010) shows. Also the speed of these structures can vary from quasi-stationary (while inducing or maintaining low-level flow) to transient. In this last case upper-level potential vorticity anomalies exist that are associated with the eastward propagation of troughs or cyclones due to deepening of the trough/cyclone in the neighbourhood of the left exit of a jet streak. This eastward propagation leads to positive vorticity advection and results into a strong large-scale quasi-geostrophic ascent of the low-level air on the eastern flank of the trough in the precipitation region (Ivančan-Picek et al., 2003; Dayan et al., 2015; Toreti et al., 2016). Also warm air advection (thermal advection) leads to large-scale quasigeostrophic ascent of low-level air (Ramis et al., 1997; Ivančan-Picek et al., 2003). In case of positive vorticity advection, accompanying large-scale flow features encourage dynamic lifting and in case of thermal advection, thermodynamic lifting (Konrad, 1997). Potential (positive) vorticity anomalies can also be caused by the intrusion of dry, stable stratospheric air with large cyclonic vorticity into the upper-level. This so-called tropopause fold can induce low-level cyclonic vorticity thereby contributing to vertical motion (e.g. Bennett et al., 2006; Massacand et al., 2001; Martius et al., 2006; Jeong et al., 2014b).

In an attempt to classify weather systems in Europe, Porcú et al. (2003) discovered the presence of a (marked) potential vorticity anomaly as a common characteristic of the analysed events. According to these scientists, this anomaly is the most significant indicator of severity of heavy precipitation events, regardless the origin of cyclones and regardless the presence of convection. Massacand et al. (1998) state that potential vorticity often is an endemic precursor or trigger for heavy precipitation events. The upper-level flow anomalies commonly form through Rossby wave breaking and take the shape of a streamer (a meridionally elongated trough), a cut-off or occasionally a broad trough (Barton et al., 2016; Martius et al., 2006). Generally, in case of heavy precipitation the upper-level trough is smaller and also deeper (Funatsu et al., 2009). This precursor can be considered as a dynamical link between the large-scale flow evolution and the mesoscale storm with its moist low-level airflow towards the precipitation area. Though this link is smaller in summer than in other seasons, nevertheless it is important (Funatsu et al., 2009).

Besides its significance as a precursor for precipitation forecasting and warning, a streamer also has significance for the location and intensity of precipitation (Massacand et al., 2001; Martius and Schwierz, 2008). Both significances are related to the dynamical characteristics of a streamer. The presence of a streamer is associated with dynamical lifting through positive vorticity advection, a reduction of static stability in the troposphere through upper-level cold air advection and/or low-level warm air advection and with strong low-level poleward moisture transport by low-level airflow. This low-level airflow is the result of the penetration to the ground of the upper-level flow along the eastern flank of the streamer, thereby acting like a warm conveyor belt
(Schlemmer et al., 2010). As the streamer influences both the tropospheric stability and strength of the low-level airflow, it has major implications on orographically mediated precipitation, together with the slowdown of the streamer itself by the mountain. In addition, a streamer usually has a region of ascent on its forward flank when it travels eastward (Massacand et al., 2001) and this ascent can initiate convection along its downward flank (Schlemmer et al., 2010).

Demirtaş (2016) remarks that the interaction between the potential vorticity at upper levels and the thermodynamics processes at low levels induces a positive dynamical feedback from the low level to the upper level that culminates into an enhancement of the upper-level flow and so of low-level warm, moist air advection. This feedback can occur when the low-level thermal advection supplies warm, moist air dynamical optimally situated at the upper-level that is made possible by the co-alignment of these thermodynamical structures. In addition, Ullah and Shouting (2013) and Milrad et al. (2015) show the possibility of using the potential vorticity (anomaly) and its moist equivalent, the moist potential vorticity (anomaly) for assessing the atmospheric instability and the accompanying atmospheric flows in understanding the genesis and the development of a severe weather system like a convective heavy precipitation producing storm. Herewith, a high moist potential vorticity enhances a mesoscale convective vortex and largescale cyclonic circulation being related to low-level moist convergence, and a negative moist potential vorticity anomaly enhances the vertical ascent being related to anticyclone upper-level divergence and accompanying upper-level trough and westerly flow. Finally, Li et al. (2017) have shown that incorporation of the effect of moisture in the dynamic parameters moist vorticity and moist divergence significantly can improve the ability of dynamic parameters to predict the location of heavy precipitation.

Sun et al. (2015) revealed the significance of the influence of the upper-level temperature on heavy precipitation. The two circulation structures they discovered in central North China, the upper-level anticyclonic and the cyclonic anomaly (cold trough), appear to be characterised by remarkable upper-level temperature anomalies, the extensive upper-level warm anomaly and the upper-level cold anomaly (cold trough) respectively. Strengthening of the upper-level anticyclonic anomaly and the lower-level southerly flows via the warm anomaly mediated pressure changes, result in upper-level divergence and lower-level moisture flow convergence. Both airflows provide a favourable (thermo-)dynamical background for the generation of heavy rainfall. Due to the upper-level cold anomaly a cyclonic anomaly or cold trough appears in the upper stream and together with the lowerlevel warm anomaly an unstable environmental air configuration developed. This unstable configuration provides a favourable thermodynamical background (strong instability and high CAPE conducive) for the generation of heavy rainfall. Caracena et al. (1979), Sohn et al. (2013) and Sun et al. (2015) concluded that heavy rainfall can also be generated in upper-level warm air anomalies and discovered that circulation structures leading to heavy rainfall can be revealed by temperature anomalies.

\subsubsection{Lifting}

The moist and warm (or unstable) air that advected into the precipitation area, next needs to be converted into liquid water. Only when adiabatic lifting or upward vertical motion occurs, condensation of water vapour to liquid water - a fundamental process in the rainfall formation processes preceding rainfall - can take place. In turn, vertical motion (convection mostly) can take place if an air parcel is warmer than its environment - the air parcel has buoyancy. This is commonly the case if a rising parcel becomes saturated (as its wet adiabatic lapse rate is less than the environmental lapse rate) and if it is able to reach the level of free convection on its own.

A distinction has been made between surface-based convection and elevated convection (though in reality a spectrum of convective types and transitions exist between these basic convection types) 
(Horgan et al., 2007; Schumacher, 2015; White et al., 2016; McCoy et al., 2017). Surface-based convection occurs when the boundary layer is unstable and convection starts near the surface. Elevated convection occurs when a stable layer within the boundary layer precludes the lifting of a moist air parcel (commonly indicated as convective inhibition) by which an external trigger, i.c. vertical motion, is needed to force the moist air to its level of free convection (forced convection). This inhibition or suppression of convection give rise to a sudden and explosive deep convection (Dodla and Ratna, 2010). Though during night the stabilisation of the boundary layer restricts convection and associated cold pool formation, nocturnal convection can yet occur when squall lines and supercells remain present during night. Lifting can remain surface-based through deep cold pool lifting and lifting by enhanced vertical perturbation pressure gradients respectively (Billings and Parker, 2012).

The vertical motions are based upon several mechanisms. According to Ducrocq et al. (2008) the focus of low-level mesoscale ingredients (like moisture and heat advection), inherent to these mechanisms by large-scale weather conditions, appears to be of crucial importance for sustaining convection for several hours at the same region.

Quasi-geostrophic flow can induce vertical motions (ascent). However, these motions usually are too slow or too weak to lift a buoyant air parcel to its level of free convections in the required time, or stated otherwise to trigger and focus the initiation of the convection (Doswell, 1987; Jeong et al., 2016b). To achieve this, a mesoscale trigger mechanism is required (Dayan et al., 2015; Doswell, 1987; Doswell et al., 1996). However, if the ascent of moist air is forced by quasi-geostrophic flow against a topographical barrier for sufficiently long time (quasi-stationary meteorological conditions), heavy precipitation yet can occur (Doswell et al., 1998; Lin et al., 2001; Toreti et al., 2016). In this case orography enhances the generation of rainfall without blocking the large-scale flow or the precipitation system itself (Ducrocq et al., 2008). This is a clear example of non-convective heavy precipitation. It shows that convection is not a prerequisite for heavy precipitation. Given the right conditions moderate rain intensities due to orographic lift, combined with a long duration large-scale flow can also result in heavy precipitation (Doswell et al., 1996).

Along the equator and in de tropics large convergence zones exist. These quasi-stationary zones are characterised by strong rising motions caused by low-level convergence (Fig. 3a) (Lima et al., 2010). This convergence is instigated by the planetary-scale Hadley cell circulations and shows the significance of large-scale circulations in the occurrence and generation of heavy precipitation.

Large-scale systems can provide a contribution of different degree (Milrad et al., 2015) to the lifting of moist air due to convection (Toreti et al., 2016). Several contributions of large-scale systems conducive to convection exist: low-level flow by low-level warm air advection (due to quasi-geostrophic flow) and by frontogenesis (Fig. 3d) (Konrad, 1997; Milrad et al., 2015; Sun et al., 2015), low-level flow by a slow-moving cold front or a near-stationary low-pressure system (Dayan et al., 2015), strengthening of the low-level jet by eastward propagation of an upper-level trough/cyclone (Lin et al., 2001; Nuissier et al., 2008; Toreti et al., 2016) and (together with upper-level jets) by convective heating (Shin and Lee, 2005), or upper-level jet streaks (Konrad, 1997). The strengthening of a low-level jet by convective heating is responsible for the creation of a positive feedback loop. Also, convergence along the nose of a low-level jet can induce low-level uplift (Peters and Schumacher, 2015). If a warm and moist low-level jet is forced to rise over a nearly stationary front (isentropic upglide), atmospheric boundary (like a dry line or outflow boundary) or mountain (especially for some time), heavy precipitation can occur (Mastrangelo et al., 2011; Moore et al., 2012; Peters and Schumacher, 2015; Pontrelli et al., 1999). These contributions all have in common that they induce low-level moisture convergence into the precipitation region thereby triggering and enhancing the convection (see Fig. 3 for an overview of different mechanisms of lifting).
The leading edge of a baroclinic (or frontal) zone as present in, or induced by, weak large-scale systems can also provide a possible convergence and so a lifting mechanism for convection (Konrad, 1997; Lee et al., 2016; Nuissier et al., 2008). The inducement of upper-level diffluent flow or upper-level divergence by a synoptic-scale trough or cyclone can also provide the (dynamic) uplift (Fig. 3b)(Konrad, 1997; Nuissier et al., 2008). If these synoptic systems are connected to an upper-level jet stream by a-geostrophic circulations resulting in upperlevel divergence of air, low level convergence and uplift are even more enhanced and so is convection (Fragoso and Tildes Gomes, 2008; Jeong et al., 2014b; Kastman et al., 2017a; Lima and Wilson, 2008). This is illustrated in Figs. 4 and 5. The rationale behind the influence of largescale systems is that they supply sufficient (thermo-)dynamic support which permits strong convection. This support entails the thermal and vorticity advection which drive the flow out of thermal balance inducing upward vertical motion (Dayan et al., 2015; Doswell et al., 1998) and underlie elevated convection as present in elevated thunderstorms.

Elevated convection or lifting is most frequently observed at night in the warm season in the US (Moore et al., 2003; Reif and Bluestein, 2017; Schumacher, 2015) and also, but rarely at daytime in the UK (White et al., 2016). According to Reif and Bluestein (2017) and White et al. (2016), nocturnal elevated convection can occur above or ahead a surface frontal boundary layer (and can begin above or on the cold side of this layer), but can also occur without an elevated frontal inversion (like a cold pool outflow layer) or a nearby surface boundary layer, in short: a low-level stable layer. A low-level jet, transporting warm, moist air above the stable frontal surface layer (large-scale isentropic ascent) and dynamic uplift by an upper-level jet are instrumental for the elevated convection. In addition, the low-level jet and a mid-level flow of relatively cold and dry air contribute to the convergence of moisture and so to the initiation and enhancement of deep convection in the unstable layer. If no nearby stable surface boundary layer occurs, a zone of large-scale elevated convergence and an area of mid-level instability can provide conditions for the initiation of elevated convection (McCoy et al., 2017; Moore et al., 2003; Reif and Bluestein, 2017) while this large-scale convergence is not needed for the maintenance of convection (Schumacher, 2015). An overview of the large-scale environment belonging to a precipitation system based on elevated convection (MCS) with the main processes of this system, is given in Fig. 4 (plane view) and Fig. 5 (cross sectional view).

Deep convection in elevated thunderstorms can be maintained by low-level jets, rear inflow jets, waves and sometimes cold pool outflows at the surface (depending on the stability and depth of the low-level stable layer). MCSs with a large trailing region of trailing precipitation (like squall lines) often have a rear inflow jet, a system-scale flow of air from mid-levels at the rear of the system into the trailing region. This rear inflow jet provides by evaporative cooling dry. Cold air to the downdrafts that can combine with cold pool outflows from connective scale downdrafts if the rear inflow jet can descent to the surface thereby increasing convergence and maintaining the convection. A rear inflow jet can also have impact upon the surface layer (when it doesn't penetrate the surface layer) and can generate waves that provide the required lifting for the maintenance of deep convection. The wave generation is part of a feedback between convection, rear inflow jet, wave and triggering of new convection and has been observed in study about elevated daytime thunderstorms (Peters and Schumacher, 2015; White et al., 2016).

Elevated storm systems and surface-based thunderstorms both can produce heavy precipitation (Kastman et al., 2017b). The heavy precipitation from surface-based systems is mainly due to the slow movement of the storm system. If the cold pool outflow is nearly balanced by the environmental inflow, a slow motion with stationary convection will occur (Davolio et al., 2016). The large-scale airflows as present in elevated systems (low-level jets particularly) are responsible for a higher moisture supply and a stronger lift that culminate into larger, longer and heavier precipitation events of these systems. Elevated 


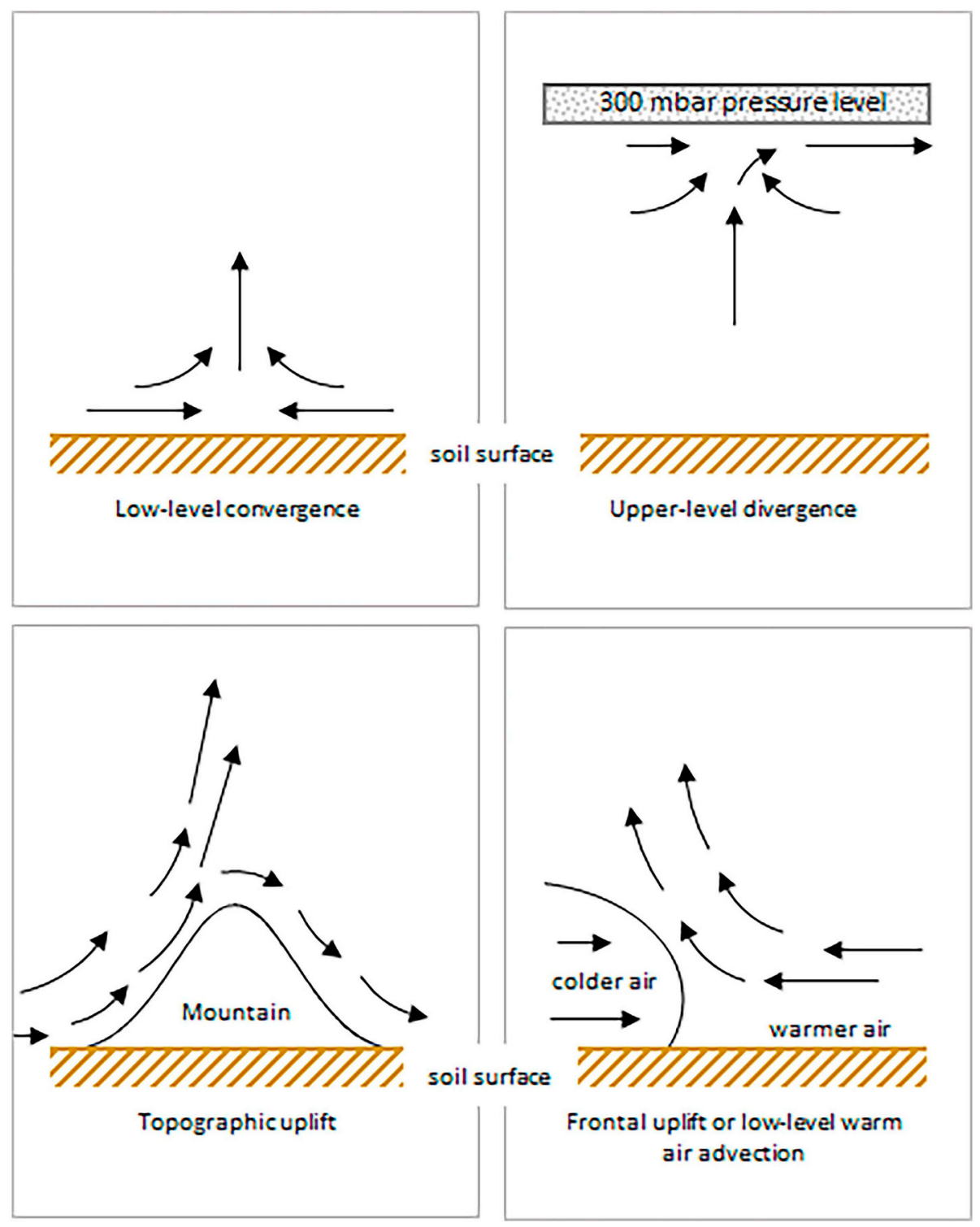

Fig. 3. Four types of lifting mechanisms.

thunderstorms even can produce excessive amounts of rainfall when the necessary ingredients synergistically interact within a vertically coupled jet system (Kastman et al., 2017a).

In the discussion of the transport of moisture by an atmospheric river in the Alberta region of Canada, Milrad et al. (2015) remarkably noticed that the transport of moisture itself is insufficient for the generation of a heavy precipitation event. Only if moisture convergence resulting in lifting of moist air takes place as well, a heavy precipitation event can develop. This example shows that the supply of moisture itself is insufficient for the generation of heavy rainfall; lifting has to take place as well.

Besides lifting mechanisms based on the interaction between largescale systems and mesoscale systems, lifting also occurs along mesoscale surface boundaries or convergence zones. Apparently, convection is not necessarily associated with upper-level flow structures of these large-scale systems as also noticed by Russell et al. (2012). Two groups with several situations conducive to convection exist: i) a group that is topographically induced (baroclinic zones): sea breeze circulation induced by differential heating of land and sea surface, cold air damming near mountains, and ii) a group that is not topographically induced: surface cold pools (or gust fronts) and cold domes, induced by evaporation and sublimation of precipitation (diabatic cooling) from prior convection reaching the sub-cloud layer that acts as a relief-like feature (Ducrocq et al., 2008) and cold outflow boundaries or downdrafts from a thunderstorm (Doswell et al., 1996; Maddox et al., 1979; Wang et al., 2014c; Luo and Chen, 2015) that force lifting. The effect of a cold pool on convection and rain distribution is shown in Fig. 6 . Ducrocq et al. (2008) have shown that downward motion occurs immediately above the surface cold pools with significant downdrafts originating in the mid-troposphere. A mesoscale cold front (meso-low) (Peters and Schumacher, 2015) and a mesoscale cyclonic/convective vortex (Dodla and Ratna, 2010; Kozaric and Ivančan-Picek, 2006; Ullah and Shouting, 2013) as well the interaction between a mesoscale convective vortex (Schumacher and Johnson, 2008) (or other mid-level circulations like cut-off lows; Schumacher and Johnson (2009)) or a front (Jeong et al., 2016b; Konrad, 1997) and a low-level jet also can contribute to the convergence and uplift as well as the destabilisation of low-level air (Kastman et al., 2017b; Peters and Schumacher, 2015; Schumacher and Johnson, 2009). The mid-level positive potential vorticity anomaly as associated with a mesoscale convective vortex originated from a decaying mesoscale convective vortex or from a cutoff low will force ascent in an environment with ambient vertical shear (Schumacher et al., 2013; Schumacher and Johnson, 2009) and resembles the large-scale potential vorticity anomaly and its large-scale 

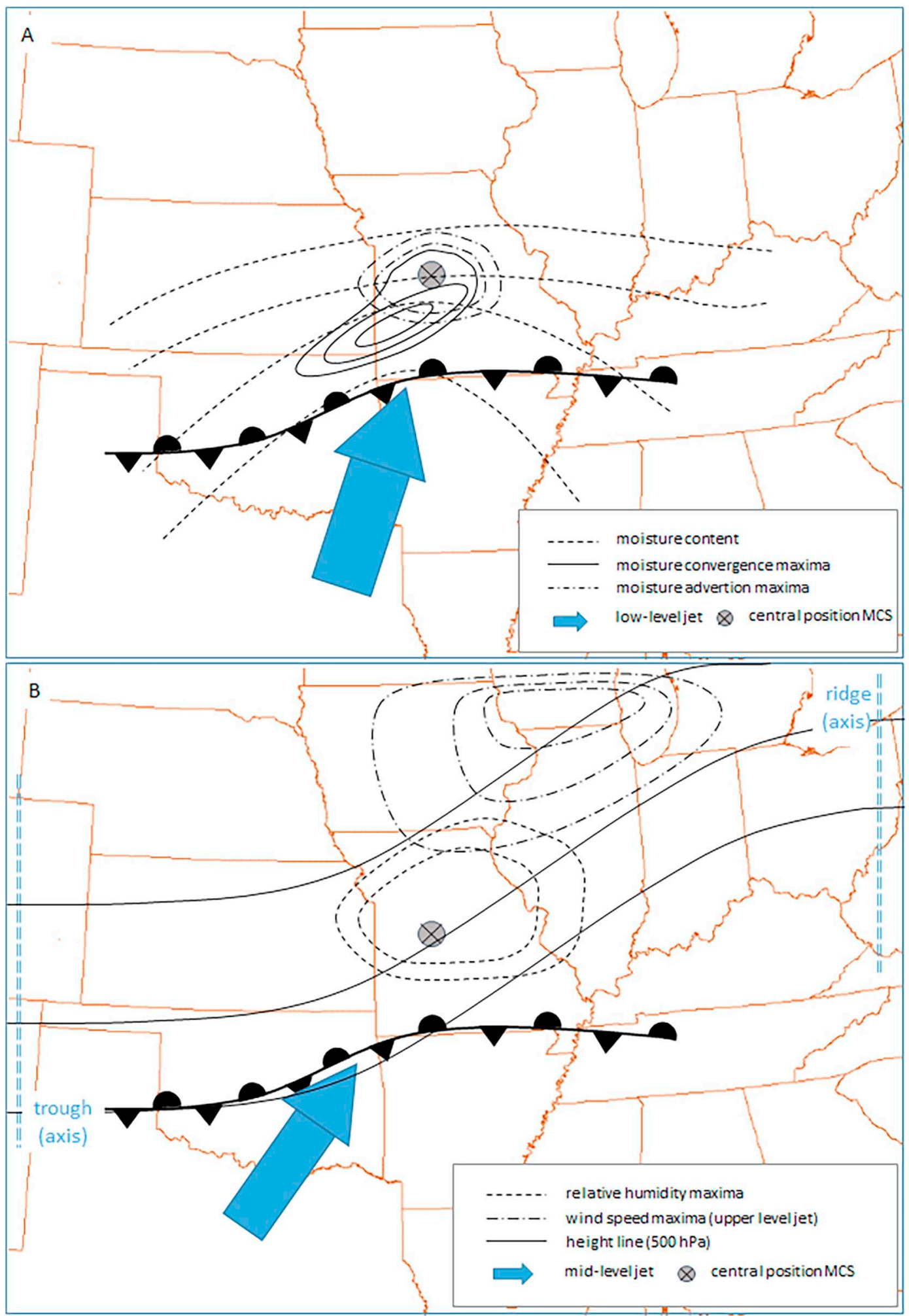

Fig. 4. Conceptual diagram of the synoptic environment of an elevated convection precipitation system (plane view), A: low-level, B: middle-upper-level. Adapted from Moore et al. (2003).

ascent as mentioned before. Finally, gravity waves and bores residing along the interface between the stable boundary layer and the overlying conditionally unstable air layer also can induce uplift (Billings and Parker, 2012; Peters and Schumacher, 2015; White et al., 2016). These types and situations all have in common that they induce low-level moisture convergence into the precipitation region at the mesoscale thereby enhancing the convection. Convection convergence can also triggered by the convergence of low-level airflows of different directions (Lee et al., 2016) like the collision of gust fronts (Lima and Wilson, 2008).

Another lifting mechanism entails the formation of a low-level cold pool. Cold pools can be generated by evaporation and melting of precipitation in sub-saturated air and cooling due to subsequent downdrafts below precipitation forming clouds or by low-level jets that 


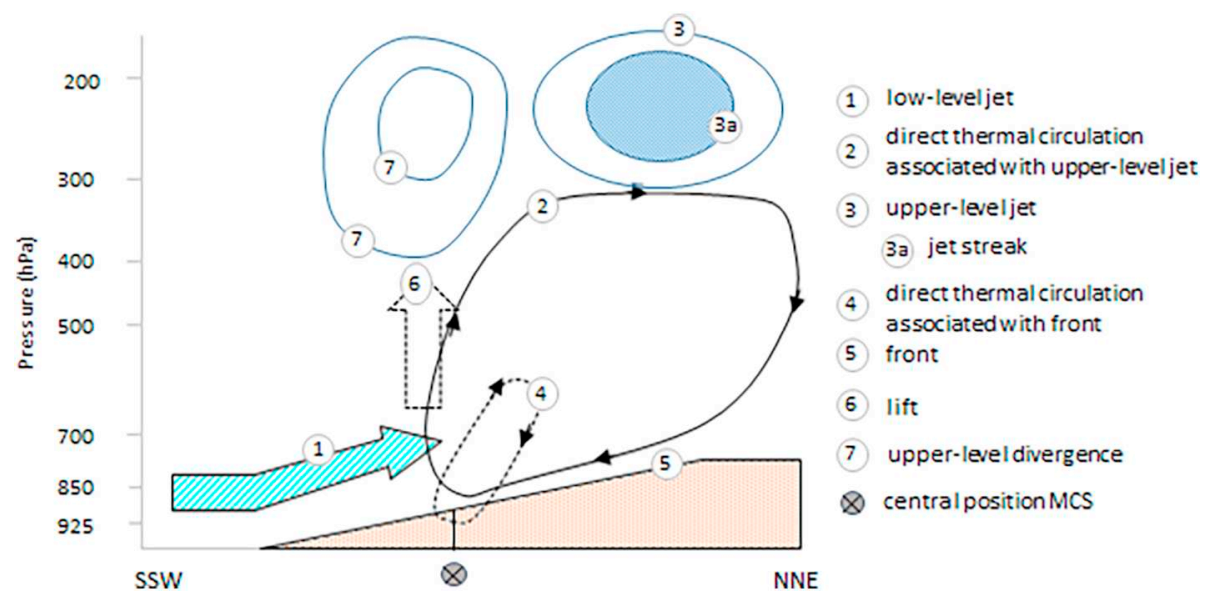

Fig. 5. Conceptual diagram of the synoptic environment of an elevated convection precipitation system (cross sectional view). Adapted from Moore et al. (2003).

transport cold air masses from cold air source regions. The cooling of low-level air can create a ridge and the development of a mid-level ridge and trough pair (Lee et al., 2017a). The stronger the evaporative cooling, the stronger and larger the cold pool (Tu et al., 2017). The resulting cold air parcels propagate downwards and spread to form a cold pool. Because this cold pool is denser than the incoming low-level moist and warm airflow, it acts like a relief by blocking, uplifting and forward shifting this incoming flow to trigger deep convection. Besides by direct lift, cold pools also can trigger deep convection by horizontal deflection of the incoming flow and subsequent support or enforcement of the low-level convergence. Interaction or competition of cold pools lifting with orographic lifting can result in indirect lifting. Cold pools can play a key role in the localisation, strength and distribution of deep convection and associated heavy precipitation (Bouin et al., 2017; Tu et al., 2017). An example of this key role is a blocking of the thunderstorm cold pool between mountains (Ducrocq et al., 2008; Nuissier et al., 2008). According to Bresson et al. (2012), cold pools are particularly convenient when the incoming flow is relatively dry or weak.

Cold pools play an important role in the rapid transition from shallow to deep convection after the onset of precipitation and in the
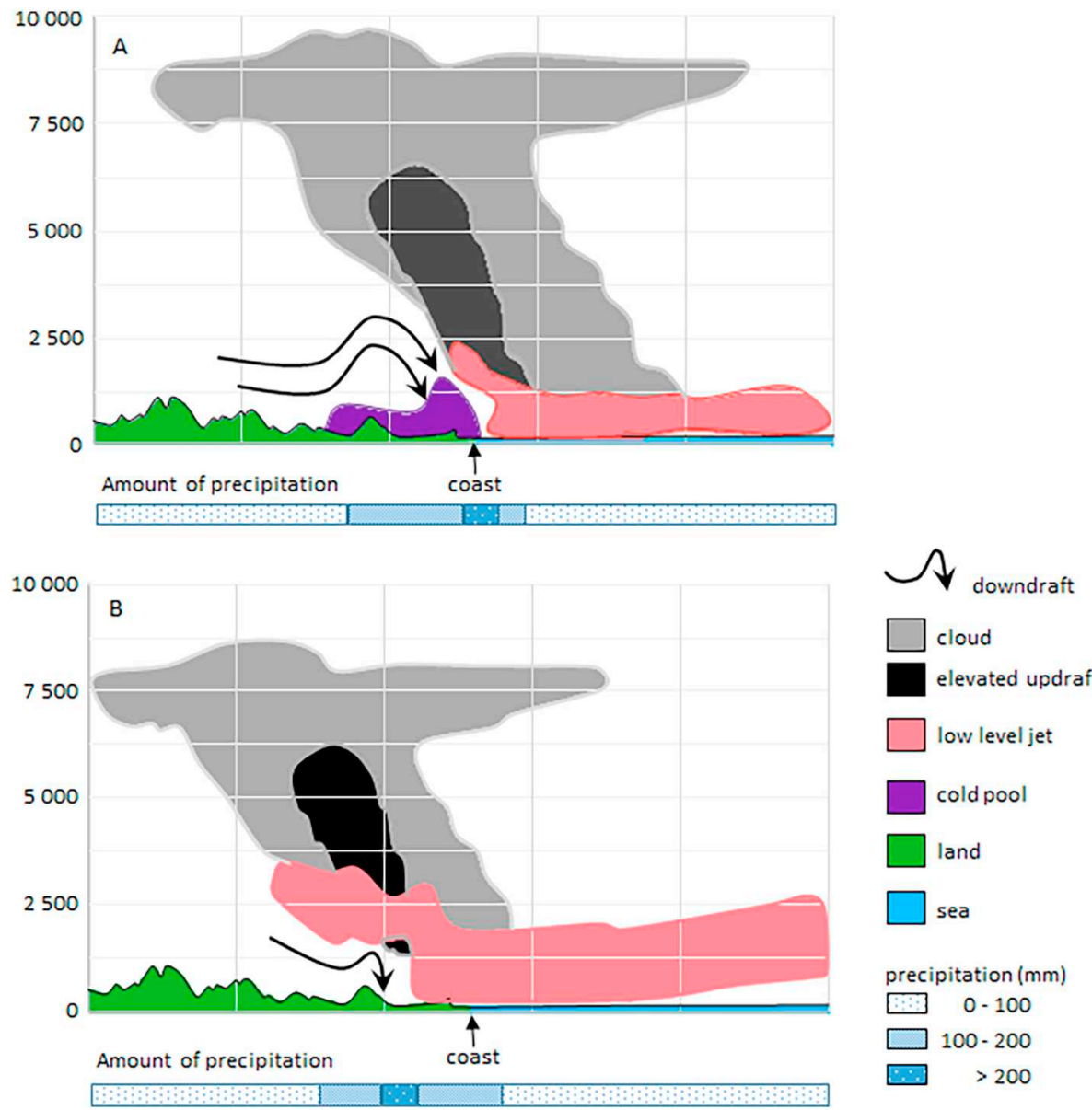

Fig. 6. The effect of a cold pool on convection and rain distribution. Note the lifting of warm, moist air over the cold pool right-above the cold pool (left) and the warm perturbation behind the convection line (right). Adapted from Jeong et al. (2016a). 

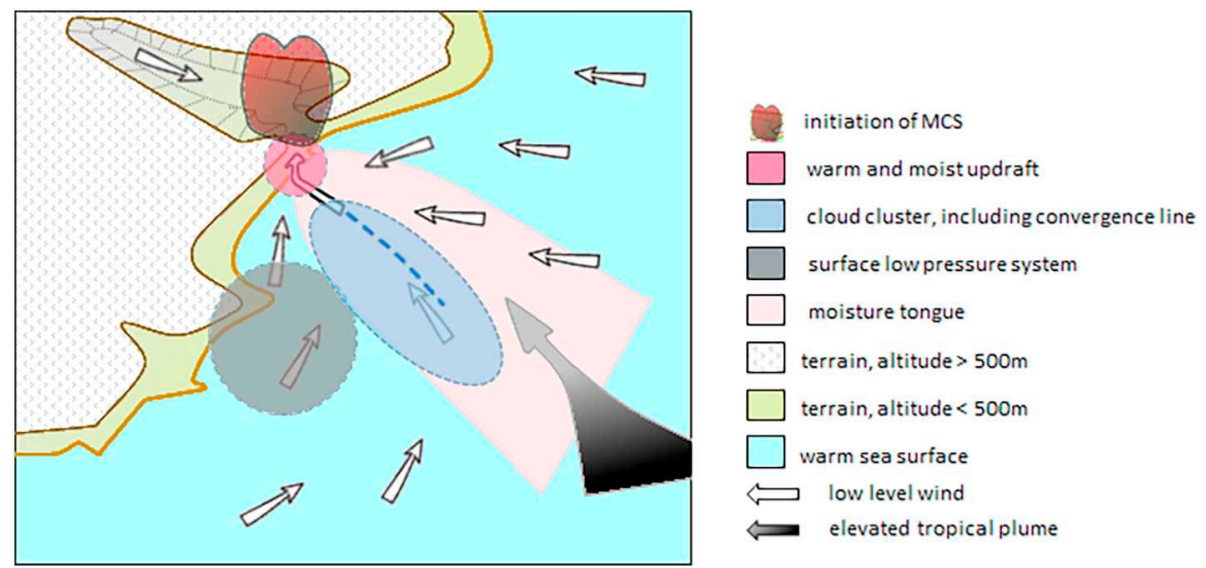

Fig. 7. Schematic illustration of the importance of low-level and terrain-induced convergence of warm, moist air on the location of initiation of an MCS. Adapted from Lee et al. (2017b).

organisation of multi-cell convection (Böing et al., 2012; Schlemmer and Hohenegger, 2014). As such they can be considered as key ingredients of deep convection (Torri et al., 2015). The presence of cold pools promotes the formation of deeper, wider, and more buoyant clouds with higher precipitation rates, which in turn lead to stronger cold pools (positive feedback). This feedback loop depends on the presence of cold pools rather than the differences in the vertical profiles of the mean state variables of the subcloud layer. Besides its role in the transition from shallow to deep convection, the feedback loop is also relevant for the timing in the diurnal cycle of moist convection (Böing et al., 2012) and so the peak time of precipitation (Schlemmer and Hohenegger, 2014).

Several mechanisms are given to explain how the cold pools support the triggering and organisation of deep convection (Böing et al., 2012; Bryan et al., 2006; Jeong et al., 2016a; Schlemmer and Hohenegger, 2014; Tompkins, 2001). In addition to the already introduced trigger (dynamic or mechanic) mechanism it should be mentioned that the lift takes place at the leading edge (outflow boundary) of the cold pool where a gust front occurs. New convection can be triggered where different gust fronts collide or where they interact with low-level airflows or mesoscale flow systems like sea-breeze circulations. Another mechanism triggering and organising new convection is the accumulation of moisture around the edges of cold pools and the subsequent cloud development on these moist and relatively warm edges (thermodynamic mechanism), as observed by Tompkins (2001) in environments with low vertical wind shear. This moisture stems from the evaporation of rain in the sub cloud layer which is pushed outward by outspreading dense airflow and can provide enough buoyancy to trigger new convection. Larger cold pools have larger moist edges and the larger the moist edges of the cold pools, the more clouds, the larger the cloud sizes and the larger the convective moisture transport. Because wider clouds are less affected by entrainment of environmental air, they can acquire more easily larger cloud depths. Deeper clouds have larger downdrafts which produce larger cold pools yielding larger moist edges. The moist edges also are the locations where the gust fronts of different cold pools collide and result in enhanced convergence and lift which in turn enlarges the trigger for convection favouring the formation of wider and deeper clouds.

Both the dynamic and the thermodynamic mechanism can take place independently of atmospheric and surface conditions as land and sea surface, dry and wet environments, stable and unstable atmosphere, with and without wind shear and for shallow and deep convection. However, both moisture accumulation and lift are enhanced in a moist environment and so is the transition to deep convection (Schlemmer and Hohenegger, 2014). In a computer experiment Torri et al. (2015) succeeded in disentangling these mechanisms. Though both mechanisms cooperate, each of them is important at different stages of the uplift. The dynamic mechanism is important in the first stage of the uplift and the thermodynamic mechanism is necessary to move through the inhibition layer. At the surface the dynamic mechanism is necessary to start the uplift as the strong buoyancy of the air parcels is nearly compensated by the resistance encountered by parcels moving through the surrounding air. In the inhibition layer, the thermodynamic mechanism particularly is needed to reduce the inhibition met by parcels in this layer.

\subsubsection{Influence of land surface and mountains on lifting}

The land surface itself has an important influence on heavy precipitation. According to Funatsu and Waugh (2008) and Renard (2017) local land surface characteristics exert primary control on the existence and strength of convection (i.c. occurrence, intensity and area of rainfall or precipitation cells). Modifications in the characteristics of land surfaces can significantly change the thermodynamics - the surface heat and moisture fluxes - of a region and so can greatly affect the initiation and evolution of convection and accompanying weather systems (Fig. 3a). Well-known examples of these land surface heterogeneities are land-sea (Fig. 7) and urban and non-urban contrasts. Sea breezes (with their fronts and horizontal convective rolls) provide mechanical forcing to overcome convective inhibition, supply moisture and vertical ascent along their fronts and so can induce convection even under weather conditions that appear to be too stable for convection from sounding indices like CAPE and convective inhibition (CIN) (AzorinMolina et al., 2015). As a response to the changes in these fluxes lowlevel convergence zones are formed. More specifically, convergence lines are regions of low-level convergence arranged along a line (Bennett et al., 2006).These lines can produce more extensive and longlived convection (lines of convection). When convergence lines intersect because of convergence of low-level airflows of different directions, they can trigger the convection thereby creating preferred locations for convection (Iwai et al., 2018; Lee et al., 2017b) and is (together with the impact of a low-pressure area) illustrated in Fig. 7. An example of this intersection is the urbanisation along major land-water boundaries. Urban heating (urban heat island mechanism) and thunderstorm downdrafts due to this urbanisation are able to enhance the inland breeze, thereby stimulating the formation of a convergence line. Other mechanisms of urbanisation on precipitation are enhanced convergence due to surface roughness, increased cloud condensation due to increased aerosol concentrations and diversion of precipitation systems by urban orography (Mohapatra et al., 2017; Piotrowski, 2017). Urbanisation also can enhance the intrusion of lake and sea breezes and so facilitate the formation of a convergence zone providing favourable conditions for deep convection along the city. This in turn can modify the distribution of organised convection. It appears clearly that urbanisation can have significant impacts on (local) heavy precipitation 
(both intensity and distribution) within and downwind of cities even under conditions of strong large-scale flow. Nevertheless, low-level moisture advection remains important for the development of strong convective storms (Ntelekos et al., 2008; Ryu et al., 2016; Yang et al., 2013; Yang et al., 2014b). In addition, besides the oceans/seas with sea surface temperature as an important factor (Demirtaş, 2016) local land surfaces themselves also can act as significant moisture source of the low-level atmosphere during the warm season (Li et al., 2017; McCorkle et al., 2016; Teufel et al., 2017). Areas and periods of enhanced evapotranspiration (e.g. due to a regional precipitation gradient or precipitation preceding the heavy precipitation event) increase the low-level moisture content of the air which in turn increases the convective precipitation intensity. This gives cause for a positive feedback between precipitation and evapotranspiration (e.g. Martius et al. (2013)). Besides moisture sources from outside the precipitation area, also moisture sources within a precipitation area do occur.

Mountains or mountain ranges (and other local features like upwind islands and complex coastlines) are of great significance in the generation of heavy rainfall (Baldwin et al., 2019; Demirtaş, 2016; Lin et al., 2001). Their main role consists of forcing the lifting of low-level flows of warm, moist air for the initiation or enhancement of convection (Fig. 3c) (Couto et al., 2012; Delrieu et al., 2005; Fiori et al., 2017; Nuissier et al., 2008). They focus and maintain the uplift. Convection often starts in a concave region of a mountain that induces confluent low-level flow and enhances the lifting (Lin et al., 2001). Mountains also can increase the convection that already exists in the rainfall producing storm, like the intensification of frontal precipitation (Kozaric and Ivančan-Picek, 2006) or that is already created by an approaching trough (Lin et al., 2001). Another role of orography is the production of small-scale convergence by canalisation or reinforcement of low-level flow, flow deflection and barrier blocking (Ducrocq et al., 2008; Kozaric and Ivančan-Picek, 2006; Laing, 2004; Nuissier et al., 2008; Ramis et al., 1998). A famous example of this blocking is the formation of cloudbursts in the Indian Himalayas as a result of the interaction between convection and orographic lifting (Dimri et al., 2017). Once convection is triggered/once cells are convectively triggered, convection is enhanced by steep orography. This combination of convection and orography results in rapid lifting and so in orographic locking of already convectively triggered cells, which leads to shedding off the precipitation at one site. Mountains can also influence convection by cold pool blocking within their valleys (Ducrocq et al., 2014). Deflection of low-level flow by mountains also acts to enhance the low-level jet (Ducrocq et al., 2008). A typical role of orography entails the forcing of the convection by the generation of mesoscale disturbances like the development of a surface mesoscale cold front by latent heat release or lee cyclogenesis (cyclogenesis describes the process of cyclone formation and intensification) e.g. by the development of a shallow low in the lee of a mountain range (Dayan et al., 2015; Doswell et al., 1998; Ducrocq et al., 2008; Milrad et al., 2015; Nuissier et al., 2008; Ramis et al., 1997). Finally, aspects of a mountain itself do matter: orientation relative to low-level flow, steepness and slope length: the more perpendicular the low-level flow, the steeper the mountain and the longer the slope, the larger the effects on the generation of heavy precipitation are (Ducrocq et al., 2008). According to Rudari et al. (2005) and Jiang et al. (2018) an interaction exists between large-scale flow (and so between upper-level flow, lowlevel flow and regional moisture supply or moisture convergence) and regional topography or local topographic barriers in producing localised heavy precipitation, and orographic precipitation is the strongest type of interaction between surface and large-scale flow (Couto et al., 2012).

\subsubsection{Instability}

The lifting of moist, warm air, being conditionally or convectively unstable, needs to take place over a large vertical distance in the troposphere (deep convection). Only when there is deep, moist convection, high rainfall rates can be obtained. Deep, moist convection makes demands on the local atmospheric environment of the troposphere: it needs to be conditionally unstable. This means that the environmental lapse rate lies between the dry and moist adiabatic lapse rate. Only if this is the case a saturated air parcel remains warmer than its environment (it maintains its buoyancy) and it can continuously rise over a long distance in the troposphere: sustained or deep convection. The instability of the air is a typical local-scale characteristic of the air.

Low-level air at a certain location can be destabilised through quasigeostrophic motion by the large-scale advection of warm, moist air (Dayan et al., 2015; De Vries et al., 2016; Delrieu et al., 2005; Doswell, 1987; Funatsu et al., 2008; Nuissier et al., 2008; Ramis et al., 1997). The larger the heat and moisture content of the incoming air, the more unstable the air and the higher the energy potentially available for convection (i.c. CAPE) of that air. The CAPE produced depends on the exchange of heat and moisture between low-level flow along the way to the location of convection and the land- or sea surface below it. A CAPE is a measure of the instability of the air (Borga et al., 2007) and it indicates the potential of deep convection (Smith et al., 2000). Another large-scale mechanism of destabilisation (to the west of the precipitation region on the northern hemisphere) entails the potential vorticity and the cold air advection as induced by the upper-level propagation of cold troughs and cyclones; a higher level of upper-level potential velocity means a decreased static stability (Funatsu and Waugh, 2008; Lin et al., 2001; Sun et al., 2015; Toreti et al., 2016). The degree of destabilisation of low-level air also depends on the speed of the synoptic scale system: a slow moving cyclone permits a greater destabilisation of low-level air due to a longer lasting (several days) transport of heat and moisture to a certain region (Doswell et al., 1998). A decrease in static stability, together with the advection of potential vorticity results in vertical motions at low levels (Funatsu and Waugh, 2008). Low-level air at a certain location also can be destabilised by surface sensible and latent heating, a typical local-scale contribution to the instability of air.

Lifting itself, as induced by quasi-geostrophic ascent and low-level convergence (both large-scale) and orographic ascent and mesoscale surface boundaries (both mesoscale) and surface sensible heating (local scale), contribute to the stabilisation of the air by the release of convective instability (Nuissier et al., 2008; Ducrocq et al., 2008). Due to the lifting, the moist air is forced to condensate, causing heat to be released and the air particle obtains additional buoyancy that contributes to upward motions. The more moisture an air parcel has, the more heat can be produced and the higher its buoyancy. If a stable layer in the boundary layer exists, CAPE will be built up by the rising motions due to strong surface sensible heating, in addition to the CAPE the air already has obtained via advection. A low-level vortex also can contribute to the build-up of low-level latent instability (Dodla and Ratna, 2010). In this case heat can only be released when a triggering mechanism forces the air particle to lift to the level of free convection (Ducrocq et al., 2008).

Destabilisation of the local air column is an important process because it enhances convection through which deep convection can occur (as it influences the buoyancy of the lifting air parcel) and consequently rainfall will increase (Ivančan-Picek et al., 2014). Due to this deep convection the consumption rate of moisture is high, often much higher than the rate at which moisture can be transported by synoptic scale processes in conventional circumstances (Doswell et al., 1996). Consequently, deep convection can only occur and persist if a sufficiently large moisture transport can be sustained or if a large amount of moisture can be accumulated in the boundary layer. It appears that the destabilisation of air is an important feature for the sustainment of advection of heat and moisture, and so for the acquisition of heavy precipitation. 


\subsubsection{Duration}

Recalling the statement of Chappell from section 4.1, the duration of a rain event strongly determines the heaviness of precipitation. The duration of a (convection-based) precipitation event at a certain location or region is determined by the speed of the convective system, the size of the convective system and the within-system variation in rain intensity. A system responsible for an event of long duration moves slowly and/or has a large area of high rain intensities along their motion. The speed of a convective system is determined by the speed of the synoptic system. A quasi-stationary synoptic system acts to retard or impede the convective system and helps to produce long-lasting or persistent rainfall over a region. According to Lee et al. (2017b), the large-scale environment is particularly important for long-lasting heavy precipitation events. Mountains can play a major role in slowing down synoptic systems like fronts (Delrieu et al., 2005). For the resulting slow moving convective system experiencing high rain intensities, its size and rain intensity variability usually are not very important. For a large convective system, the duration of moderate to high rain intensities can be long (Sun et al., 2015), despite the speed of this system (Doswell et al., 1996; Lin et al., 2001). The physical background of "duration" concerning the production of heavy precipitation is the sustaining of the vertical moisture flux for a sufficiently long time (Doswell et al., 1996).

For a convective system also the number of convective cells (a convective cell is an entity of convection) it consists of, determines its duration or quasi-stationarity. When several convective cells obtain maturity after each other, a convective precipitation event can achieve a long duration. This is an important aspect of a convective system as the lifetime of an individual convective cell usually is too short to produce heavy rainfall, although its rain intensities can be high. Another important aspect in the context of the production of new convective cells is the line at which these new convective cells are produced relative to the direction of the synoptic system movement. If most cells are produced parallel to the large-scale system motion, a certain region will obtain a longer lasting rain that results into a higher precipitation (Curtis, 2017; Doswell et al., 1996; Lin et al., 2001). Both aspects of a convective system will be elaborated upon in section 5.3.3.

\subsubsection{Precipitation efficiency}

This ingredient gets less attention in literature in comparison to the other ingredients. It can simply be described as: the more water in the air evaporates, the less water reaches the soil surface and the lower the efficiency will be. According to Doswell et al. (1996) precipitation efficiency is not an important topic unless it is reasonable to assume that it will be unusually low. Precipitation efficiency is high in moist environments and low in dry ones. This latter occurs in cases of deep convection (as upper-level air moisture content is usually low) (Doswell et al., 1996), dry air intrusion aloft (Doswell et al., 1998; Kozaric and Ivančan-Picek, 2006) and of a dry air layer occurring at the mid-level of the troposphere (Doswell et al., 1996; Warner and Mass Jr., 2012). In respect to flood potential, precipitation efficiency of the flood producing storm system consisting of several clouds does make sense and not that one of an individual cloud.

Precipitation efficiency is largely determined by the evaporative capability of the air. This capability mainly depends on environmental factors like the humidity, the horizontal and vertical wind shear and the entrainment rate. According to Doswell et al. (1996) the relative humidity is a key factor: the higher the relative humidity, the lower the evaporation and the higher the precipitation efficiency. Entrainment indicates the incorporation of unsaturated air into clouds and it tends to promote the evaporation. In this respect an isolated cloud likely suffers more entrainment than a cloud embedded within a larger cloud system and so more evaporation will occur. Wind shear, finally, influences the sweeping away of cloud droplets to evaporate elsewhere (Doswell et al., 1996, 1998; Lin et al., 2001). Another key-factor is the presence or absence of downdrafts: if they are absent, the precipitation efficiency is also high (Doswell et al., 1996).

\subsection{Final remarks}

Though similarities between different heavy precipitation events exist in the physical principles (the ingredients discussed), it is important to notice that each heavy precipitation event has its own characteristics (Doswell et al., 1998; Lee et al., 2017b). In fact, each heavy precipitation event is unique by nature. The occurrence and development of a heavy precipitation event is also influenced by the unique physical geography of the precipitation region (Lee et al., 2017b; Moore et al., 2015; Toreti et al., 2016) and also depend on the season (Dayan et al., 2015; De Vries et al., 2016; Moore et al., 2015). According to Doswell et al. (1996), the persistence of the convection is the most relevant factor in the production of heavy rainfall and not the top height or the size of the cold anvil of the convective cloud. Basically, after Moore et al. (2012) and Martín et al. (2013) the most heavy precipitation is produced when the ingredients responsible for convection occur persistently over the same region, either by a back-building process or by topographic forcing (Unuma and Takemi, 2016; Warren et al., 2014). Heavy precipitation is not only the result of intense rainfall of short duration, it can also be the result of persistent moderate (or heavy) rainfall (Jessup and Colucci, 2012; Martín et al., 2013). Persistent moderate (or heavy) rainfall can also occurin a wet spell (consequent days with significant precipitation) (Zolina et al., 2013).

The ingredients and accompanying mechanisms leading to the formation, distribution and persistence of heavy precipitation occur on all existing scales: synoptic, meso- and local scale (Buzzi et al., 2014; Lee et al., 2017b). According to Pfahl et al. (2014), due to the small-scale character of precipitation, its occurrence is commonly influenced by meso- and local scale ingredients as well. In fact, generally spoken, all scales do matter, but the relative importance can differ as is the case in the forcing for the ascent (Milrad et al., 2015). Some heavy precipitation events are mainly caused by mesoscale mechanisms and are not significantly associated with synoptic scale mechanisms with certain upper-level flow structures (Toreti et al., 2016). An example of an event type caused by mesoscale mechanisms is the orographically forced ascent of the quasi-geostrophic flow. Another example concerns the notobligatory presence of an upper-level trough or cyclone for the production of heavy precipitation: although many heavy precipitation events are tied to upper-level flow structures, there are also many that don't produce heavy precipitation. This example suggests that other aspects of synoptic flow may also determine the prediction of heavy precipitation, e.g. low-level moisture advection and/or convergence and their duration. Fiori et al. (2014), Lind et al. (2016) and Funatsu et al. (2008), amongst others, indicate the importance of local landscape environment in the genesis and development of heavy precipitation and Warren et al. (2014) and Tu et al. (2014) the importance of mesoscale and local/storm scale processes determining the exact location and timing in the initiation and intensification of convection. Though the large-scale and the mesoscale environment are similar, precipitation patterns can be very different (Davolio et al., 2016). Another important fact to mention in this respect is the relations between synoptic scale and mesoscale/local scale mechanisms: synoptic-scale mechanisms generate tropospheric conditions of thermodynamic nature that are conducive for the development of convective heavy precipitation events (Dayan et al., 2015; De Vries et al., 2016; Doswell, 1987; Tudurí and Ramis, 1997) or even crucial for the development of deep convective heavy precipitation events (Aylward and Dyer, 2010; Fragoso et al., 2012) and mesoscale or local scale mechanisms mainly act to initiate convection (Doswell, 1987). The interaction between synoptic-scale induced low-level flow and topography or generally local-scale structures, determines the localisation of an 
event (Doswell et al., 1998; Ramis et al., 1997) or the geographical distribution of events (Jiang et al., 2018).

\section{Weather systems producing heavy precipitation}

\subsection{Identification and classification}

As discussed in chapter 4, heavy precipitation occurs under a variety of synoptic and mesoscale meteorological conditions (Maddox et al., 1979; Zhou et al., 2013). Consequently, it can be produced by a series of storm types (Doswell et al., 1996; Smith et al., 1994b; Sun et al., 2015). A literature search produces several ways to identify or sum-up storms (Sun et al., 2015; Wang et al., 2014a) or to classify them into certain types (Hand et al., 2004; Schumacher and Johnson, 2005). The most basal (and simple) classification system entails the distinction in the two principal rainfall generation types: convective and non-convective storm type (or localised and non-localised precipitation (Mohapatra et al., 2017)) according to the prevalence of the ingredient 'instability' (see section 4.2.4). Another name for convective precipitation is thermodynamic precipitation, non-convective precipitation is called dynamic precipitation (Dayan et al., 2015; Delrieu et al., 2005). These types are mainly influenced by local and large-scale weather conditions respectively (Mohapatra et al., 2017). This distinction makes sense in flood science as most flash floods are produced by a convective storm type (Doswell et al., 1996; Doswell et al., 1998).

Classification of heavy precipitation events is contributing to a better (thermo-)dynamical process understanding of these phenomena by means of analysis and comparison of the phenomena. Classifications are also motivated by operational forecasting considerations: if is known which storm type can be expected, operational weather models will give more accurate forecasts on probabilities of heavy precipitation and accompanying amounts and intensities. However, it was noticed that the observed precipitation patterns are mostly caused by a combination and interaction of different rainfall processes at different scales (Speer and Leslie, 2000; De Lannoy, 2001; Nuissier et al., 2011; Yu et al., 2015), which makes classification much more complicated. Strictly speaking, every heavy precipitation event is an unique event with its own meteorological characteristics (Doswell et al., 1996; Smith et al., 2010b). In addition, classification becomes more complicated by the pronounced influence of topography (even at small-scale) on heavy precipitation storms throughout the world (Smith et al., 1996). Apparently, the generation and development of heavy precipitation storms is not sole a meteorological issue. In this context one can think of the prominent role of orography in the formation of heavy rainfall (Hand et al., 2004; Smith et al., 2010b; Zhou et al., 2013) and the role of terrain on terrain-forced convection by means of differential surface heating and moisture availability (Nuissier et al., 2008; Schumacher and Johnson, 2005; Zhang et al., 2009).

A quite generally mentioned classification system is the distinction of storms into tropical cyclone, extratropical (i.e. mid-latitudinal) cyclone and Mesoscale Convective System (MCS) (e.g. Smith et al., 2010; Moore et al., 2015). This distinction is related to the spatial dimensions of the storm type and the degree of convective organisation. The dimensions decrease in the order tropical cyclone, extratropical cyclone and MCS. While an MCS is highly convective organised, a tropical cyclone and extratropical cyclone both are individual or unorganised weather systems. The above-mentioned classification system has a high resemblance with the system of Schumacher and Johnson $(2005,2006)$ consisting of the types TC, frontal/synoptic system and MCS. This resemblance appears clearly from the existence of fronts being associated with synoptic cyclones (Moore et al., 2015). The classification system of Zhou et al. (2013) distinguishes the types synoptic system, MCS and orographic system and the classification system of Hand et al. (2004) (in their study on heavy precipitation events in the UK) the types frontal system, convective system and orographic system. These last two mentioned classification systems are similar. The main difference is that Zhou et al. (2013) specify the convection driven system as an MCS and Hand et al. (2004) keep the generalized term convective system. The peculiarity of these systems is the explicit recording of the class orographic system. This makes sense as orographic lifting is the most common forcing in cases at which free convection is absent (Doswell et al., 1996) or less dominant (Houze, 1993). Stated otherwise: orography plays a significant role in many cases of heavy precipitation (Ducrocq et al., 2008; Zhou et al., 2013).

In addition to the preceding about the classification systems, Smith et al. (1994a) and Hand et al. (2004) made their own subdivisions. Smith et al. (1994b) analysed the space-time structure of extreme storms in the Southern Plains of the US and distinguished linear and chaotic convective systems (based on the storm organisation at convective systems made by Blanchard (1990)), weak and strong dynamic forcing systems (based on the absence/presence of a strong upper-level disturbance like a short wave trough or cut-off low as made by Bradley and Smith (1994)), and spring and fall systems. Spring and fall systems are characterised by high levels of moisture and convective instability and often show strong dynamic forcings. Hand et al. (2004) subdivided the class frontal system into frontal systems with and without embedded instability and the class convective system into strongly and weakly forced convective systems. The latter sub-classification was also made by Aylward and Dyer (2010) and Schumacher and Johnson (2005, 2006) who additionally remarked that nearly all the synoptic systems involved repeated (deep) convection. The first subdivision shows the possibility of the existence of thunderstorms within a frontal system. In this context, Dayan et al. (2015) speak about frontal thunderstorms and non-frontal thunderstorms. While a strict frontal system is characterised by widespread and continuous precipitation over a large area, a frontal system with embedded instability is additionally characterised by pulses of heavy precipitation, either along the warm front or in the north west quadrant relative to the low centre (Hand et al., 2004). Both classes are characterised by a slow-moving low-pressure system and a warm, moist ascending airflow within the warm sector of this system. The strongly forced convective system of the second subdivision consists of storm systems at which the forcing from a synoptic scale feature like a front, up-draughts and downdraughts was very strong. In case of a frontal triggering mechanism, the front was of the cold type: a cold front, cold inclusion or a trough. The weakly forced convective system consists of storms at which the forcing was a mesoscale feature like a sea breeze or a convergence line, or a local scale feature like insolation. Both classes are (in comparison with a frontal system) characterised by much more localised and less continuous precipitation, even if the convection was triggered by a frontal system. From the studies of Schumacher and Johnson $(2005,2006)$ it can be concluded that heavy precipitation (in the US) is mostly caused by MCSs (around 67\%, primarily in the warm season), followed by synoptic systems (around 25\%, of which around 3\% without convection, primarily in the cool season) and tropical systems (around 8\%), which is an underpinning of the importance of MCSs in case of the production of heavy precipitation.

Many attempts have been made to classify the many morphologies of MCSs. Schumacher and Johnson (2006) arranged the MCSs observed in the US into sub-classifications based on their organisational structures and accompanying evolutions, i.c. the spatial distributions of convective and stratiform development. The dominant pattern of organisation at the time when the MCS was producing the heavy precipitation, was determinant in this case. Seven sub-classifications were identified by Parker and Johnson (2000) and by Schumacher and Johnson (2005): training line/adjoining stratiform, back-building/ quasi-stationary, trailing stratiform, leading stratiform and parallel stratiform, multiple MCSs and other MCSs (Schumacher and Johnson, 2006). Zheng et al. (2013) designed a classification system of MCSs that occur in Central East China. Differences in large-scale dynamics between China and the US lead to distinct convective organisation 
characteristics of the MCSs in China. The corresponding types are one non-linear mode and six linear modes: trailing stratiform, leading stratiform, parallel stratiform, bow echoes and embedded lines. A major distinction between the types is the distinction linear - non-linear. Linear MCSs contain a convective line. A convective line is "a (nearly) contiguous chain of convective cells that share a nearly common edge and move approximately in tandem, whether they are arranged in a nearly straight line or a moderately curved arc" (Parker and Johnson, 2000). Non-linear MCSs are "large convective systems with highly eccentric precipitation patterns but without convective lines" (Parker and Johnson, 2000). Both linear and non-linear MCSs can produce heavy precipitation (He et al., 2017). Jeong et al. (2014b) distinguish four types of convective systems: isolated thunderstorm, convective band, squall line and cloud cluster. In this classification system, contrary to the previous one, the distinction between the fast-moving squall line and the slow-moving convective band is emphasized. Convective bands cause the strongest and most localised precipitation in the shortest time, partially due to their slow motion. The peculiarities that are relevant to the production of heavy precipitation will be dealt with in section 5.3.3.

In comparison to classification systems that are qualitative by nature, Porcú et al. (2003) proposed a more quantitative classification of weather systems leading to floods in Europe. The weather systems selected consist of cyclonic systems and fronts. This system shows that heavy weather systems can be classified by characteristics, either of qualitative or of quantitative nature: origin, relative strength and position of the low system, type of related trough, potential vorticity anomaly (classes based on dynamical characteristics) and presence and type of convection and cloud type: frontal cloud bands or convective clouds (classes based on structural characteristics). This classification system might be considered as a further particularisation of the heavy weather systems.

\subsection{General characteristics of heavy precipitation storm types}

Heavy precipitation systems can have different spatial and temporal dimensions. Generally the spatial and temporal dimension of storm systems or types are linked: the larger the storm system, the longer the storm will last (Sun et al., 2015; Zhou et al., 2013). This clearly applies to the well-known division of storms into non-convective and convective types: the non-convective types are much larger and function much longer than the convective ones (Moore et al., 2015; Sun et al., 2015) and reflect the importance of internal organisation (Stevenson and Schumacher, 2014). According to Rebora and Ferraris (2006), midlatitude convective rain cells commonly involve heavy precipitation over $5-10 \mathrm{~km}$ and typically last $30 \mathrm{~min}$. In a study on the 50 largest storms that mostly consists of organised convective systems in a region around Milwaukee (Wisconsin, USA), Thorndahl et al. (2014) conclude the existence of increasing characteristic length scales and increasing time scales for these storms. Their study also underpins the linkage between the spatial and temporal scale within one class of storm types.

A larger storm system with a longer lifetime results into a higher local precipitation amount at a larger area (widespread precipitation) (Moore et al., 2015). A small system with on average a higher rain intensity however doesn't necessarily result into a high amount of local precipitation in a relatively small region (concentrated precipitation) because of a potentially short lifetime. Nevertheless, relatively small storm systems can produce high precipitation amounts if their lifetime increases considerably. Increased lifetime is made possible by elongated moisture and energy supply (Delrieu et al., 2005; Jeong et al., 2016b; Zhou et al., 2013) which is basically the result of the interaction between the storm's downdraft or outflow and the surrounding air (Bennett et al., 2006). As is the case with small storm types, the lifetime of large storm types also can increase. This occurs when a frontal system is slowed down by mountains (Delrieu et al., 2005) or by atmospheric blocking (Dayan et al., 2015).

Besides the dimensions of the storm systems themselves, the systems are also characterised by a certain tendency of occurrence in a geographical region and in a season. From the storm type point of view, its occurrence can vary significantly throughout locations and seasons due to the different local and climatic conditions (Yu et al., 2014). Tropical cyclones occur mainly in the (sub-)tropical (land) regions as they form in the tropical oceans and may afterwards move over land. Extra-tropical storm types can have a typical region of occurrence. This occurrence is associated with a certain distinct (recurrent) synoptic circulation (inducing heavy precipitation) and it has become a climatological fact of that region (Dayan et al., 2015; De Vries et al., 2016; Kahana et al., 2002; Milrad et al., 2015). Synoptic types like Active Red Sea Trough and Syrian Low, as distinguished by Kahana et al. (2002), are associated by their unique spatial distribution in the region (Red Sea and Syria respectively). Especially convective dominated storm types preferentially occur at certain geographical regions, particularly when all conducive ingredients (see section 4.2) for (deep) convection in that region simultaneously exist (Ducrocq et al., 2008; Nuissier et al., 2008). A well-known example in the occurrence of convective dominated storm types is the West-Mediterranean region (Dayan et al., 2015). The conducive ingredients are the existence of a source of moisture and energy or heat from the lower troposphere from the Mediterranean Sea, the south-eastern flow that transports moisture and heat to this region meanwhile providing instability, and the orography that triggers the deep convection of the conditionally unstable local air (Nuissier et al., 2008; Ducrocq et al., 2008). Another example of the prevalence of convective dominated storm types is the region East China: more than $90 \%$ of the monsoon precipitation is caused by these storm types (Wang et al., 2015a).

The occurrence of storm types also depends on the season of the year and on the diurnal cycle of the day (e.g. Kahana et al., 2002; Schumacher and Johnson, 2006; Yu et al., 2014; Hitchens et al., 2013; Dayan et al., 2015; Moore et al., 2015). Tropical cyclones almost exclusively occur in summer and autumn due to their dependency on the warming of the sea. As this warming depends on the sea, tropical cyclones in e.g. western North Pacific can occur every month. Extra-tropical or synoptic storm types are distributed fairly evenly throughout the year with a slightly higher occurrence in spring and fall when largescale temperature differences are largest and so large-scale flow patterns like low-level jets and atmospheric rivers that continuously replenish moisture and heat (conditional instability), are more prominent. This specifically holds for the stationary atmospheric rivers (Moore et al., 2012). In this context, Schumacher and Johnson (2006) speak about the baroclinic conditions necessary for the synoptic systems that are most often in place in spring and fall. Convective storm types however, are highly unevenly distributed throughout the year and are region-dependent (Funatsu et al., 2009). These systems tend to occur in summer and early fall because of the presence of moist, conditionally unstable conditions supportive of deep convection - though they can also occur in conjunction with weak baroclinic conditions and accompanying synoptic storm types. The synoptic and convective storm types were also indicated respectively as cool and warm season systems (Milrad et al., 2014; McCorkle et al., 2016; Moore et al., 2015) or winter and spring extratropical and warm season convective systems (Smith et al., 2010). In the US and Canada, heavy cool-seasons precipitation is often associated with substantial moisture and heat transport by atmospheric rivers from the subtropics and accompanying (anti) cyclones (extratropical) from the Pacific Ocean leading to intense orographic precipitation and fast snowmelt (Lackmann and Gyakum, 1999; Roberge et al., 2009) or by cold fronts and (anti-)cyclones (tropical and extratropical) from the Atlantic Ocean (with synoptic scale forcing for ascent, provided that the air mass in the frontal cases is characterised by low static stability) (McCorkle et al., 2016), and warm season precipitation with mesoscale processes (with mesoscale forcing for ascent) (Milrad et al., 2009b; Milrad et al., 2010a; Milrad et al., 2014; McCorkle et al., 2016; Moore et al., 2015). Besides the seasonal cycle, convective storms also have a daily cycle (Moore et al., 2015; Schumacher and 
Johnson, 2006; Thorndahl et al., 2014; Zhang et al., 2009). The activity of the convective storms is maximal in the afternoon, evening or at night, concurrent with the course of daily warming. In addition, diurnally forced convection can also be linked to topographically induced baroclinic zones possibly associated with processes like sea-breeze circulations and cold-air damming (Ducrocq et al., 2008; Moore et al., 2015). The timing of the interference between the daily cycle and large-scale flow can also the activity of rain storms (Laing, 2004).

Next to their dimensional, seasonal and geographical characteristics, storm types are also characterised by their structure, motion and evolution. These development characteristics can be space and time dependent (Javier et al., 2007) and are (beside on the meteorological situation) also dependent on the characteristics of the land surface (Ntelekos et al., 2008). The structure of a storm gives expression to its spatial form. It depends very much on the distinction between nonconvective and convective storm types. A strict non-convective storm type has a banded cloud-structure (with widespread precipitation) related to the position of the warm and cold front that belong to a lowpressure centre. A strict (single) convective system has a more or less cell-like structure (with concentrated precipitation) containing the updraft and the downdraft of this convective storm. However, most storm types in reality do have a much more complicated structure with several storm elements and their own typical spatial distribution of storm elements (see section 5.3 and 5.4). Conceptual models of a storm structure have been developed to better understand and forecast the distribution of precipitation (Porcú et al., 2003; Smith et al., 2005b). Modelling needs to go hand in hand with monitoring as each heavy precipitation event is an unique event, limiting the sole use of a precipitation model (Terranova and Iaquinta, 2011; Terranova and Gariano, 2014). In addition, topographic features play a large role in the structure of heavy precipitation storms (Doswell et al., 1998; Ivančan-Picek et al., 2003; Zhang et al., 2009) underpinning the need of monitoring precipitation too.

The motion of a storm is the displacement of the storm in time. It is dependent on the horizontal wind speed and vertical shear in the troposphere. The wind speed of the lower layer of the troposphere is determinant for the motion of synoptic storms and that of the middle and upper layers for the motion of convective storm types. Low storm speeds (a quasi-stationary storm) usually produce high storm precipitation amounts (Doswell et al., 1996; Nuissier et al., 2008; Smith et al., 2000). A high-speed motion with high rain intensities however, limit rainfall to very short durations and so the precipitation amounts to modest quantities (Smith et al., 2001). The track of storms manifests itself in track- (or orientation) dependent distribution of precipitation (Borga et al., 2007; Smith et al., 2001). Most storms have a more complicated structure than that of the strict synoptic and convective storm type. Such storms also have a more complicated motion than that of the basic storm types (see section 5.2).

The storm motion is the result of advection and propagation. Advection (cell movement) of an individual cell or updraft almost entirely takes place via the tropospheric wind and propagation by the production of new storm cells. The larger the tropospheric wind, the lower the potential for long convective precipitation at a given region (Doswell et al., 1996). The more important the propagation, the more the track of the storm will deviate from the mean wind direction (Smith et al., 1996). When advection and propagation are comparable in strength but in opposite direction, storm motion will vanish (storms become quasi-stationary) and so the duration of precipitation of a certain region will enlarge. According to Chappell (1986), it is the slow motion of the precipitation system that dominates in most cases of flash flood producing heavy precipitation.

Propagation can be influenced by internal (like convective downdrafts) and external processes (like fronts, outflow boundaries and mesoscale boundaries like sea-breeze fronts). In this respect, two factors are important: the strength of the wind shear and the strength of the low-level outflow. If both wind shear and outflow are weak, new cells will form in close proximity of the precipitation cascade. A strong outflow promotes undercutting of the updraft and so dissipation of the existing convective cell. A strong outflow is promoted by dry mid-level air: dry air produces significant evaporative cooling of the sinking air that in turn creates negative buoyancy by which the outflow is strengthened. If the wind shear is strong, new cells will be formed at considerable distance from the existing cells. While this reduces the risk of undercutting of the existing cell, the existing cell cannot aid the convective updraft of the new cell (Doswell et al., 1996). When neighbouring convective cells interact and local divergence develops, propagation is inhibited. Consequently, these cells sustain longer and so can develop into much larger cells (Choi et al., 2011).

The (temporal) evolution shows the development of a storm structure over time (storm's lifecycle). The lifecycle of a storm type can usually be divided into three stages: the developing, the mature and the dissipation stage. Each stage is characterised by a certain structure and the presence of certain processes. These processes in turn can influence the structure of the storm. The successive stages of the synoptic type consist of the formation, the occlusion and dissolution of fronts and those of the convective storm type of the triggering of convection or formation of the updraft, the formation of the downdraft (simultaneous presence of both updraft and downdraft) and the dissolution or closedown of the of the updraft (presence of downdraft only). The evolution of most storm systems is more complicated as will be seen in section 5.3 and 5.4. Usually the mature stage is the most determinant one in the production of heavy rainfall. The total area of precipitation and the areal precipitation are directly related to the thunderstorm intensity. The thunderstorm intensity itself is related to the duration of the maturity stage (Rigo et al., 2010). Besides meteorological processes at both synoptic and meso-/local scale, also surface features like topography influence the evolution of a storm (Ducrocq et al., 2008; Nuissier et al., 2008). The evolution also is a part of the description of the storm types in conceptual models (Porcú et al., 2003).

The storm's characteristics structure, motion and evolution are of fundamental importance for the spatiotemporal variability of its precipitation - both rate and amount (Smith et al., 2013a; Smith et al., 2000; Smith et al., 2001), especially for the variability of short-term convective precipitation (Smith et al., 2009). Consequently, contrasts in these characteristics translate themselves directly into contrasts in variability. Specifically, variability of precipitation rate at short time scales is closely related to time-varying characteristics of storm elements (Yang et al., 2014b). According to Smith et al. (1994a) and Javier Julie Rose et al. (2010) heavy precipitation exhibits large spatial and temporal variability. The precipitation (spatiotemporal) variability can be further increased by the storm's propagation mechanism (Smith et al., 1996), the storm's microstructure (Smith et al., 2001) and the irregularity of the topography (Yu et al., 2015) or land slope (Renard, 2017), especially in mountainous areas (Buytaert et al., 2006; Pinto et al., 2013; Yang et al., 2017b) and in urban areas even in a small area (Piotrowski, 2017). In this respect one can consider the altitude, slope and aspect of the topography that influence rain shading and wind speed and so precipitation variability. According to De Lannoy (2001), precipitation exhibits large variability at every scale, from global to local scale; even a small area can have a non-uniform precipitation. Convective precipitation by thunderstorms/ rain cells is characterised by high central precipitation rates for a short duration (Peleg and Morin, 2012; Rebora and Ferraris, 2006) and a high spatiotemporal variability (Dayan et al., 2015; Yang et al., 2017b) and this variability can be described by a 2D Gaussian or exponential distribution or exponential decline from the cell centre (De Lannoy, 2001; Rebora and Ferraris, 2006; Morin and Yakir, 2014). The spatiotemporal variability of frontal precipitation is much less than that of convective precipitation. As far as known, the (statistical) distribution of precipitation variability of frontal precipitation is not explicitly mentioned in literature. According to Smith et al. (2005b), conceptual models can 
Table 3

Overview of main storm characteristics.

\begin{tabular}{l} 
Characteristic \\
\hline Size, height, strength \\
Structure \\
Evolution \\
Motion/speed \\
Intensity \\
Location \\
Frequency \\
Organisation \\
Type
\end{tabular}

provide a useful framework for characterising the spatiotemporal variability of precipitation. Table 3 presents an overview of the main storm characteristics.

5.3. Specific characteristics and causes/backgrounds of heavy precipitation convective storm types, and precipitation variability

\subsubsection{Introduction}

In literature four main types of convective storms or thunderstorms are distinguished (Doswell et al., 1996; Rigo and Llasat, 2004; Tudurí and Ramis, 1997): single-cell, multicellular, squall-line and supercell thunderstorms. Zhou et al. (2013) and Smith et al. (2000, 2013b) identify the squall-line and supercell types with Mesoscale Convective Systems. All types have in common that they result from the rapid ascend of warm, moist air due to local instability or to a line of convergence. Clouds associated with them are of the Cumulonimbus type. Thunderstorms are normally accompanied by heavy precipitation, though this is relatively rare in case of a single cell type (most heavy precipitation producing thunderstorms are multicellular) (Doswell et al., 1996); an example of a single cell storm is the Rapidan storm in the USA as given by Smith et al. (1996). Intense short-term precipitation (or peak) rates are often associated with collapsing thunderstorm cells (Smith et al., 2016; Yang et al., 2016). An episode of thunderstorms however, is often the result of the interaction of convection favouring weather conditions and large-scale flow conditions: locally a low thermal stability and weak wind, aided by surface lows' induced large-scale lifting that persist over several days due to atmospheric blocking (Piper et al., 2016). As a consequence of the low midlevel wind speeds the convective cells are nearly stationary which results in large local precipitation amounts. In addition, during a monsoon period heavy precipitation by local thunderstorms (driven by local instability due to solar heating) can significantly contribute to the total monsoon precipitation amount (Luo et al., 2013). In addition, limitations in atmospheric moisture availability significantly influence the convection intensity (Peleg and Morin, 2012). Complex interactions between local heating, sea breeze circulation, orography and large-scale flow greatly can affect both the timing and the intensity of these local thunderstorms by modification of the convection (Sow et al., 2011). These interactions also influence the spatiotemporal characteristics of (single) convective cells, like intensity, number, size/area, shape/orientation, speed and lifetime (Peleg and Morin, 2012). Apart from that, thunderstorms can also initiate and develop over the sea. When reaching coastlands they can cause severe damage there (Cohuet et al., 2011).

The type of thunderstorm present depends on the local instability (or CAPE) and vertical wind shear (Moller et al., 1994). In respect of this typology a major distinction has been made between unorganised and organised thunderstorms. While unorganised thunderstorms usually are associated with low vertical wind shear and weak winds, organised thunderstorms are commonly associated with high vertical wind shear and strong winds. The higher the instability and vertical wind shear, the more organised the thunderstorms are. An important characteristic of distinction is that unorganised thunderstorms only live short and produce new convective cells in any consistent location relative to their predecessors, while organised ones live relatively long and produce new cells in preferred location relative to their predecessors, mostly on the right storm flank (relative to storm motion) or down-shear flank in case of long and continuous cold pool edges. Dissipating cells occur at the left flank. The short-lived thunderstorms have a pulse character or a series of pulses in case of unorganised multicellular storms and the long-lived ones an episodic character (Moller et al., 1994).

\subsubsection{Single-cell, multicellular, squall line and supercell thunderstorms}

A single-cell thunderstorm has one updraft and occurs at a certain level of CAPE and at a very low level of wind shear. As it forms in troposphere's with low wind shear, its downdraft's precipitation will cancel out the updraft and quickly causes dissipation; single cell thunderstorms normally last no longer than an hour. Its motion can take place by advection by the mean wind speed of the (lower) troposphere and propagation by an outflow boundary. If a thunderstorm develops an outflow boundary, this boundary can set up the development of a new thunderstorm (Fig. 8)(Ducrocq et al., 2008). If a thunderstorm generates a nearly stationary outflow boundary, a meso-high develops (Bradley and Smith, 1994). Single-cell thunderstorms and supercells can merge when several thunderstorms or supercells exist in proximity to each other (Billings and Parker, 2012; Doswell et al., 1998; Sow et al., 2011), which is facilitated by outflow boundaries. Propagation and merging can result into an increase in high precipitation

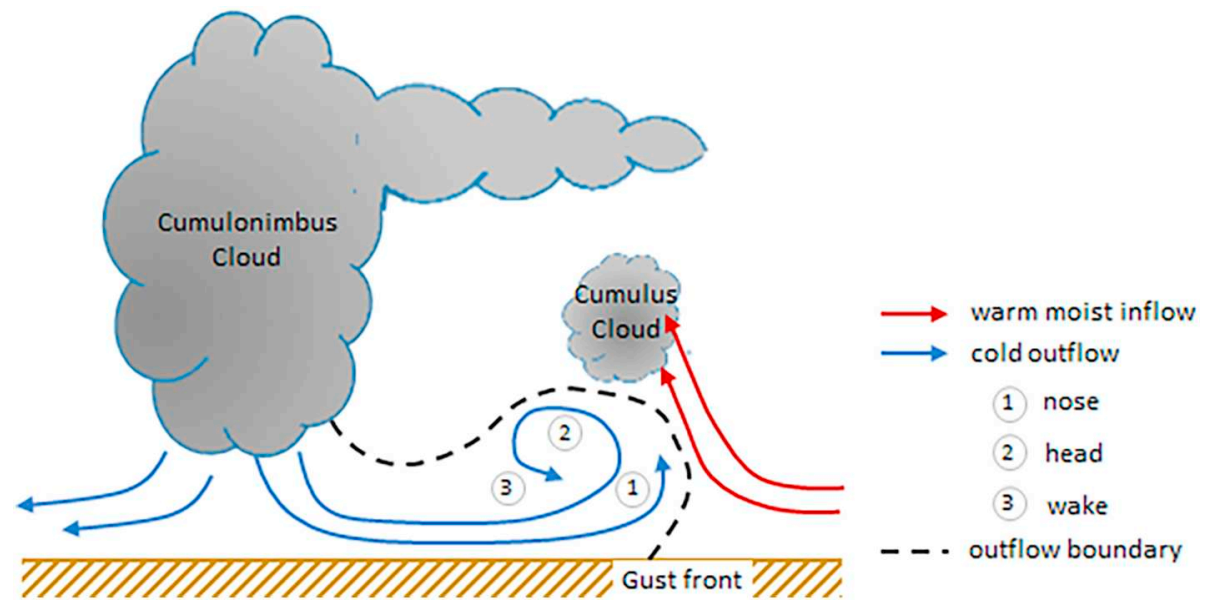

Fig. 8. The generation of a thunderstorm outflow with an outflow boundary or gust front. 
(Smith et al., 1996). The showery precipitation is characterised by rapidly changing intensities, both in time and place.

A multicellular thunderstorm type consists of multiple cells that are at a different developmental stage. It is stronger than the single-cell type. This type occurs at higher values of CAPE and wind shear. The resulting stronger downdraft can act as a barrier for the airflow which forces renewed convection. Consequently, new cells generally form upwind of an existing cell where the downdraft meets the tropospheric airflow. A multicellular thunderstorm often arises from updrafts at mountains and linear boundaries like low-pressure cold fronts. While an individual cell is some kilometres wide and can last for an hour, a multicellular thunderstorm is several hundreds of kilometres wide and can last for hours. An increased lifetime can result in an increase in heavy precipitation (Bennett et al., 2006; Zhang et al., 2001; Zhang and Smith, 2003).

A squall line thunderstorm type is an elongated band of strong thunderstorms that have a common lifting mechanism. Examples of lifting mechanisms that tend to occur in bands are sea breezes, (coastal) fronts, drylines and large outflow boundaries (low-level convergence lines) (Curtis, 2017; Iwai et al., 2018; Meng et al., 2013; Smith et al., 2000). Squall lines also are considered as (quasi-)linearly organised mesoscale convective systems with a precipitation band and usually a cold pool in the convective region adjoined by a large region of stratiform precipitation, the stratiform region (Meng et al., 2013; Uebel and Bott, 2015). The classic squall line will develop ahead or along a cold front or dry line boundary due to the presence of significant moisture and strong upper level divergence. Strong updrafts occur ahead of the line and in front of the cold pool in the convective region while moderate up- and downdrafts occur behind the line in the stratiform region. Updrafts until the tropopause indicate deep convection and high local instability. Squall lines usually occur in environments with moderate to high instability and low- to midlevel vertical shear. High environmental shear determines into large extent the structure, strength and lifetime of subtropical squall lines (Bryan et al., 2006; Cohuet et al., 2011; Meng et al., 2013; Weisman and Trapp, 2003; Zhou et al., 2013). According to Bryan et al. (2006) high vertical shear of horizontal wind is an essential feature for the development of large and strong cells in the squall line and the deepest lifting of air and the most effective convective retriggering occurs when the vertical shear strength as confined to the cold pool depth (approximately) balances cold pool intensity as the convection is upright (and not tilted). The associated theory of a balance between cold pool intensity and environmental shear and its applicability is further worked out in Bryan et al. (2006) and Weisman and Rotunno (2004). Organisational aspects of squall lines are elaborated at discussion of the MCSs.

A strong squall line with strong low/mid-level wind shear consists of a continuous line of deep convection with a deep and strong rear-inflow jet related to organised horizontal convective outflow, while a weak one exhibit several isolated multi-cell thunderstorms with a shallow and weak rear-inflow jet (Uebel and Bott, 2015). A descending convectively generated rear inflow jet (density current) occurring under the stratiform part of the squall line, can function as a barrier (cold pool) to increase the convection of incoming moist and warm air at the other side of the squall line. In addition, if a dry layer exists above a thermal boundary and below the stratiform part, evaporation of falling precipitation in this dry layer can contribute to the enhancement of this inflow jet and can increase the convection this way (Cohuet et al., 2011).

The tendency for the formation of a linear structure of the convection cells in a squall line is not only related to the linear lifting mechanisms causing the initial convection to be organised in lines, but also to the outflow boundaries themselves and their interaction. Downdrafts of several neighbouring storms can merge into one stronger outflow boundary along which new convection develops. Outflow boundaries that result from evaporative cooled downdrafts can be the locus for the development of new updrafts. Outflow boundaries also can enhance existing banded lifting mechanisms by their merging. On the other hand, mesoscale circulations can change convective structure from a band of multicell convective storms in into a squall line with narrow convective bands (Jung and Lee, 2013). Only if the tropospheric wind speed matches the updraft speed, locally high precipitation rates can be expected (Doswell et al., 1996).

A high updraft velocity creates a meso-low and the associated high downdraft velocity a meso-high (Schumacher and Johnson, 2005; Smith et al., 2000), that interact to develop stationary convection (Ramis et al., 1998). If instability and moisture remain present ahead of the squall line, the squall line can sustain itself by the production of its own lift being caused by its outflow boundaries (leading edge lifting mechanism) (Smith et al., 2000). The heavy precipitation occurs at the downdraft side of the squall line and has the form of a rain shield. Yang et al. (2014a) noticed the link between the strength of the downdrafts (and convective intensity) and the height of precipitation rates at short time scales.

A supercell thunderstorm type is a thunderstorm characterised by the presence of a strong and persistently rotating updraft (mesocyclone) and can have different cellular morphologies (Duda and Gallus Jr., 2010; Moller et al., 1994). Moller et al. (1994) distinguish classic, low-precipitation and high-precipitation supercells at what high-precipitation ones are characterised by the production of heavy precipitation in and near the mesocyclone. A supercell is a large, mostly isolated (sometimes embedded in a squall line) and quasi-steady state thunderstorm that can have different cellular morphologies and forms in a troposphere with a high vertical wind shear (induced by the jet stream) and in an environment with very high CAPE. The high wind shear (both in speed and direction) is an extra ingredient, additional to the ingredients moisture, instability and lift (see section 4.3), necessary for the formation of a mesocyclone in a supercell (Bennett et al., 2006; Doswell et al., 1998; Duda and Gallus Jr., 2010; Moller et al., 1994; Rigo et al., 2010; Tudurí and Ramis, 1997). More specifically, high vertical wind shear from locally backed surface winds along thermal boundaries or highly baroclinic boundaries mostly is very conducive for the development of high-precipitation supercells (Moller et al., 1994). According to Moller et al. (1994) the same holds for a storm motion well to the right of the mean environmental wind. In addition, Doswell et al. (1998) remark that helicity (a measure of rotation) also is an important ingredient for the formation of a supercell, albeit it is not necessary for the production of heavy precipitation itself.

A certain configuration of the high shear does tilt the updraft by which the downdraft is separated (i.e. horizontally displaced) from the updraft (Moller et al., 1994). This happens because the strong upper tropospheric winds evacuate mass from the top of the downdraft meanwhile reducing the precipitation loading. When the updraft is displaced from the downdraft, the updraft will not be cut off by the precipitation falling through the updraft. Consequently, a supercell thunderstorm can last for hours and therefore they are called quasisteady state storms. When the shear is very high however, the CAPE needs also to be very high. A capping inversion is usually required to obtain this high CAPE. A strong updraft (resulting from /caused by a very high CAPE) together with a big updraft prohibit chopping of the updraft. Both the tilt and the rotation make deep convection and so high precipitation is possible (Doswell et al., 1998; Smith et al., 2001; Smith et al., 2013b). According to Yang et al. (2014b), supercells are the most convectively intense storms of the world and can produce the largest precipitation rates at short time scales. In the US, supercell thunderstorms form an important storm type in view of the production of heavy precipitation (Hitchens and Brooks, 2013; Moller et al., 1994), especially in spring when wind shear usually is larger than in summer (Duda and Gallus Jr., 2010). Supercells are found in the warm sector of a low-pressure system and propagate in line with its cold front. Supercells mostly have two downdrafts: the forward flank and the rear flank downdraft. Around the forward flank downdraft (in fact between forward and rear flank downdraft) the most heavy and widespread 
precipitation occurs at which the precipitation is bounded by a shelf cloud (Smith et al., 2001). The distribution of the total precipitation of supercells is characterised by a large spatial variability (Smith et al., 2001). Mid-level tropospheric winds of relatively cool air colliding with the updraft and when redirected downward, also bring precipitation due to convergence of rear flank downdraft and updraft airflows.

\subsubsection{Mesoscale Convective Systems}

A Mesoscale Convective System (MCS) is a complex of thunderstorms that are organised in clusters or lines on a scale larger than individual thunderstorms but smaller than extratropical cyclones, which is embedded within a mesoscale region of stratiform precipitation and that generates a common cirrus shield of mesoscale dimensions (Browning and Hill, 1984; Schumacher and Johnson, 2005, 2006). This complex can include storms systems such as tropical cyclones, squall lines and Mesoscale Convective Complexes (MCCs). While MCS is a more generalised term, MCC is a more specialised one, fulfilling stricter criteria. A MCS is mostly linked to the eastward movement of a weak, mid-level shortwave trough and tends to form near (stationary) surface fronts, in the warm sector or in the cold side of a warm or stationary front of a low-pressure system within the mid-latitudes or along a convergent zone within the tropics, that provides the synoptic and mesoscale environment for deep convection (Aylward and Dyer, 2010; He et al., 2017; Warren et al., 2014). A stationary front decreases the motion of convective cells which increases the duration of precipitation over a certain area (Jeong et al., 2014b). MCSs and their characteristics (like their diurnal occurrence) generally are associated with certain large-scale flow types or circulations (He et al., 2017; Peters and Schumacher, 2015) which has relevancies for their predictability. Besides surface fronts, MCS can also develop at outflow boundaries and mountains or at convergence lines that are associated with mesoscale depressions and low-level flows/jets (Lee et al., 2017a; Schumacher and Johnson, 2009). The overall cloud and precipitation pattern of a MCS is more or less elliptical in shape (clusters or lines) being much larger than the size of individual updrafts in thunderstorms (Schumacher, 2009). The MCSs formed in the US e.g. are often long-lived, large weather systems that mostly tend to form overnight, continue their lifecycle the next day and have their maximum in activity during late afternoon and early evening - mainly in the warm season (Ducrocq et al., 2008; Jeong et al., 2016b; Maddox, 1983; Maddox et al., 1979; Parker and Johnson, 2000; Schumacher and Johnson, 2006; Smith et al., 2013b) and commonly occur in regions of strong low-level heat advection (Reif and Bluestein, 2017). Around 30-70\% of the warm-season precipitation in the US is caused by MCSs (Fritsch et al., 1986) which are mostly composed of elevated thunderstorms (Moore et al., 2003).

As MCSs are initiated by deep convection, they occur most frequently over warm continental interiors and warm tropical oceans. During their life cycle individual cumulonimbus clouds cluster into a cloud band capped with a cirrus shield. The precipitation produced by MCS is a combination of the convective and the stratiform precipitation type (Fig. 9) (Browning and Hill, 1984). The area of high convective activity is usually along the flank of a MCC (or the leading edge of the precipitation area) that is exposed to low-level warm, moist inflow and mostly coincides with the area of heavy precipitation that quickly starts after initiation of convection (Kane Jr. et al., 1987). The size of this area depends on the forcings from the large-scale dynamics and the dynamics of the convective system. A large forcing from the large-scale dynamics occur at the start of the warm season and results into a large rain area and high precipitation. From late spring to late summer the large-scale forcing weakens and the size of the rain area and the precipitation become more dependent upon the (thermo-)dynamics of the convective system. The portion of the life cycle from the maximum rain intensity to the maximum area is termed intense meso-convective stage' because of the large areal extent and the large convective precipitation intensity of the MCC (McAnelly and Cotton, 1989). During this stage a large area of stratiform precipitation develops and becomes increasingly dominant when the convective activity subsides through the latter stages of the life cycle. The spatial pattern of the precipitation forms a reflection of the time-dependent evolution of the MCC at which a small, intense system steadily grows into a larger, less intense system, and then it slowly shrinks. The convective pattern usually is linear whether arched or not - while the stratiform pattern is more concentric and MCC-centered.

Though heavy precipitation is frequently caused by MCSs (Doswell et al., 1996; Jeong et al., 2016b; Mohapatra et al., 2017; Nuissier et al., 2008; Wang et al., 2015a), not all MCSs cause heavy precipitation (Schumacher and Johnson, 2005). The production of heavy precipitation (both location and amount) is strongly dependent on motion and organisation characteristics of MCSs (Schumacher and Johnson, 2008, 2009; Schumacher and Peters, 2017) and on the lowlevel and mid-level moisture content of the air (Schumacher, 2015) and on vertical wind shear (Jeong et al., 2012; Laing et al., 2012; Unuma and Takemi, 2016). In slow moving MCSs precipitation intensity is correlated with convective instability and precipitation area with vertical wind shear. In slower moving MCSs precipitation intensity is larger (due to higher instability and lower vertical shear) and the precipitation area smaller (due to lower vertical shear) than in slow moving ones. A higher low/mid-level moist content and a higher vertical shear favour the development of stronger and more organised MCSs and so the enhancement of their precipitation.

Several mechanisms exist by which mesoscale processes specifically associated with MCSs can contribute to the production of heavy precipitation (Doswell et al., 1996; Jeong et al., 2016a; Jeong et al., 2016b; Moore et al., 2012; Schumacher and Johnson, 2005, 2008; Smith et al., 2000; Smith et al., 2010b). The first mechanism is the training effect: the process by which deep convective cells (that produce high rain intensities) form and pass repeatedly and in succession over the same location. This process results from a linear organisation of the convective cells and is held responsible for the production of the highest precipitation amounts. The duration of the precipitation (and so the precipitation amount) on that location can increase even further when the motion of the MCS is slow. The second mechanism is called the trailing effect. Like training, trailing also refers to an organisational aspect of a MCS. MCSs usually have a large region of stratiform precipitation trailing the leading convection line. This trailing stratiform precipitation increases the duration of the precipitation event by a prolonged period of relatively moderate precipitation that follows a relatively short period of intense precipitation of the convective line. Commonly, the trailing effect significantly contributes to the precipitation associated with this convective line. The third and fourth mechanism refer to the dimensions of an MCS. Because of their dimensions, MCSs can produce large and persistent outflow boundaries (meso-highs) that play an essential role in the continuous upstream initiation of deep convection (the back-building process) and that in turn can develop into a new MCS. The evaporation of precipitation (due to local heating of the land surface) in deep convective induced downdrafts produces cold and dense air spreading outward at the surface (a surface cold pool generated by deep convection) that further increases the airflow at the outflow boundaries (Browning and Hill, 1984; Jeong et al., 2016a, 2016b). By cutting off the internal circulation, pushing against an incoming flow and the occurrence of advection, a cold pool can maintain convection lines in an MCS (Billings and Parker, 2012; Jeong et al., 2016b) but fasten propagation speeds that limits localisation of the precipitation (Schumacher and Johnson, 2009; White et al., 2016).

Also, land-sea contrasts and dry-lines can further increase this airflow (Fritsch et al., 1986). The differential modification of rain-cooled air over land versus water can create a thermal boundary inland from the coast that enhances the ascent of air. Because of their dimensions, MCSs also can affect the airflow and accompanying wind shear and pressure anomalies by which they influence the production of new convection cells. When strong low-level jet occurs in moist, weak mid- 


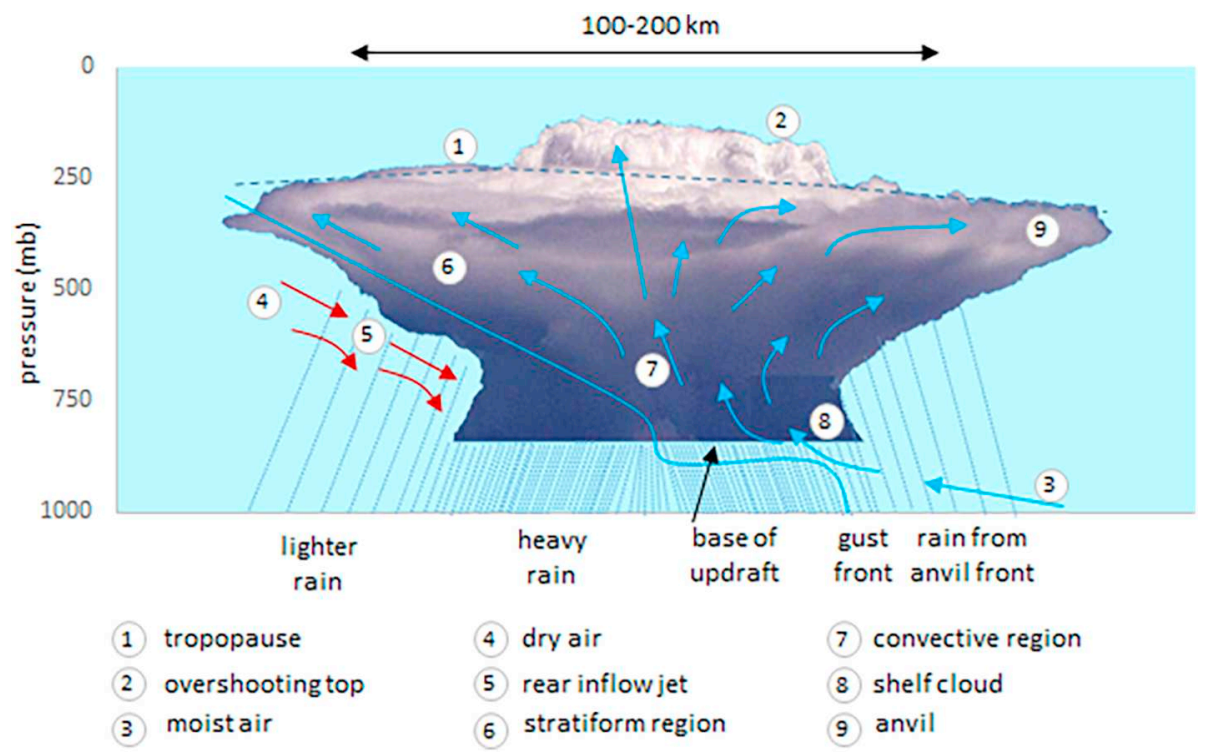

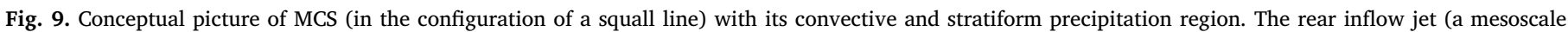
airflow) is invoked by the horizontal pressure differences that are caused by convective circulation.

level air, a strong reversal of the wind shear and pressure anomalies develop which result in favouring development of new convective cells and a slowdown of the MCS. In this moist environment, the production of convectively generated cold pools is precluded by the high relative humidity (Schumacher and Johnson, 2009; Unuma and Takemi, 2016), whereas in a dry environment cold pools are stronger and the overall convection is weaker by which back-building becomes disrupted (Schumacher, 2015). This leads to a reduction in precipitation both at local and at system level. The mesoscale convective vortex, that MCSs contain, leads to a persistent and strong ascent near its centre (i.e. at mid-levels) resulting into slow moving, deep convection. Both the strong convective heating and the cold dome, resulting from the large low-level evaporative cooling, assist in the maintenance of a mesoscale convective vortex and the associated, subsequent initiation and maintenance of convection in the following afternoon and evening. Though lifting at an outflow boundary is the common mechanism of back-building, lifting by wind shear and pressure anomalies also does occur (Schumacher et al., 2013; Schumacher and Johnson, 2009; Wang et al., 2015b). As Schumacher and Johnson (2005) already concluded, the characteristics organisation, motion and dimension are key factors that determine whether MCSs produce heavy precipitation.

According to these authors, many of the heavy precipitation events were caused by a linearly structured MCS. According to Konrad (1997, 2001) a linear orientation of a given lifting field with the mean tropospheric wind vector encourages convective training and heavy precipitation as in this orientation the support of convection is the greatest. A surface cold pool and a nearly stationary low-level gravity wave can help to organize the convection into a quasilinear system (Billings and Parker, 2012; Schumacher, 2009; Schumacher and Johnson, 2008), and a cold pool (Jeong et al., 2016b) and a mesoscale convective vortex (Schumacher, 2009; Schumacher and Johnson, 2009) into a quasi-stationary system. Both system configurations are conducive to high local precipitation amounts. All organisation structures given in section 5.1 are examples of a linear organisation structure. Though the trailing stratiform types have bowed segments, they allowed for a period of time when cell motion was parallel to the convective line that causes them to produce heavy precipitation. The slow motion of the leading stratiform type is responsible for the production of heavy precipitation. Due to the strong line-perpendicular shear, the trailing stratiform and leading stratiform types generally have a line-perpendicular motion direction that diminish their total precipitation amounts. The parallel motions of both the stratiform region and the line of convective cells of the parallel stratiform type are the cause of the production of heavy precipitation. The training line/adjoining stratiform and back-building/ quasi-stationary types however, are the most frequently observed MCSs in the US (Schumacher and Johnson, 2005) and will be described in more detail below. However in China, the embedded lines and parallel stratiform MCSs types were most frequently associated with short term heavy precipitation. The mid- and upper tropospheric winds with associated shear and the atmospheric stability determine the occurrence of the different types (Jeong et al., 2016a). Jessup and Colucci (2012) yet remark that mostly organisation structures of convection conducive for producing sustained moderate to high precipitation rates are responsible for heavy precipitation events and that not only back-building or training line/adjoining stratiform events but also events with large areal coverages make part of these structures.

The training line/adjoining stratiform type is characterised by the training effect at which newly developed cells (slowly or more quickly) pass over the same region along the convection line and the very little motion in the line-perpendicular direction (mainly motion in line-parallel direction) because of their occurrence in environments with largely line-parallel mid-level shear. This combination of motion characteristics results into heavy precipitation along the convective line. The region of stratiform precipitation forms almost parallel to the convective line and moves in the same direction as the convection line. Both the convective line and the stratiform region form on the cool side of and nearly parallel to a pre-existing slow-moving synoptic - or mesoscale boundary which is usually a warm or stationary front. The stratiform region forms farther away from this boundary. The configuration of the convective line and the stratiform region determine the high precipitation variability of this MCS type (Aylward and Dyer, 2010; Schumacher and Johnson, 2005).

The back-building/quasi-stationary type is characterised by a line of back building deep convection cells at which decaying cells move downstream and new cells repeatedly form upstream of their predecessor cells (back-building) passing the same locations along the convection line for hours (echo training). This opposite motion results in slow movement of the convection line itself (quasi-stationary behaviour): near cancellation of cell motion and cell propagation. This cancellation is responsible for the production of heavy precipitation since the total precipitation amount is directly proportion to the (high) rate and (long) duration of rainfall (see 4.2); back-building increases 
rainfall duration (Curtis, 2017). In many cases, convection initiates along pre-existing mesoscale boundaries like downdraft induced outflow boundaries and is maintained by the generated outflow boundaries of the newly developed cells that interact with low-level wind shear. In some cases convection is initiated and maintained without any surface boundaries but with nearly stationary (due to strong reversal of the wind shear) convectively generated low-level gravity waves (Bennett et al., 2006; Schumacher and Johnson, 2008). The backbuilding/quasi-stationary types are less dependent on pre-existing synoptic scale boundaries than the training line/adjoining stratiform type. They cover a smaller region than the training line/adjoining stratiform type, however the potential for the production of heavy precipitation is higher. In some cases the back-building/quasi-stationary type develops a region of stratiform downstream that increases the potential of heavy precipitation (Schumacher and Johnson, 2005, $2006,2008)$. Though the moist unstable air above convectively generated cold outflows can easily be lifted to produce precipitation, the creation of a persistent MCS in south-eastern Korea requires a continuous convective updraft redevelopment by a confluence between downdraft and the low-level jet, and upstream maintenance by feeding of warm, moist air by this low-level jet (Jeong et al., 2016a, 2016b). According to Borga et al. (2007), the stationarity of rain bands led to highly variable precipitation amounts and extreme precipitation gradients.

Wang et al. (2014c) investigated a long-lived MCS in southern China. They discovered two scales of training at the mature stage of this MCS. The first one (line training) occurs in the morning at which convection is repeatedly triggered along individual rain bands at which new convection cells are repeatedly formed by convergence along a mesoscale boundary between precipitation-induced cold storm outflows and warm, moist airflow from the adjoining sea, resulting in the development of several parallel rain bands. The second (band training) occurs in the afternoon at which the individual rain bands move successively and parallel over the same region to the coast. This two-scale training can be interpreted as an extension of the training concept developed by Schumacher and Johnson (2005).

MCSs can also be involved in so-called warm-season heavy precipitation episodes such as they occur in e.g. eastern Asia (Tibetan Plateau), the US (Rocky Mountains) and in North-Africa (eastern Sahel). These episodes have a coherent and longevity behaviour and exhibit frequent or periodic development of convection and subsequent eastward propagation at the lee of large mountains. This periodic behaviour with a diurnal cycle is caused by the mountain-plain solenoid that develops in response to stronger solar warming over elevated terrain during the day in summer. This mountain-plain solenoid induces a low-level flow that flows upslope to recurrently initiate convection at daytime over the mountain in the afternoon. After this initiation, the convection cells grow and organise into MCSs. Next overnight they propagate trough adjacent low-lands downstream by cold-pool dynamics in a sheared environment when favourable upper-level largescale flows or mechanisms like gravity waves exist. The pattern of the mountain-plain solenoid reverses at night, and widespread ascent over the plains east of the mountains occurs. Both the reversal itself and the development of a nocturnal low-level jet (via the supply of warm, moist air) assist in the periodic maintenance of the MCSs at the leeside of the mountain by low-level destabilisation (Trier et al., 2010; Tuttle and Davis, 2006; Wang et al., 2014a and Wang et al., 2014b). The recurrent behaviour of convection in the plain of adjacent mountains can also be caused by low-level stabilisation and reduction of daytime heating due to residual clouds stemming from the previous diurnal cycle, together with the weakening of the vertical shear by temporary disruptions of a low-level jet (Laing et al., 2012).

From the forgoing, it becomes clear that these eastward propagating precipitation episodes (consisting of eastward propagating MCSs) are controlled by both large-scale conditions and mesoscale or local scale features like land-sea distribution and low-level frontogenesis, and topography (inducing local and diurnal variability). Low-level jets play an important role in the development and maintenance of these episodes through their role in moisture transport, frontogenesis, convergence and lifting. Over East Asia the large-scale flow (nocturnal lowlevel jet) is more important for the development, organisation and propagation of convection in these episodes than in the US or NorthAfrica as the summer monsoon or Meiyu front over East Asia is an important feature for precipitation formation. Further, besides an eastward moving episode a rare westward one (that forms upstream of the mountain) exists. These episode types differ in the location of the low-level jet and consequently also in the movement direction of the episode eventually resulting in a shift of the region of convection (mesoscale effect). This shift does also coincide with changes in organisation, maintenance and in the way of propagation. Changes in organisation are a result of change in the strength of the low-level jet and in the vertical wind shear: the low-level jet and vertical wind shear are strong in the westward episode and weak in the eastward episode. While in the eastward episode the convection is well-organised in a squall line shaped MCS that propagates by cold pool dynamics and advection through the low-level jet, in the westward episode the convection was scattered and individual cells move with the background flow. As the low-level jet is strongly controlled by large-scale flow conditions, these conditions are highly determinant for the regional of heavy

precipitation in east Asia (Davis and Lee, 2012; Jeong et al., 2012; Laing et al., 2012; Trier et al., 2010; Tuttle and Davis, 2006; Xu et al., 2011; Wang et al., 2012; Wang et al., 2014a; Wang et al., 2014b).

Though the general location and timing of heavy precipitation (the overall precipitation pattern and distribution) are primarily controlled by favourable large-scale flow conditions i.c. low-level jets, the local convective behaviour is subject to terrain-associated circulations. These influences are caused by land-sea contrasts and differences in topography that result in diurnal precipitation cycles, particularly in the local enhancement of precipitation in the afternoon. In addition, the evaporation of previous precipitation resulting in the formation of cold domes aren't only responsible for repeated convection, they also contribute to the diurnal or periodic behaviour of the precipitation cycles. Finally, the topography also exerts influences on the large-scale flow. The blocking and thermal effects of this topography result in a deflection of the large-scale flow and of the convergence upstream (Trier et al., 2010; Tuttle and Davis, 2006; Tu et al., 2014; Wang et al., 2014a; Wang et al., 2014b).

\subsection{Heavy precipitation synoptic storm types}

\subsubsection{Extratropical cyclones}

An extratropical cyclone is a storm system characterised by a lowpressure and cold-core centre with weather fronts that can produce thunderstorms and heavy precipitation. Regional areas occur where over $80 \%$ of heavy precipitation is caused by extratropical cyclones (Pfahl and Wernli, 2012). Contradictory to tropical cyclones, extratropical cyclones occur in the mid-altitudes and obtain their energy from horizontal temperature and dew point gradients on the land surface that exist along these weather fronts and they form along these fronts when significant vertical wind shear exits. This wind shear is induced by upper-level divergence as created by the jet streak of the jet stream. This divergence results respectively in a lower pressure of the core, in low-level convergence, in an upward motion and in the production of clouds and precipitation in the core of the system. According to Field and Wood (2007), extratropical cyclones induce a poleward moisture transport along a front that results into substantial surface precipitation at which the mean precipitation intensity is related to cyclone's intensity (linearly, according to Flaounas et al. (2018)) and its amount of water vapour. An extratropical cyclone can also cause heavy precipitation (Kahana et al., 2002; Ulbrich et al., 2003; 
James et al., 2004; Hawcroft et al., 2012; Grams et al., 2014; Pfahl, 2014) if several factors and mesoscale structures simultaneously occur (Pfahl and Wernli, 2012). When the extratropical cyclone occludes at which the warm sector air is pushed upwards into a trough of warm air aloft by undercutting of cold air, a comma-like shape of cloud develops within this occlusion in a region at the north-west of the core. If this lifted warm air has enough instability, within this region thunderstorms and so heavy precipitation can locally occur. The repeated passage and widespread occurrence of convective thunderstorms are responsible for the heavy precipitation (Schumacher and Johnson, 2005; Smith et al., 2010). Also, slow moving extratropical cyclones can be involved in the production of heavy precipitation (Doswell et al., 1998). Extratropical cyclones have a strong variant that can cause heavy precipitation within the comma-head region but also along the cold or stationary front (cold frontal region) culminating in comma-shaped pattern in the southern, eastern and northern part of the cyclone and so an asymmetric precipitation distribution (Field and Wood, 2007; Raveh-Rubin and Wernli, 2016). The cyclones of the mid-latitude may occur during the entire year, but will occur mostly in the winter season when the temperature and dew-point gradients on the land surface are the largest. They have a life cycle of 2 to 6 days.

Extratropical cyclones can contribute to large-scale precipitation in e.g. Central and Alpine Europe, in the Mediterranean and in Pakistan for a number of days. These low-level (surface) cyclones are mostly formed by upper-level troughs or upper-level depressions or lows and meridional jets (certain coherent features of the large-scale circulation) and sometimes by surface troughs or depressions. Various types of cyclones can occur, e.g. Atlantic cyclones, Cyprus lows, warm-season thermal lows, Indian monsoon depression, and lee cyclones (see also 5.2). Heavy precipitation can commonly attributed to anomalous occurrences/frequencies of cyclones and blocking anticyclones. These blocking anticyclones can assist wave breaking, cold air advection and trough formation and can determine recurrent wave breaking at a certain location (Aylward and Dyer, 2010; Barton et al., 2016; Hai et al., 2017; Martius et al., 2013; Pfahl, 2014; Raveh-Rubin and Wernli, 2016). In addition, cold-air outbreaks of a Siberian high (Hai et al., 2017) and tropical forcing's like Madden-Julian oscillations (also named as teleconnections) or the recurrent extratropical transition of tropical cyclones also can increase the frequencies of cyclones (Archambault et al., 2013; Barton et al., 2016). For the clustering of European winter heavy precipitation events caused by extratropical cyclones, the meridional extent and the strength of the North-Atlantic extratropical jet are of central importance (Pinto et al., 2014). In these cases the blocking anticyclones, tropical forcing's and extratropical transition function as mechanism for sub-seasonal clustering of cyclones, either individual or in combination. If such a (quasi-) stationary upper-level flow in a trough or Rossby wave pattern and its upper-level breaking instigates a sequence of consecutive cyclones with similar tracks, they can result in heavy precipitation at the same region for several days. This precipitation develops predominantly within the warm sector ahead of the cold front of these cyclones where air ascends (large-scale and persistent lifting) over a long track distance along the sloped isentropes (i.e. lines of equal potential temperature) into the upper troposphere within warm-conveyors belts. Though this ascent is usually poleward and warm, moist air originates from oceanic regions, nevertheless equatorward ascent of continental moist air coming from land evaporation, also occurs and can produce large-scale precipitation (Grams et al., 2014; Madonna et al., 2014; Martius et al., 2013; RavehRubin and Wernli, 2015; Sodemann et al., 2009; Ulbrich et al., 2003; Winschall et al., 2014).

A particular heavy precipitation event is the result of the merger and the re-cyclogenesis of twin cyclones around Japan in 2001 (Yamoto, 2012). This merger process is caused by the dynamic coupling of the upper and low vortices of these cyclones and enhanced by diabatic heating. Although the twin cyclones are not strong a heavy precipitation event could develop because of formation of a moist low-level jet at the merger process responsible for the large supply of moisture. When after the merger the moist low-level jet is located below the upper-level jet, these jets become coupled by which the upward flow and precipitation are enhanced.

In a study on the precipitation of Mediterranean cyclones (which are one of the most prominent causes of flooding risks) it is concluded that both deep convection and warm conveyor belts are the main mechanisms for the production of heavy precipitation in these cyclones. The commonality is that both mechanisms are characterised by intense latent heat release and precipitation formation. Nevertheless, the production mechanisms are principally different. Where deep convection refers to strong vertical updrafts of air, warm conveyor belts refer to fast and slantwise rising air over the warm front of the extratropical cyclone. These warm conveyor belts highlight the importance of baroclinic instability and large-scale ascent for the production of heavy precipitation. Warm conveyor belts supply moisture over a long duration of time and over a large region. They also exploit moisture from more remote and larger regional moisture sources than deep convection. In addition, on the northern hemisphere deep convection usually occurs close to cyclones' centre and to their eastern side along the cold front, warm conveyor belts occur to their north-eastern side. These sides concur with the area of horizontal moisture convergence and form the area with most precipitation. A large part of deep convection is associated with embedded convection in warm conveyor belts. Deep convection commonly produces higher precipitation intensities than warm conveyor belts. Warm conveyor belts are highly relevant for heavy precipitation in many parts of the extra-tropics (e.g. southern South America and Japan): more than $70 \%$ of the heavy precipitation is directly associated with a warm conveyor belt, though the frequency of their occurrence usually is less than $10 \%$. Additionally, Browning (1990) mentioned that in these cases conveyor belts are mainly associated with extratropical cyclones (Flaounas et al., 2015; Flaounas et al., 2018; Flaounas et al., 2019; Gimeno et al., 2016; Pfahl et al., 2014; Raveh-Rubin and Wernli, 2015, 2016).

The heavy precipitation of Mediterranean cyclones due to the above-mentioned mechanisms is made possible by high moisture transport from the sea, together with strong convection and deep clouds. They also have a higher precipitation efficiency when their precipitation takes place over land than over sea and also in comparison with Mediterranean cyclones producing lower precipitation amounts. It appears that the production of heavy precipitation of Mediterranean cyclones is related to both moisture transport and to precipitation efficiency. However, as a low moisture transport can be compensated by high precipitation efficiency, cyclones with low moisture availability also can produce heavy precipitation in the Mediterranean coastal-inland areas (Flaounas et al., 2019).Divergent outflow of and upstream cyclogenesis in the extratropical cyclone's warm conveyor belt as a result of the diabatic heating processes due to strong cross-isentropic ascent does play a role in the ridge amplification and subsequently has consequences for the evolution of the accompanying trough (trough amplification or formation of a potential vorticity streamer) and next the triggering of downstream cyclogenesis or the intensification of the extratropical cyclone in the lower troposphere with its associated production of heavy precipitation. Diabatic heating that occurred in an equatorward ascending warm conveyor belt, however, resulted in a partial erosion of the upper-level flow (cut-off) structure with positive vorticity (Barton et al., 2016; Grams et al., 2011; Madonna et al., 2014; Martius et al., 2006; Martius et al., 2006; Martius et al., 2013; Massacand et al., 2001; Milrad et al., 2009b; Piaget et al., 2015; RavehRubin and Wernli, 2015; Schlemmer et al., 2010). These consequences of diabatic heating are elaborated in the context of tropical cyclones. Besides by diabatic heating (related to extratropical cyclone's warm conveyor belt), the ridge also can be amplified by a tropical cyclone undergoing extratropical transition and possibly a subsequently developing extratropical cyclone/upstream cyclogenesis (Barton et al., 2016; Grams et al., 2011; Archambault et al., 2013) and baroclinic coupling 
with the developing warm sector downstream of the cyclone (Piaget et al., 2015). In addition, baroclinic coupling can also amplify the accompanying trough of the cyclone. This amplification is a result of the cold airflow upstream of this trough by which baroclinic instability releases (Piaget et al., 2015).

Besides modification of the (large-scale) upper-level flow (reduction of potential vorticity), diabatic heating processes along warm conveyor belts do also modify the (small scale) low to mid-level flow (production of potential vorticity). In these cases this diabatic potential vorticity modification influences the evolution of a cyclone (including the extratropical transitioning cyclones) and its intensity or the poleward advection of warm, moist air downstream of the warm conveyor belt (Grams et al., 2011; Madonna et al., 2014; Pfahl et al., 2014).

\subsubsection{Cold, warm, monsoon-related and stationary fronts}

A cold front is the leading edge of a relatively cool air mass that normally lies within a sharp surface trough of a low-pressure system. A front is often related to atmospheric rivers (Catto and Pfahl, 2013; Moore et al., 2012). A cold front develops in the wake of an lowpressure centre at the leading edge of its region of cold air advection. Usually, cold fronts have a narrow, strong precipitation band along its leading edge. When cold fronts are very strong (usually in spring), they have a line of thunderstorms or they are occasionally preceded (in time) by a squall line or a dry line (in the warm sector). Wider rain bands with more stratiform and less convective precipitation (widespread, repetitive passage, in the warm sector), also can occur behind a cold front and can occasionally cause heavy precipitation. When, in addition, in case of strong meridional flow the accompanying storm moves slowly, the possibility of heavy precipitation will increase (Browning and Roberts, 1996; Zhang et al., 2009).

A warm front is a density discontinuity at the leading edge of a homogeneous warm air mass that lies within a broader surface trough of a low-pressure system than the sharp trough belonging to a cold front. Precipitation forms ahead of a warm front (in the cool sector north of the warm front or in the region north and west of the (surface) low-pressure centre) and is mostly long-duration stratiform of nature (Schumacher and Johnson, 2005). If the warm air mass is unstable also, thunderstorms develop (widespread, repetitive passage) and heavy precipitation can occur. Heavy precipitation located along fronts, is associated with low-level convergence of moisture (Martín et al., 2013).

In some parts of major mid-latitude storm track regions, over $90 \%$ of the heavy precipitation events is caused by fronts, with a larger portion associated with warm fronts than cold or stationary fronts. These heavy precipitation producing fronts have up to $35 \%$ stronger frontal gradients than normal fronts. While in the mid-latitudes a large part of the heavy precipitation events belonging to these fronts is connected to cyclones, in other regions these events belong mostly to either fronts or cyclones. However, a large part of these fronts without a connection to cyclones, is connected to cyclones somewhere along their track and have a relation with mid-latitude weather systems (Berry et al., 2011; Catto and Pfahl, 2013). Frontal precipitation events can cause severe floods in the regions of occurrence (Mills and Wu, 1995; Laing, 2004; Lavers et al., 2011; Catto et al., 2012).

In regions with monsoon mediated precipitation regimes, fronts (like the Meiyu front: formed in June/July by the meeting of maritime tropical and continental polar air) play an important role in the development of heavy precipitation. Heavy precipitation can develop under highly baroclinicy without large instability (Choi et al., 2011). Fronts can influence the propagation of mesoscale depressions (Jung and Lee, 2013) and can enhance the convergence of moisture if sufficient moisture is locally present (Jeong et al., 2014b; Luo and Chen, 2015; Wang and Gu, 2016) and being supplied by a low-level jet in case of the development of MCSs (Choi et al., 2011; Jeong et al., 2012). These jets (related to the extratropical cyclone's warm conveyor belt) also can contribute to low-level convergence (Jung and Lee, 2013). A modification in the upper-level flow resulting into the extension of a subtropical high at the post Meiyu period, can provide the necessary supply of moisture via the warm, moist low-level jet. If southward extended troughs from the extratropics reach a front in these regions, these troughs can favour the intrusion of cold and dry air in the upper-level along this front thereby enhancing local instability and convection. These phenomena show that in a case of extratropical influences in tropical regions, a front can be a favourable environment for the occurrence of heavy precipitation and that both the large-scale environment and its interaction with convection are relevant for this occurrence (Lee et al., 2017a). The occurrence of a tilted updraft at nearly stationary front can increase the longevity an MCS considerably (Jeong et al., 2014a). In these regions, a front can also favour the isentropic ascend and thermally direct circulation of moist air provided by tropical cyclones before making landfall (Baek et al., 2013). This is elaborated upon below.

Heavy precipitation can also occur at synoptic systems without the presence of convection. Besides the near-stationary extratropical cyclones described above, also stationary fronts are an example of these systems (without the development of thunderstorms). A stationary front is a non-moving boundary between two different air masses. When a warm or cold front stops moving, it becomes a stationary front. Fronts begin to stall if upper-level airflow runs nearly parallel to the surface airflow. In these specific synoptic systems, the accompanying largescale ascent of air functions as the forcing mechanism for the lift of air (Schumacher and Johnson, 2006; Smith et al., 2000). In addition, the large-scale airflow forces moisture into the same region for a prolonged period of time resulting in long-duration, moderate stratiform precipitation (Schumacher and Johnson, 2005) that also can give high precipitation (Milrad et al., 2015; Perry et al., 2017). Precipitation will continue as long as moisture is supplied by this airflow. In contradiction to the convective precipitation, the non-convective or stratiform precipitation occurs in the cool sector north of the warm front or in the region north and west of the (surface) low-pressure centre (Schumacher and Johnson, 2005). A common characteristic of all these synoptic systems is that large-scale (quasi-geostrophic) ascent by flow along the baroclinic zone or fronts is the primary lifting mechanism.

\subsubsection{Subtropical cyclones}

Subtropical cyclones are characteristically upper-level cold-cored and low-level warm-cored cyclones that develop in the subtropics. They are non-frontal, low pressure systems that have characteristics of both tropical and extratropical cyclones. While tropical cyclones are fully warm-cored, non-frontal cyclones with deep convection whose primary energy source is thermodynamic, extratropical cyclones are fully coldcored, frontal cyclones whose primary energy source is baroclinic. Subtropical cyclones have both energy sources. They can form at much lower sea surface temperatures and in environments with much stronger vertical shear than those conducive for the formation of tropical cyclones. All subtropical cyclones interact with a mid-latitude baroclinic zone (an old frontal baroclinic zone at the surface) ahead of an approaching trough, though the developmental patterns are different between both hemispheres. They initiate via quasi-geostrophic dynamics (baroclinic forcing, from the extratropics) and intensify trough convective diabatic heating from the surface upward (convective forcing, from the tropics) though their relative contributions can differ (Cavicchia et al., 2018). This baroclinic forcing for the genesis of a subtropical cyclone is an essential difference with the genesis of a tropical cyclone (Evans and Guishard, 2009; Evans and Braun, 2012; Garde et al., 2010; González-Alemán et al., 2015; Guishard et al., 2009). In comparison to the genesis of extratropical cyclones, this forcing nevertheless is relatively shallow and weak (Davis, 2010; González-Alemán et al., 2015). Like tropical cyclones, they can also be responsible for heavy precipitation (González-Alemán et al., 2015).

Basically, two mechanisms of subtropical cyclone genesis exist: genesis related to Rossby breaking (both on $\mathrm{NH}, \mathrm{SH}$ ) and lee cyclone genesis (only on $\mathrm{SH}$ ). With regard to the first mechanism, the formation 
of a subtropical cyclone is preceded by Rossby wave breaking and its interaction with the baroclinic zone results in the genesis of a weak lowlevel vortex ahead of an approaching trough (baroclinic forcing). As the mean genesis environment is nearly moist neutral, a deep, forced ascent (as induced by the approaching trough and stimulated by its depth) is required for the convection to be maintained. When the vortex has moved to in a region of either a high sea surface temperature or with strong warm-air advection and below the cold upper low, destabilisation of the air column to near-neutral stability takes place, that facilitates local convective (or thermodynamic) forcing. This forcing intensifies the low-level vortex (strong surface circulation and gale-force winds) by which deep convection and a low warm core can be maintained. Guishard et al. (2009) consider the maintenance of deep convection as a key to the genesis of subtropical cyclones. Both the organisation and the persistence of this convection are a key to the reduction of vertical shear in a stalled cyclonic system. This reduction is caused convection-induced diabatic redistribution of potential vorticity (by means of non-conservative redistribution of potential vorticity and diabatically induced outflow) (Davis and Bosart, 2003; Evans and Guishard, 2009). The superposition of this forcing results in a hybrid cyclonic structure with an upper-level cold core and a low-level warm core (Evans and Braun, 2012; Evans and Guishard, 2009; Guishard et al., 2009).

The second mechanism, lee cyclone genesis, is preceded by an anticyclonic wave breaking, or instability on the subtropical jet, or a cyclone transiting the Andes and result in the formation of a low-level vortex in the near-coastal zones of south America. and a low shear environment. This wave breaking results in the formation of a low-level vortex (also due to interaction upper wave and baroclinic zone) and intensifies when the upper level system is on the lee side (development of a baroclinic structure favourable for convection). Further, the environment in the lee of the Andes with its relatively low shear as well as the coastal trough and the warm Brazil Current favour the development of a subtropical cyclone. In addition, a decoupling of the low- and upper-level vortex for cyclones that transit the Andes, also can favour the development of a low-level warm core cyclone. Finally, the locally high sea surface temperatures or the poleward advection warm, moist air provide conditions favourable for the convective forcing in the Andes region due to a reduction of the atmospheric stability (Vera et al., 2002; Evans and Braun, 2012).

When an upper-level trough with its corresponding relatively lowlevel high-shear environment intrudes into a region with a relatively high sea surface temperature and low static stability in the warm season of the North Atlantic, a dominant pathway develops for the genesis of and subtropical cyclone. When the approaching trough responsible for this high shear, is situated above the high sea temperature environment, a configuration conducive for baroclinic forcing establishes. The accompanying forced ascent can result in deep convection and due to the resulting near-neutrality of the air column, it can even extend down to the surface. Characteristic to this pathway is the reduction in the environmental shear on the time of the genesis of the subtropical cyclone. This reduction has been caused by convection due to its diabatic redistribution of the upper-level potential vorticity (convective feedback). As this redistribution mechanism also occurs at the re-intensification of a tropical cyclone after landfall (see also section 5.4.4), subtropical cyclones exhibit in this season a tendency to continue their development into a tropical cyclone (tropical transition of subtropical cyclones) being an additional genesis mechanism of tropical cyclones (Evans and Guishard, 2009; Guishard et al., 2009). It appears that in environments with a relatively high shear, subtropical genesis can take place if shear reduction occurs. Analogously, in environments with relatively low sea surface temperatures, if warm, moist air advection takes place enabling the maintenance of a low-level warm-cored cyclone.

In the preceding, the genesis of a subtropical cyclones from a vortex has been written. However, subtropical cyclones also can originate from tropical cyclones via extratropical transition (Hart and Evans, 2001) or from extratropical cyclones via tropical transition (Davis and Bosart, 2003). In the first case, the tropical cyclone moves over colder water and into higher environmental shear at higher latitudes (Hart and Evans, 2001). Extratropical transition is further dealt with in section 5.4.4. In the second case, quasi-geostrophic dynamics induces a baroclinically surface depression by vertical ascent that can focus convection. When this depression becomes isolated from the upper-level flow, that can have different anomalies, it amplifies/deepens through diabatic heating to build a warm core from the low-level upward by sustained convection (Davis and Bosart, 2003; González-Alemán et al., 2015). Apart from that, Caruso and Businger (2006) remark that deep convection can occur in conjunction with upper-level lows like cut-offs without the development of a surface low. These transitions let show that the three cyclone types form a continuum of cyclone types (Guishard et al., 2009).

\subsubsection{Medicanes}

The semi-enclosed Mediterranean basin, characterised by the Mediterranean Sea with its surrounding mountains, offers favourable conditions for the development of Mediterranean cyclones (intense low pressure systems) and is one main cyclogenesis regions in the world. Though most of the cyclones in the Mediterranean basin are extratropical cyclones of a baroclinic and orographic origin, occasionally a few of them can develop to take on features that are characteristic of tropical cyclones (with typical cloud structures and dynamical features) and also can develop a dynamical evolution similar to the one of the tropical cyclones (intensification of their strength during their lifetime, sometimes even to hurricane strength) in their mature stage. These most intense, tropical-like cyclones of Mediterranean origin have been termed Mediterranean hurricanes (medicanes) and explosive cyclones (Fita et al., 2007; Flaounas et al., 2015). Even though their spatial extent is usually smaller (up to $300 \mathrm{~km}$, mesoscale), their intensity weaker and their life cycle shorter than those of tropical and extra-tropical cyclones (a few days), medicanes can produce heavy precipitation events in coastal regions around the Mediterranean Sea. Their formation usually occurs in the western and central apart of the basin, mainly during the cold season (Cavicchia et al., 2014a, 2014b; Flaounas et al., 2016; Flaounas et al., 2018; Mazza et al., 2017; Miglietta and Rotunno, 2019; Nastos et al., 2018; Pfahl and Wernli, 2012; Pfahl et al., 2014; Ragone et al., 2018; Tous and Romero, 2013). This section mainly deals with medicanes as an example type of intense cyclones. The explosive ones will get some attention at the end of this section.

Due to the complex geography of the Mediterranean region, Mediterranean cyclogenesis is influenced by several mechanisms including large-scale forcing by Rossby waves and their breaking, air-flow steering by mountains and air-sea interactions (Flaounas et al., 2016). Medicane cyclogenesis vortex, taking place in a baroclinic environment (a well-defined or remnant frontal zone), is typically triggered by narrow upper-level potential vorticity anomalies or potential vorticity streamers like cutoff-lows, troughs and wave breakings from Rossby waves that intrude dry, cold air to upper tropospheric levels (Flaounas et al., 2015). This dry, cold air intrusion enhances the low-level atmospheric/baroclinic instability by cooling and moistening of the lowlevel air (thermodynamic disequilibrium) and the air-sea interaction instability to a level that is sufficiently high to trigger the genesis of medicanes which can occur above waters with surface temperatures substantially lower than those of tropical oceans (Cavicchia et al., 2014a, 2014b; Carrió et al., 2017). Therefore, in comparison to the tropical equal, the cold air aloft is a requirement for the medicane genesis being associated with it. This requirement is caused by the environment in which the cyclones form: while tropical cyclones occur in a moist environment, medicanes occur in much drier environments (Emanuel, 2005; Fita et al., 2007). Emanuel (2005), Carrió et al. (2017) and Fita et al. (2006) have established the dominant role of these upper- 
level anomalies in forcing the medicane baroclinic genesis (dynamic/ baroclinic forcing) by deepening of medicane's surface pressure, thereby mainly contributing to the intensification (i.e deepening central pressure) of the Mediterranean cyclone during its initial stage by stimulating deep convection (Fita and Flaounas, 2018). In addition however, Emanuel (2005), Carrió et al. (2017), Fita et al. (2006) and Homar et al. (2003) have also shown the highly significant impact of the interaction (feedback) between low-level baroclinicity and low/ mid-level diabatic heating on this intensification (both deepening and circular-shaping of the cyclone). This diabatic heating generates a warm core and is a key mechanism in the cyclogenesis because the accompanying (mid-level) vorticity generation facilitates the interaction between upper-level and low-level anomalies that get closer by reduction of the vertical tilt (Carrió et al., 2017; Homar et al., 2003). Diabatic heating also generates wet potential vorticity by latent heat release due to condensation by convection around a low-level vortex opposite to dry potential vorticity generated by the intrusion of dry stratospheric air into the troposphere (Homar et al., 2003; Miglietta et al., 2017). This diabatic heating can be associated with latent heating in deep convection systems, in warm conveyor belts or in a combination of them (Flaounas et al., 2016; Fita and Flaounas, 2018). Accompanying strong convection in the initial stage is responsible for heavy precipitation from a dense cloud coverage, anticipating its maximal strength obtained in the mature stage (Claud et al., 2010; Miglietta et al., 2013). Due to wrapping of this cloud coverage, the spirally shaped eye forms (Fita and Flaounas, 2018).

With regard to the mechanism of the air-flow steering by mountains, Nastos et al. (2018) mention that the specific orographic structures surrounding the Mediterranean Sea can trigger air flow to vortex development favouring convection and Fita and Flaounas et al. (2018) mention about a medicane whose genesis has been attributed to both upper-level diabatically and orographically produced potential lowlevel vorticity (though its triggering took place by the upper-level potential vorticity anomalies). The same is valid concerning the mechanism of the wind-induced sea heat and moisture exchange or air-sea interactions: medicanes (like tropical cyclones) tend to develop only within environments of high diabatic heating caused by higher latent heat fluxes from the sea to the cyclone's centre that favour small-scale convection and contributes to low-level circulation and cyclone deepening (Fita and Flaounas, 2018; Homar et al., 2003; Tous and Romero, 2013). They also tend to develop within environments of high surface heating that contribute to scale reduction of the vortex and modification of the stability (Mazza et al., 2017). These fluxes exist because of the thermodynamic disequilibrium between sea and air (Tous et al., 2013). This higher flux in turn is caused by the upper-level potential vorticity anomaly that enhances surface cyclogenesis or low-level circulation of a synoptic scale low pressure area (Homar et al., 2003; Mazza et al., 2017). In addition, this low pressure area can induce and enhance the advection of moisture and heat from the sea, both the Mediterranean and the subtropical Atlantic Sea (Flaounas et al., 2019; Homar et al., 2003) and this advection is usually larger than the evaporation from the sea (Huang et al., 2014). It appears that the upperlevel potential vorticity anomalies occur in combination with the diabatially produced low-level potential vorticity anomalies. The role of the low-level vorticity production mechanism, the mountain steering mechanism and of the air-sea interaction mechanism are of secondary importance for the intensification the Mediterranean cyclone, controlling and modulating the intensity of a medicane, while the primary role (i.c. triggering) is reserved for the upper-level potential vorticity anomalies (Tous et al., 2013; Miglietta et al., 2017) unless regional wind outbreaks occur (Miglietta and Rotunno, 2019). In this case, both baroclinic triggering and air-sea interaction are important for the intensification. However, during the mature stage this air-sea interaction is generally considered as the main mechanism for the maintenance against dissipation of medicanes, similar to tropical cyclones (Miglietta, 2019; Tous and Romero, 2013). The latent heat fluxes, stemming from this interaction, sustain the development of deep convection at this stage and induce further cyclone deepening by diabatic heating (Carrió et al., 2017; Homar et al., 2003). Along this mature stage also the vertical shear decreases by the interaction between the upper-level vorticity and the diabatic heating, which favours the formation of a tropical cyclone (Mazza et al., 2017; Michaelides et al., 2018).

Tropical-like cyclones can also originate from extratropical cyclones undergoing tropical transition. Characteristic to this transition is the evolvement of extratropical cyclones into self-sustaining low-level vortices caused by the development of convection in their centre. Consequently, subtropical cyclones develop. These cyclones are hybrid cyclonic systems consisting of both extratropical (dry air intrusions, baroclinic triggering and frontal structure) and tropical cyclone characteristics (warm core, axisymmetric cloud structure (spirally shaped cloud cover with a clear eye), low vertical wind shear and strong convection in the centre) and develop in the subtropics. They can produce heavy precipitation (Evans and Braun, 2012). The medicane (deep) warm core can also be obtained effectively by the seclusion of warm air in the cyclone core by cold air (Fita and Flaounas, 2018; Mazza et al., 2017; Miglietta and Rotunno, 2019), and the dry eye by dry air intrusion within the cyclone centre (Fita and Flaounas, 2018). The warm-air seclusion process usually starts from a strong extratropical cyclone that consists of a vertical tilt, a warm sector and a frontal structure. This seclusion manifests itself as a warm conveyor belt around the centre's pressure minimum and contributes significantly to latent heat release. After the seclusion the warming of core the warming continues by latent and sensible heating and ultimately delivers a deep warm core (Mazza et al., 2017; Michaelides et al., 2018). Subtropical cyclones also are described as systems which develop at seas with lower temperatures than $26^{\circ} \mathrm{C}$ (but higher than $15{ }^{\circ} \mathrm{C}$ ) and which have strong convection due to forcing by upper-level potential vorticity anomalies. Additionally, there is a tendency of subtropical cyclones to undergo tropical transitions (Evans and Guishard, 2009). This can occur when a cyclone crosses a jet stream from the warm to the cold side (that induces ascent via quasi-geostrophic forcing) thereby contributing to its intensification (Chaboureau et al., 2012; Miglietta et al., 2017). It appears that different medicane development mechanisms occur, depending on the meteorological environment (Miglietta and Rotunno, 2019). In addition, it appears that tropical transition is another mechanism for the development of tropical cyclones (that appears later in cyclone lifetime as opposed to the already mentioned intensification, early in lifetime) when extratropical cyclones move into a favourable meteorological environment and that medicanes might also be characterised as subtropical cyclones (Fita and Flaounas, 2018; Miglietta, 2019; Ragone et al., 2018; Tous and Romero, 2013). The definition and classification of medicanes is still a subject of ongoing discussion.

\subsubsection{Explosive cyclones}

Explosive cyclones are cold seasonal, extratropical cyclones, characterised by a large and rapid pressure drop at sea level and associated with heavy precipitation. Just like the medicanes, the explosive cyclones also belong to the intense Mediterranean cyclones, though not restricted to the Mediterranean area. They are generally larger in size and have larger lifetimes than the regular medicanes, and their characteristics are similar to tropical cyclones (Heo et al., 2019; Kouroutzoglou et al., 2011, 2014; Michaelides et al., 2018). The development mechanisms are related to those of the medicanes described above.

In the cyclogenesis of explosive cyclones baroclinicity plays an important role. This role is related to the large thermal contrasts (due to typically large sea surface temperature gradients) between two synoptic systems delivering two types of Mediterranean cyclogenesis. The first type is characterised by the interaction between an upper-level baroclinic, synoptic wave penetrating the Mediterranean and a low-level 
subsynoptic cyclone, usually in the lee of the Alps. The second type results from the interaction between an African mid-latitude subsynoptic depression and a cold, mid-latitude synoptic cyclone penetrating the Mediterranean. The role of baroclinic forcing is supported by the low-level cold air advection (thermodynamic forcing) and the upper-level dynamic evolution by advection of positive potential vorticity anomalies (upper-level forcing). This evolution forces surface pressure deepening due to vertical ascent (low-level cyclogenesis). The diabatic heating, due to convection in the core of the cyclone, can also significantly contribute to this pressure deepening. This diabatic heating together with sea surface heat and moisture transport weakening of static stability and favouring convection (thermodynamic forcing), contribute to and act in conjunction with baroclinic and orographic forcing, delivering a synergetic response due to the enhanced low-level baroclinicity (Fita et al.,2007; Homar et al., 2002; Kouroutzoglou et al., 2011, 2012, 2014; Michaelides et al., 2018). It is supposed that both the strength of these forcings and the tightness of their interaction determine the explosive nature of these explosive cyclones (Kouroutzoglou et al., 2014). The general idea is that the upperlevel dynamic forcing precedes the genesis of explosive cyclones and has a primary role in the cyclogenesis, while the baroclinic forcing mainly acts in the mature phase and a has a secondary role. However, as the upper-level dynamic forcing is insufficient for the explosive cyclogenesis, also an interaction exists between this upper-level forcing and the low-level baroclinic forcing, stressing the role of low levels in baroclinicity (Flaounas et al., 2015; Lagouvardos et al., 2007; Michaelides et al., 2018). This is in agreement with observations on the spatial density of explosive cyclones: when different forcings act in concert (i.e. small space and time domain), their density is higher (Kouroutzoglou et al., 2014).

The importance of forcings and interactions in the development of explosive cyclones are investigated by potential vorticity analyses. From these analyses, it appeared that an upper-level trough or cut-off low (high potential vorticity) can produce a large upper-level potential vorticity advection (and so strengthen vertical ascent/divergence) and low-level heat, moisture advection. together with diabatic heating, this advection results into an increase of baroclinic stability and warm core development. Above all, diabatic heating increases the intensification, the extent and the movement speed of the explosive cyclone. It promotes the genesis of a cut-off low and the generation of low-level potential vorticity (with deepening of the low and increasing convergence), an increase of advection (due to enhanced baroclinicity) and a decrease of static stability. The interaction between an upper-level anomaly due to dry air intrusion and low-level adiabatically produced potential vorticity anomaly is an important factor for the development of an explosive cyclone: it can lead to intensification of the cyclogenesis and the creation of a potential vorticity tower promoting cyclonic circulation and deepening. The potential vorticity tower is the result of vertical coupling of positive upper- and low-level potential vorticity anomalies. This coupling can be caused by the maintenance of a phase tilt by retardation of the positive upper-level potential vorticity and is associated by diabatic heating. This increased circulation in turn can result into higher diabatic heating by which a feedback develops. It is thought that the feedback mechanism is a main factor in the development of explosive cyclones (Heo et al., 2015; Heo et al., 2019; Kotal et al., 2012; Pang and Fu, 2017).

\subsubsection{Tropical cyclones}

A tropical cyclone is a rapidly rotating storm system which has a typical structure consisting of eye (or cyclonic centre), eyewall, inner rain bands and outer rain bands (Fig. 10) and is characterised by a lowpressure and warm core centre, a closed low-level circulation and a spiral arrangement of thunderstorms producing heavy precipitation (in fact the most wide spread precipitation of the heavy precipitation producing storms) (Schumacher and Johnson, 2005). Both the eyewall and the rain band structure are highly determinant for the space-time variability of tropical cyclones (Smith et al., 2005a). Tropical cyclones form almost exclusively over large, warm water bodies that are present in tropical seas and therefore this origin is found back in the nomenclature of this system. As tropical cyclones can transport abundant water vapour from the ocean to the land, they provide favourable meteorological conditions for the occurrence of and contribution to heavy precipitation, both in coastal and in inland areas (Aryal et al., 2018; Prat and Nelson, 2016; Zhang et al., 2018). Contradictory to mid-latitude systems, tropical systems obtain their energy from the warm seas destabilising the overlying air. Therefore, their occurrence and development is strongly dependent on the El NiñoSouthern Oscillation (Khouakhi et al., 2017; Zhang et al., 2018). Tropical cyclones tend to be large (their size ranges from $100-2000 \mathrm{~km}$ diameter) and have a long lifetime. They are significantly larger, live longer and are stronger than non-tropical cyclones (Moore et al., 2015). A tropical depression and a tropical storm are lower intensity (or maximum wind speed) variants of tropical cyclones; tropical storms also can cause heavy precipitation. This heavy precipitation reveals particularly at coastlines when tropical cyclones fall on land and may be associated with the transition from updraft-dominated motion over sea to downdraft motion over land (Smith et al., 2010; Smith et al., 2005a). Therefore, after making landfall cyclones normally weaken to cloud remnants and precipitation decreases correspondingly (Bao et al., 2015; Dong et al., 2010). The presence of tropical cyclones can result in a pronounced temperature gradient that can lead to extreme amounts of precipitation (Milrad et al., 2009a). Tropical cyclones play a prominent role in the generation of heavy precipitation in different continents of the world (Prat and Nelson, 2016; Khouakhi et al., 2017).

In addition to the three basic ingredients for heavy precipitation (as described in section 4.2), the formation and development of tropical cyclones do need three extra ingredients. A tropical cyclone needs low levels of shear to avoid the disruption of its structure and accompanying circulation (Davis and Bosart, 2003; Zhou et al., 2013). As a tropical cyclone is characterised by a deflecting airflow to its low-pressure centre and circulation of air around this centre, it can only (by the Coriolis force) form five degrees of latitude away from the equator and only when it has a certain minimum size. Also the development of a low-pressure centre requires a sufficiently large Coriolis force. Finally, a tropical cyclone needs a pre-existing low-level disturbance like a tropical wave, a depression in the Inter Tropical Convergence Zone, a broad surface front or an outflow boundary. These disturbances supply the necessary vorticity and convergence to start with tropical cyclogenesis or formation of a tropical cyclone (González-Alemán et al., 2015).

Landfalling tropical cyclones can be a tropical cyclone occurring either over land or in offshore waters approaching the land. Generally, when cyclones make landfall they rapidly dissipate by the cut-off of moisture supply from the ocean and by the increase of friction from the land surface. Some cyclones however do sustain over land due to their high intensity, particularly if there remains a strong and long-lasting water vapour transport in the lower layer of the atmosphere (Huang et al., 2014; Jiang et al., 2008). In addition, weak remnants of land falling cyclones can re-intensify (around 10\% of the cyclones making land fall in China) if favourable atmospheric conditions occur by which they acquire new energy from land; the two main energy sources are baroclinic potential energy and latent heat, though sensible heat also can play some role (Zhang et al., 2011). In this way remnants can even produce more intense precipitation than cyclones making landfall. Landfall and extratropical transition do greatly change the structure and intensity of a tropical cyclone with its accompanying precipitation intensity and typical distribution in rain bands and focus the precipitation over a small area resulting increased precipitation amounts (Bao et al., 2015; Chen et al., 2010; Dong et al., 2010; Liu and Smith, 2016; Xie and Zhang, 2012; Yang et al., 2017a). Consequently, both landfall (Villarini et al., 2011) and extratropical transition (Konrad 


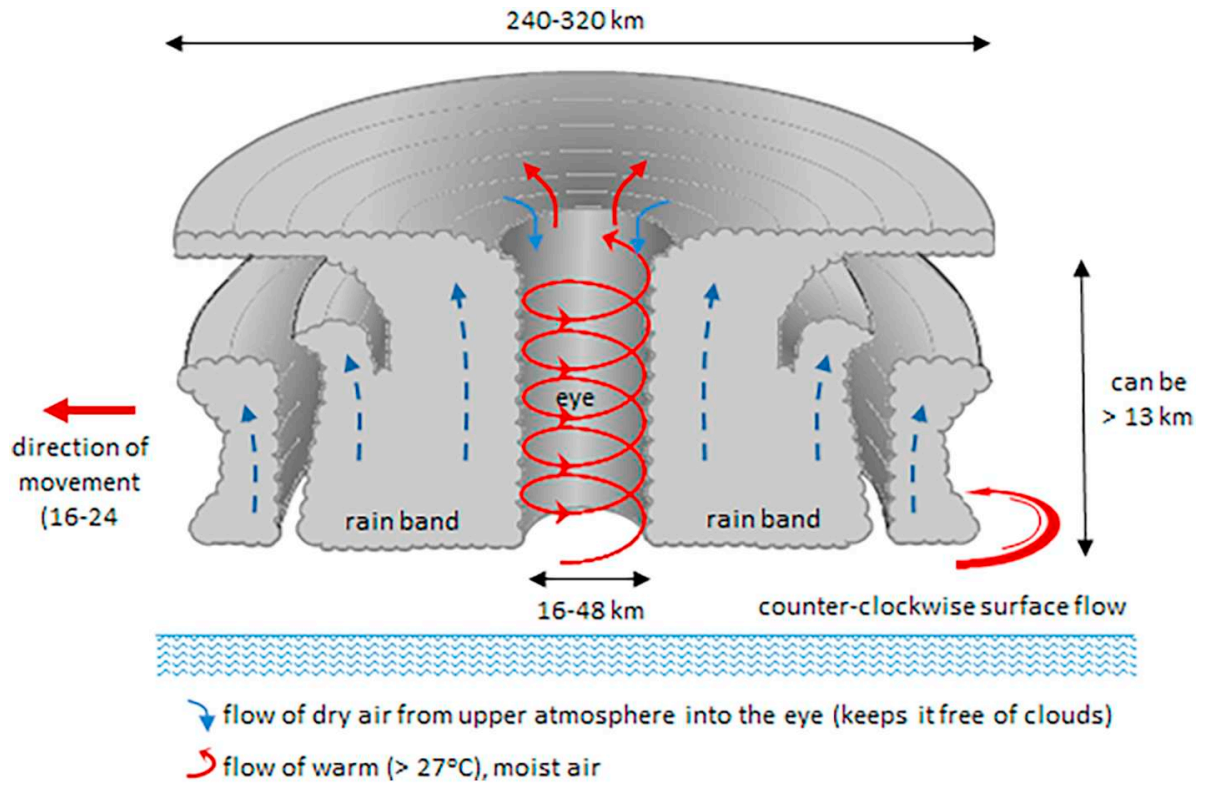

Fig. 10. The structure and dimensions of a tropical cyclone.

and Perry, 2010; Liu and Smith, 2016) result into large rainfall variability.

In general, heavy precipitation induced by land falling tropical cyclones can be divided into two types: direct precipitation and indirect precipitation. Direct heavy precipitation is induced by the tropical cyclone's circulation itself (mostly by the inner circulation), while the indirect heavy precipitation is induced by strong interactions between the tropical cyclone and other large-scale or mesoscale systems as well as topographical barriers. While direct heavy precipitation is concentrated around landfall, indirect precipitation is induced by the tropical cyclone well-before making landfall outside of the direct influence of tropical cyclone's circulation and is also called as remote or predecessor precipitation. Direct precipitation occurs much more frequently than indirect precipitation (Galarneau et al., 2010; Baek et al., 2014; Bao et al., 2015; Xing et al., 2016; Chen and Wu, 2016; Zhang et al., 2018). Apart from that, heavy precipitation can even occur when the core does not pass a land surface or island along its track (Hernández Ayala and Matyas, 2016).

Several mechanisms are held responsible for the maintenance and/ or intensification of (the remnant of) a (land falling) tropical cyclone by which heavy precipitation can develop. Weakened tropical cyclones with slow motion or stagnation are most conducive to re-intensification (Dong et al., 2010). One principal mechanism is the low-level transport/supply of moisture by monsoonal flows with cloud clusters or MCSs and corresponding water vapour channels, by another cyclone (together with potential vorticity and warm air advection) or by the warm, moist land surface itself. Variabilities in the monsoon (so-called oscillations) can increase monsoonal flows and accompanying transport of moisture to the cyclone. Another mechanism is the interaction between a tropical cyclone and a westerly trough (or boreal monsoon) and a low-level jet for the maintenance of water vapour supply which may cause extratropical transition. This interaction entails the intrusion of cold air from this trough into the cyclone (encircling the warm core vortex) by which the temperature-pressure structure of the cyclone changes and a extratropical cyclone develops with its typical baroclinic surface providing baroclinic potential energy (frontogenesis) and potential instability that favours vertical motion and the formation of MCSs, thus contributing to rainfall increase. Both the tilt of the trough and distance trough - tropical cyclone do matter in respect of this interaction (Milrad et al., 2009a). However, as Atallah et al. (2007) remarked, a transitioned cyclone doesn't have to be intense to have large impact, as heavy precipitation also can accompany remnant cyclones. In the same way MCSs can also form from the interaction between the north dry, cold winds and the south-easterly warm, moist circulation winds of the cyclone (convergence along mesoscale shear lines). However, if cold air intrusion is too strong and is filling up the core, production of rain will be suppressed. Coastal and mountainous topography as well as cold air damming and coastal frontogenesis associated with the interaction between cold air from the north and warm air from the south of the cyclone, strengthen the ascend (and convergence) of air of approaching cyclones (third mechanism). An interaction of a landfalling cyclone with the local topography can induce a low-level jet that causes low-level convergence and enlarges moisture supply (Xie and Zhang, 2012) and mesoscale vortices/MCSs which conventionally produce heavy precipitation accordingly (as vortices or vortex-shear interactions function as a lifting mechanism due to a low-pressure disturbance and accompanying developing positive feedback (Gao et al., 2009)) and, reciprocally already existing mesoscale vortices can intensify a cyclone remnant. Mesovortex interactions with local topography can keep a mesovortex over an island and when this mesovortex is persistent, heavy precipitation occurs (Nugent and Rios-Berrios, 2018). In addition, landfalling cyclones themselves can also induce upper-level divergence and associated cold intrusion that aid in the formation of MCSs. Finally, moisture and heat transfer from land surface remarkably can increase cyclone's precipitation over land. It appears that heavy precipitation is related to the atmospheric environment, the land surface and the occurrence of mesoscale convective system of landfalling tropical cyclones and is made possible by the acquisition of new energy, baroclinic potential energy or latent heat energy (Bao et al., 2015; Chen et al., 2010; Dong et al., 2010; Jiang et al., 2018; Meng and Wang, 2016b; Pan et al., 2018; Xu et al., 2011; Yang et al., 2017a; Zhang et al., 2011).

The interaction between a tropical cyclone and a mid-latitude westerly cold upstream trough is a main factor in the extratropical transition process. The juxtaposition of cold, dry air of the (upper-level) trough and the (low-level) warm, moist air of the (remnant) tropical cyclone results into an intense, deep baroclinic zone that can culminate into very heavy precipitation. The circulation of the cyclone interacting with this baroclinic zone, results into decay and tilt of warm air aloft and deep isentropic ascent with deep convection and accompanying heavy precipitation. The divergent, convective outflow of the cyclone being associated with the upstream diabatic heating resulting from 
deep convection/ precipitation, enhances the downstream ridge by which the trough-ridge amplitude increases and the trough becomes negatively tilted. Concerning this outflow, both divergence and adiabatic heating contribute to collapse of the trough-ridge axis and to ridge amplification (Barton et al., 2016). Consequently, the jet streak enhances. Another result of the juxtaposition is the enhancement of the outflow jet of the cyclone (alternatively the enhancement of the jet streak on the east side of the trough) when the trough approaches, taking place more properly when the cyclone collocates with the cyclonic vorticity advection region of the trough. This also contributes to enhanced ridging. The combination of enhanced ridging and enhanced jet development causes an increase of the (differential) potential vorticity (i.c. cyclonic vorticity) advection and so a strengthening of the transitioning cyclone, that results into increased upper-level divergence at the equatorward entrance region of the jet streak. The resulting vertical motion becomes more enhanced and, with the large moisture availability of the cyclone this culminates into (very) heavy precipitation and a large precipitation shield. This vertical motion takes place when the cyclone starts to overrun the baroclinic zone and is aided by the larger low-level warm-air advection associated with the strengthening of the transitioning cyclone. Actually, diabatic heating functions as positive feedback mechanism because it assists in increasing the cyclonic vorticity advection by which in turn, the warm air advection and convection (and so precipitation) enhances and next the diabatic process as well (Atallah et al., 2007; Atallah and Bosart, 2003; Baek et al., 2014; Gao et al., 2009; Milrad et al., 2009a).

The large-scale flow structure mentioned by Atallah et al. (2007) shows resemblances with the structure related to cyclone Fitow (mainland China) that consists of upper-level cold, dry south-westerlies together with an upper level jet entrance region overlying low- to midlevel warm, moist easterlies (from surface anticyclones), that favours isentropic ascent or warm-air advection. Both the (coastal) frontogenesis and the associated secondary circulation invoked a lowlevel convergence of the intruded cold air (that results into a cold-air boundary) from the north-west and the warm, moist air from the ocean (Bao et al., 2015). The omission of a mid-latitude baroclinic environment in the surroundings of Fitow shows that extratropical transition is not a necessary precondition for the enhancement of rainfall from a tropical cyclone.

Finally, the re-intensification of a tropical cyclone can occur both before and after extratropical transition. Once the extratropical transition has occurred and the upstream trough is positively tilted, significant post-extratropical transition re-intensification is precluded (Hart et al., 2006).

The above-mentioned interaction occurs when the trough is the dominant feature. The north-western approach of a positively-tilted deep trough shifts the forcing for ascent and precipitation to the left (north-west) of the storm track because cyclonic vorticity advection associated with this trough overspreads the tropical cyclone. This north-western approach is commonly accompanied by a region of broad, slantwise ascent favouring diabatic ridging. The enhanced ridging over and downstream of a cyclone by diabatic heating also contributes to this cyclonic vorticity advection. When the trough is weak, precipitation shifts to the right. In comparison with left of track cyclones, right of track cyclones weakly interact with mid-latitude troughs and predominantly with downstream ridges. Downstream ridging by diabatic heating results subsequently into an enforcement of the upstream trough by which the gradients of thermal and shear increase. The resultant south-westerly thermal winds shift the forcing of ascent and so the precipitation to the right (east) of the track (Atallah et al., 2007; Atallah and Bosart, 2003; Hart, 2003).

Multiple factors do influence the intensity and distribution of tropical cyclones direct heavy precipitation. These factors or characteristics relate to both the tropical cyclone and the environment (Jiang et al., 2008). Storm-specific factors include storm intensity, size, morphology consisting of several types of rain bands, track, motion (translation speed) and proximity to storm's centre. According to Pan et al. (2018) cyclone's track is the most important factor determining precipitation distribution. In view of preparedness to tropical cyclones, besides the track of cyclone's centre also the development of the spatial structure of rainfall around the cyclone's centre is an important element to take into consideration (Rios Gaona et al., 2018). A modification of the track by diabatic heating (Milrad et al., 2009a), the presence of surface high (Pan et al., 2018) or oscillations in the monsoon (Meng and Wang, 2016b) can prolong local, severe precipitation. The higher the intensity, the higher the rain rate and the relative contribution of heavy precipitation. The larger the storm and the lower its speed, the higher the rain rate. The eyewall or the inner rain bands, is the part of the cyclone that is characterised by the strongest updrafts, the strongest thunderstorms, the highest clouds and the heaviest precipitation. The precipitation rate commonly becomes higher when the distance from the centre decreases. Nevertheless, moisture convergence into the outer rain bands can also contain produce heavy precipitation like convergence into the storm's core (Bao et al., 2015; DeHart and Houze, 2017; Ge et al., 2010; Hernández Ayala and Matyas, 2016; Jiang et al., 2018; Konrad, 2001; Konrad and Perry, 2010; Liu and Smith, 2016; Pan et al., 2018).

Large-scale conditions (like upper level divergences, low-level jet moisture transport or monsoon surges) and topography (existence of mountains) play an important role in the location of re-intensified precipitation centres. Rainfall as associated with a tropical cyclone strongly depends on its track (Chen and Wu, 2016; Xie and Zhang, 2012), that together with its intensity, is strongly determined by the large-scale meteorological conditions (Lin et al., 2011) that next can be greatly modified by large-scale (mountainous or coastal) topography (Ge et al., 2010). The large-scale horizontal moisture transport delivers a large fraction of the total moisture with the boundary of the eyewall, when compared to evaporation from the ocean surface (Fritz and Wang, 2014; Huang et al., 2014; Yang et al., 2011). In case of northward moving cyclones to mainland China, precipitation centres mostly situate in the northeast quadrants (due to large-scale conditions of upper level divergence, moisture transport by low-level jets and mountainous topography) and in case of westward moving ones in the southwest quadrants (due to large-scale conditions of upper level divergence, moisture transport by monsoon surges and mountainous topography) (Dong et al., 2010). Though large-scale conditions mainly determine the precipitation centre, the location of precipitation accompanying this centre is determined by local surface topography, microphysical processes and the kinematics of a tropical cyclone itself (DeHart and Houze, 2017). Additionally, the mountainous or coastal topography can strongly increase the precipitation efficiency (increase of cloud condensation, decrease of raindrop evaporation) by lifting and so the precipitation amounts. This increase can also result from an increase of ice-phase deposition when the liquid-phase condensation becomes small when air subsides on the lee side of a mountain in its way downstream (Huang et al., 2014).

Another, typical factor related to cyclones deals with merging. The rain intensity of a cyclone can increase with mergers of storm elements into larger bands. Due to the merger process the convection intensifies and merged storm cells tend to exhibit increased storm depth and heavier rainfall. Not only storm elements but also separate cyclones (or their derivatives) can merge into a single one. It is known that the merger of a tropical depression with cyclone Nina maintained the vortex structure of this cyclone and extended the period of heavy rainfall. This merger also strongly enhanced the low-level moisture transport from the tropical ocean into this cyclone. This elevated moisture transport next increased the moisture convergence which consequently enhanced cyclone's rain intensity (Yang et al., 2017a).

Concerning the intensity and the distribution of precipitation, besides tropical cyclone's factors also do matter large and mesoscale features (vertical wind shear, upper-level trough, surface frontal boundaries), coastal and inland topography (small-scale topography 
and surface friction included) and land surface and boundary layer conditions (DeHart and Houze, 2017; Gao et al., 2009; Meng and Wang, 2016a). In view of storm's potential for (heavy) rainfall, according to DeHart and Houze (2017) it is important to distinguish between storm-specific factors and the specific topography a tropical cyclone encounters.

Of the environmental factors, the moisture distribution and the vertical shear are of great importance to cyclones precipitation's intensity and distribution (or main precipitation shield) (Jiang et al., 2008). Higher moisture amounts in the low and middle troposphere result into higher precipitation intensities. The asymmetric distribution of rainfall can be closely related to the asymmetric distribution of moisture (or asymmetric moisture flux) at which several factors lie to the asymmetric distribution of moisture. Local wind shear itself can induce vertical upward motions by balanced lifting (see for details Nugent and Rios-Berrios, 2018) and by increased CAPE by cooling aloft (Nugent and Rios-Berrios, 2018; Pan et al., 2018). Weak shear favours the development and intensification by releasing latent heat from condensation directly above the surface low, while strong shear causes the asymmetric displacement of convection into the outer regions of a tropical cyclone. When shear is low the highest precipitation occurs in front of a tropical cyclone and when it is high in the down shear left region as the cyclone becomes more tilted (due to the influence of vertical wind shear on cyclone's structure). When wind shear dominates the rainfall asymmetry, the asymmetry maximum principally is downshear left (Liu and Smith, 2016). Additionally, if dry air intrusion occurs in the northern sector, convection is prevented in the dry upshear environment but air parcels can still acquire energy and moisture when it advects cyclonally around the storm centre. When next an air parcel arrives the down shear region with its tilted potential temperature, it is able to lift (Nugent and Rios-Berrios, 2018). Besides the diabatic heating, also upper-levels winds modify the direction and the magnitude of vertical wind shear and so the asymmetry of the precipitation distribution. Klein et al. (2000) specifically remark that the inner core of a tropical cyclone loses its symmetry when frontogenesis develops at the poleward side of a tropical cyclone.

Besides the influence of vertical wind shear as determined by largescale and mesoscale meteorological features (interaction with mid-latitude weather systems included), the asymmetry of the precipitation's distribution is also influenced by the storm's motion, its strength, structure and specific circulation, the asymmetric friction in the boundary layer and the local topographic features of land's surface and can outweigh the effect of vertical wind shear itself (Gao et al., 2009). Generally, precipitation asymmetry increases when higher vertical wind shear increases and the storm's intensity decreases (Meng and Wang, 2016a). The precipitation asymmetry actually is the repercussion of the convection asymmetry and the associated asymmetry in tropical cyclone's structure (tilting).

The outer rain bands usually are the result of interactions between the outer circulation of the tropical cyclone and mid-latitude weather systems (Pan et al., 2018), a cold pool (Meng and Wang, 2016a) and the monsoon flow (Ge et al., 2010; Meng and Wang, 2016b). The formation of a surface cold pool in the outer rain band of cyclone Utor (China), being enhanced by the mid-level dry air intrusion along with the presence of a moderate CAPE and a large vertical wind shear, is also able to change the tropical cyclone's structure and so to increase the rainfall asymmetry at landfall. This surface cold pool, inducing frontogenesis and in turn quasi-balance forcing (due to convergence invoked by transverse circulation at this forcing), can enhance vertical motion and so convection. Due to the positive feedback between cold pool formation and convection, cold pool formation also can sustain convection (Meng and Wang, 2016a). At post landfall stage of Utor, the increase in the monsoon flow favours the initiation and development of the MCSs in the outer rain bands of Utor. Latent heat release by deep convection in the MCSs resulted into a positive feedback between diabatic heating and tropical cyclone's circulation, enhancing tropical cyclone's circulation after landfall together with the formation of a low-level jet or increase of the monsoonal flow and accompanying moisture convergence into the outer rain band. By the increased transport of moisture to Utor, convection can be sustained or increased (Meng and Wang, 2016b). Ge et al. (2010) report the same feedback in case of cyclone Morakot. In fact, as Xie and Zhang (2012) also reported, an interaction exists between cyclone circulation and monsoon flow.

\subsubsection{Pre-tropical cyclones}

A second type of precipitation events related to landfalling cyclones are the predecessor precipitation events (the first type are the cyclone intensification precipitation events, section 5.4). A predecessor precipitation event is an organised area of heavy precipitation that develops with moisture originated from poleward moving tropical cyclones prior to landfall, but is separated from it by a distance of about $1000 \mathrm{~km}$. This event occurs 1-2 days prior to the arrival of a tropical cyclone and lasts for about half a day (Baek et al., 2014; Ban et al., 2015; Bosart et al., 2012; Galarneau et al., 2010; Moore et al., 2013).

Pre-events usually form as the result of an interaction between the tropical cyclone and other large-scale systems like monsoon systems or mid-latitude upper-level troughs. The corresponding tropical cyclones usually originate from the North Atlantic and the North or East Pacific respectively. Additionally they are predominantly the result of an interaction between the tropical cyclone and a mesoscale system as interactions between tropical cyclone and large-scale circulation initially are not involved in their development. Examples of mesoscale systems are baroclinic convergent zones like fronts and topographic convergent zones like mountains, coasts and cold-air dams (Bao et al., 2015; Bosart et al., 2012; Chen et al., 2010; Chen and Wu, 2016; Moore et al., 2013; Park and Lee, 2007).

In case of monsoon systems, pre-events tend to develop when the flow associated with the tropical cyclone outer circulation encounters the Asian monsoon flow and enhances it. During summer the southwesterly monsoonal flow is enhanced by the southerly flow induced by the outer circulation of the TC. The accompanying transport of warm, moist air towards the coast contributes to in-stabilisation of this air and low-level frontogenesis, and so to convection. During autumn this south-westerly monsoonal flow is replaced by the cold, dry northeasterly monsoonal flow that can converge with the warm, moist southeasterly airflow as induced by the tropical cyclone's circulation originating from the TC. This convergence strongly also contributes to lowlevel frontogenesis and convection, besides the in-stabilisation and lowlevel frontogenesis due to supply of warm, moist air by the southerly flow originating from the TC. The development of both season-type preevents usually take place in interaction with topographic influences like orographic or coastal lifting and coastal frontogenesis (Chen and $\mathrm{Wu}$, 2016). Subtropical highs can be present in the large-scale meteorological environment of a pre-TC. According to Xing et al. (2016) their role is to supply moisture to the pre-tropical cyclone and the enhancement of the monsoonal flow.

In case of upper-level mid-latitude trough systems, pre-tropical cyclones tend to develop eastward of upper-level troughs, on the western flank of a upper-level anticyclone and beneath the right hand side of the equatorward entrance region of an upper-level sub-tropical jet streak where a quasi-stationary, low-level baroclinic zone occurs/is situated. At these large-scale conditions, a deep and broad, warm and moist layer of air emanating from and transported poleward by a tropical cyclone (a warm conveyor belt, Grams et al. (2011); Piaget et al. (2015)) as a low-level jet is forced to ascend over this low-level baroclinic zone. An atmospheric river (see before) resembles in the increased moisture content of the air, but differs in its dimensions and its origin: atmospheric rivers are un-deep and narrow (Schumacher et al., 2011) and commonly originate in the tropics (Madonna et al., 2014; Piaget et al., 2015). The deep moisture layer of air can increase the precipitation efficiency and sustain deep convection, thereby turning heavy precipitation into a very heavy precipitation. Otherwise, a deep moisture 
layer already can allow the development of a pre-event with a weak forcing for ascent. Pre-tropical cyclones additionally can derive moisture from other sources like bays and mergers with other pre-tropical cyclones. The baroclinic zone functions as a mesoscale focusing mechanism for ascent like mesoscale surface boundaries and coastal features can do too. The advection of moisture by impingement of the tropical cyclone's circulation upon the baroclinic zone also drive/yield frontogenesis along this zone that enhances the ascent (Moore et al., 2013) though frontogenesis principally is caused by the confluence of two airflows i.c. the south-westerly flow from the tropical cyclone and the north-westerly flow from the mid-latitude trough (Baek et al., 2014). This confluence can be enforced if the upper-level pressure gradient between trough and a subtropical high increases (Baek et al., 2013). As is the case with pacific tropical storms, the advected moisture from Atlantic tropical cyclones favours in-stabilisation and so convection of the air (Baek et al., 2014). The ascent itself principally is caused by low-level warm air and moisture advection and by upper-level divergence in the equatorward entrance region of a jet streak. In case a strong low-level jet connected to the tropical cyclone occurs, tropical cyclones play a direct role in the development of a pretropical cyclone consisting in forcing of the ascent at the baroclinic zone. If cyclonic circulation or upper-level outflow are relatively weak or small scale or if the distance between tropical cyclone and pre-tropical cyclone is very large, tropical cyclones play an indirect role by acting as a source region of moisture (and heat) that is transported by a low level jet belonging to the current large-scale flow pattern. As is the case with pacific tropical storms, topography can have significant influences on the development of a pre-tropical cyclone. The pre-tropical cyclones developed under these conditions manifest themselves as mesoscale regions of heavy precipitation and can be considered as (quasi-stationary) MCSs. Additionally, topography can have significant influences on these pre-tropical cyclones (Bosart et al., 2012; Chen et al., 2010; Galarneau et al., 2010; Moore et al., 2013; Wang et al., 2009; Zhang et al., 2018).

The frontogenetically forced ascent can become more vigorous when the low-level jet has a perpendicular orientation relative to the baroclinic zone and when it can intensify. Low level jet intensification can occur when terrain (e.g. sloping terrain) cools differentially or when the geopotential height gradient between a tropical cyclone and the upper-level ridge increases. Frontogenetically forced ascent usually occurs in conjunction with a thermally direct lower-level frontogenetical circulation. This vertical secondary circulation can lift the moisture at the baroclinic zone, thereby assisting the convection (Galarneau et al., 2010; Baek et al., 2013; Baek et al., 2014). Besides the influences of the large-scale meteorological environment on the development of a pre-tropical cyclone, also influences of the pre-tropical cyclone on the large-scale meteorological environment occur that affect their development (two-way interaction between large-scale meteorological environment and pre-tropical cyclone). The quasi-stationary upper-level, diabatically-driven outflow of a (pre) tropical cyclone amplifies the eastern ridge of the upper-level jet stream. The advancement of the western trough towards the pre-tropical cyclone shortens the distance between the (upstream) trough and the (downstream) ridge. Both effects result into jet stream intensification that augments the upper-level divergence and the low-level ascent in the equatorward jet entrance region, thereby enhancing the development of the pre-TC. This diabatic influence of pre-tropical cyclones on downstream ridge amplification is part of a large-scale positive feedback that is comparable to the feedback between diabatic heating and convection in tropical cylones, extratropical cyclones and MCSs and also influences the extratropical transition and circulation of tropical cyclones as well as the changing of the tilt in positively tilted potential vorticity streamers as has been described in the respective parts of this paper (Bosart et al., 2012; Moore et al., 2013).

\subsection{Final remarks}

Heavy precipitation can be caused by a wide variety of storm types (Doswell et al., 1996). Actually, after Nicolaides et al. (2010), the development of each storm and so each storm type is driven by a combination of thermodynamic and dynamic factors that ask ditto analyses in this respect of each storm. Though convective storm types occupy an important place amongst this variety of storm types, heavy precipitation can also be caused by non-convective or synoptic storm types like stationary fronts with long duration, moderately intense stratiform precipitation and extratropical storms or cyclones with slow motion at which large-scale ascent of moist air is the driving force for the formation of precipitation (Schumacher and Johnson, 2005, 2006). Generally, a slow system motion with sustained deep convection over the same location results in the production of heavy precipitation within a short time period - regardless the type of forcing responsible for deep convection (Ducrocq et al., 2014; Schumacher and Johnson, 2009). It is necessary to understand the background of heavy precipitation producing storms because these storms possess a large diversity in processes and characteristics that in their turn largely determine the flood response of a catchment. This is - in comparison to normal precipitation especially applicable to heavy precipitation producing storms, not solely because of the heavy precipitation itself but also because of its associated high dynamic behaviour and accompanying spatiotemporal variability. Only if this behaviour and variability are sufficiently understood, flood response of a catchment can be adequately understood, being a necessarily prerequisite for the mitigation of this response.

\section{Climate change influences on heavy precipitation}

\subsection{Introduction}

From around the 1990s onwards climate change gets increasing attention in scientific studies. According to the Web of Science (consulted August 2017) the number of publications on this topic has increased from 112 (1989) to 25.342 (2016). From these publications respectively 9 and 3901 are related to precipitation. From these numbers it can be concluded that 'precipitation' is becoming a more and more important topic within the context of climate change. Therefore, the effects of climate change should be considered within the context of meteorological aspects of floods where this paper is about. This urges the more as precipitation-derived floods are one of the most costly and dangerous natural hazards worldwide (Westra et al., 2014). A study of Zolina et al. (2010) has shown that the structure of the European precipitation in the last two decades has already changed in comparison with the 1950s and 1960s: heavy precipitation events have become much more frequently associated with longer wet spells and they have been intensified. This study is an example of many studies demonstrating that changes in precipitation structure might be a fingerprint of the (probable partial) impacts of climate change. The longer duration of wet spells can be attributed to changes in cyclone intensity, the occurrence of cyclone series and to particular regional airflow, possibly modified by regional orography. However, in the evaluation of spells' impacts, also the precipitation intensities/durations of separate events within them, have to be considered (Zolina et al., 2013). Over most of Europe, Nissen and Ulbrich (2017) expected in a model study an increase of precipitation intensity for sub-daily events with high intensities, an increase of the number of daily and multi-daily events with high precipitation amounts (though at a lower rate than the number of sub-daily events), and an increase of event sizes for sub-daily events.

This section of the paper presents an overview of the impacts of climate change on (heavy) precipitation. The number of publications and the aspects related to precipitation only, do complicate this overview. The same goes for the number of uncertainties that both 
observational trends and model outcomes surround. Thus, the text hereafter together with the publications cited should be considered as a start for acquiring more in-depth knowledge of the present topic.

The focus will be mainly on the characteristics of precipitation and precipitation events in general (as dealt with in section 3.1) and not on mean fields, annual cycles and the like. Attention will be paid to heavy precipitation events in particular as climate change not only has large direct impacts on the hydrological cycle but also and more particularly on the precipitation extremes (Trenberth, 2011). We start with some more general aspects of the hydrological cycle that are relevant to consider in the context of climate change, followed by some more detailed descriptions.

\subsection{The hydrological cycle}

The global average precipitation rate is about $2.8 \mathrm{~mm} \mathrm{~d}^{-1}$. Because moisture must balance on that spatial scale, the global evaporation rate is also about $2.8 \mathrm{~mm} \mathrm{~d}^{-1}$. Evaporation is a continuous process that takes place from open water and land or soil. In this last case, evaporation is dependent on the availability of moisture in the soil. As rainfall is an intermittent process, which means it rains only a fraction of time (5$10 \%$ on average), precipitation rates are much larger than evaporation rates. The global average actual precipitation rate equals about $45 \mathrm{~mm}$ $\mathrm{d}^{-1}$ when it is raining. This rate is about 16 times the global average evaporation rate and about 6 times the locally available moisture in the air column (about $7.5 \mathrm{~mm} \mathrm{~d}^{-1}$ on average). These mismatches show the importance of both the availability and the location of moisture sources because it will not rain unless there is a supply of moisture to the precipitation system during its lifetime because the supply by (local) actual evaporation is too low. The moisture availability depends on temperature, relative humidity and the transport of moisture from the moisture sources (Trenberth et al., 2003) and this availability is of higher significance at less frequent and longer duration precipitation events (Wasko et al., 2015).

The imbalance between precipitation rate and evaporation rate has an important repercussion: storm systems are mostly fed by the moisture already in the atmosphere (Trenberth, 1998). This holds for all kind of precipitation systems (Trenberth, 1999). Trenberth et al. (2003) mention an estimation of about $70 \%$ of moisture in an extratropical cyclone that directly comes from the moisture already present in the atmosphere at the start of the storm development and 30\% from evaporation during storm development. While light precipitation can be restored by evaporation, most of the moderate and heavy precipitation cannot. Consequently, the lifetime of moisture in the atmosphere and its availability to storm systems is a limiting factor for the amount of precipitation and its rate (Trenberth, 1999); the shorter the lifetime of the system, the more determining is the currently available moisture at the start of the storm.

Another repercussion of the mismatch is the importance of the advection of moisture to the storm system. This advection is driven by the storm-scale circulation and accompanying low-level convergence (Trenberth, 1998, 1999). The spatial scale and accompanying amount of advection is strongly dependent on the scale and strength of the developing storm system and the synoptic environmental situation. Besides the supply of moisture by advection, the weather situation also determines the supply of moisture by evaporation, the storms that develop and the way precipitation is formed (Trenberth, 2011). The time scale of advection must be compatible with the lifetime of the storm system. Together with the locally or in-situ available moisture, the advected moisture does determine the amount of moisture that is available to feed the storm. Trenberth (2011) mentions that, on average, precipitation systems reach out to gather moisture over regions that are 10-25 times as large as the precipitation area, despite the type of the system. Consequently, convergence of available moisture on the scale of the system is a limiting factor for the precipitation system. A consequence of both repercussions is that the moisture content of the atmosphere directly and (at least) locally affects the rate of precipitation and not so clearly its frequency and thus the total precipitation (Trenberth, 1999). Because not all moisture present is available to the precipitation (precipitation efficiency, see section 4.2.6), the precipitation amount is always lower than the amount of available moisture (Trenberth et al., 2003).

Though the local precipitation strongly depends on the supply of moisture by advection, supply of moisture from the soil by evaporation of soil moisture can have some impact on precipitation along the (summer) season, especially on mid-latitude continental regions. Two mechanisms of soil moisture mediated precipitation change by climate change have been proposed. Increased evaporation and earlier snowmelt (due to climate change) may cause a more rapid decline in soil moisture during spring. If soil moisture drops below a certain threshold, it reduces evaporation. If this drop continues into summer it will lead to reduced evaporation and hence reduced precipitation. Besides a decrease in evaporation (due to a reduction of moisture supply to the atmosphere), reduced soil moisture will also induce an increase in soil surface temperature, thereby decreasing evaporation further (positive feedback). Both mechanisms together are responsible for the development and persistence of drought along the summer (Trenberth et al., 2003; Kendon et al., 2009).

Local precipitation response and changes therein aren't only controlled by the hydrological cycle but also by the atmospheric circulation. Frei et al. (2000) qualify these controls as in-situ effects and farfield effects respectively. It is known already for some time that changes in natural modes of the atmospheric circulations can change the precipitation response, and in addition, changes in these modes may be linked to climate change. One way in which precipitation response can change is through a shift in storms track and speed associated with the large-scale circulation (dynamic forcing) (Pfahl and Wernli, 2012). Shift in storm tracks coincide with changes in storm activity, local convergence or in the source and supply of moisture locally. Spatial changes in average precipitation amount or rates and in frequency and duration of heavy precipitation events may be accompanying effects. An example is the dipole pattern of changes as found over Europe with lower precipitation rates and amounts in the Mediterranean area (due to decreasing convergence) and higher ones in the Scandinavian area if the North Atlantic Oscillation is in a more positive phase (due to increasing convergence) (Frei et al., 2000; Eshel and Farrell, 2000; Trenberth et al., 2003; Kendon et al., 2009; Allan, 2011; Villarini et al., 2014). A second example is the increased strength of the low-level jet on the precipitation in the Midwest of the US when the North Atlantic Oscillation is in a negative phase (Budikova et al., 2010; Aryal et al., 2018). Another way is through changes in sea surface temperatures. A well-known example is the El Niño-Southern Oscillation responsible for the shift of the Inter-Tropical Convergence Zone and the South Pacific Convergence Zone that induces a dipole pattern of change in precipitation which occurs at the southern hemisphere with lower rainfall in East Asia and higher ones in South America (Allan, 2011; Frei et al., 2000; Trenberth et al., 2003; Villarini et al., 2014). The El Niño-Southern Oscillation is also responsible for the shift in the tracks and activities of cyclones (Wang and Chan, 2002; Zhang et al., 2018) and extratropical cyclones (Laing, 2004) and is caused by the El Niño-Southern Oscillation enhanced poleward transport of heat and moisture. The enhanced generation of tropical cyclones in the western North Pacific is attributed to the increase of the low-level shear vorticity by El Niño-induced equatorial westerlies and the suppressed generation to upper-level convergence induced by the deepening of the east Asian trough and strengthening of the western North Pacific subtropical high, both resulting from the forcing by El Niño-Southern Oscillation (Wang and Chan, 2002). According to Aryal et al. (2018), El NiñoSouthern Oscillation largely influences the frequency of cyclogenesis trough variation in the vertical wind shear in the North Atlantic, and the North Atlantic Oscillation cyclone's track by modifying the location 


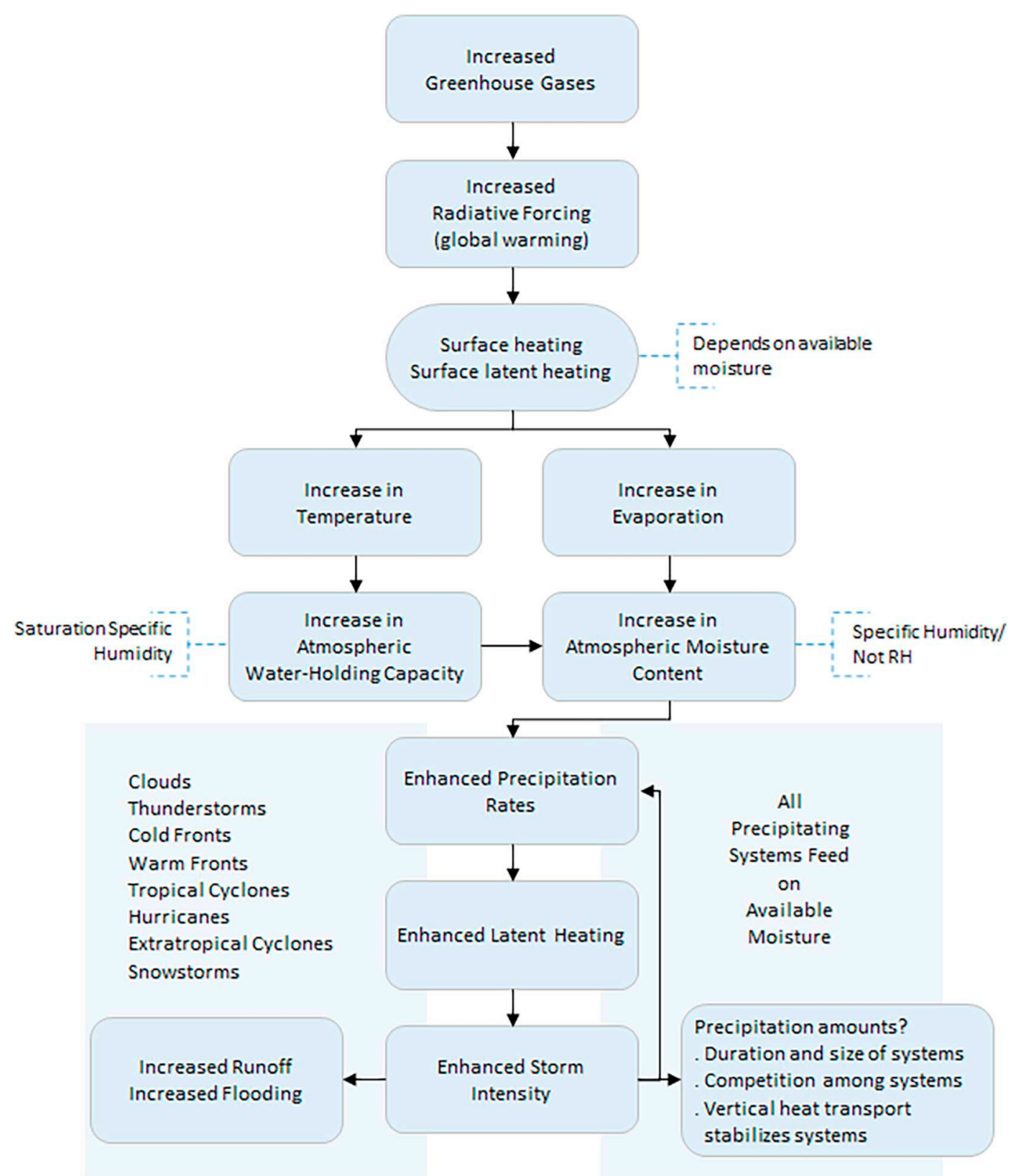

Fig. 11. Schematic outline of the sequence of processes involved in climate change and how they alter moisture content, evaporation, and precipitation rates. Adapted from Trenberth (1999).

of the subtropical high. Another example is the connection between anomalies in the North Pacific sea surface temperature and the occurrence of heavy precipitation over North China. A positive anomaly results into an increased water vapour transport by a low-level jet from the tropical ocean to North China (Li et al., 2017). A final example is the mediation of the low-level jet's transport of moisture and the monsoon by the El Niño-Southern Oscillation and North Atlantic Oscillation (Aryal et al., 2018). From these examples it appears that both the phase and the magnitude of these large scale oscillations mediate the behaviour (track and activity) of tropical cyclones. Finally, O'Gorman (2015) remarks that reductions in a meridional temperature gradient can counteract increases in latent heating.

\subsection{The influence of climate change on precipitation - general considerations}

Increased greenhouse concentrations in the atmosphere result into increased down-welling infrared radiation that next produces increased heating at the earth surface (global warming). Increased heating doesn't only increase the temperature of the surface and the atmosphere, but also the moisture content of the atmosphere as evaporation also increases (intensification of the hydrological cycle). The increase in evaporation is a direct consequence of a change in the energy balance of the earth surface: to obtain a new energy balance much of the increased energy is converted into evaporation (Trenberth, 1998; Frei et al., 2000). According to Trenberth $(1999,2011)$, the energy balance plays a critical role in the hydrological cycle in constraining the energy available to evaporation (a physical or energy constraint). Increased moisture content of the atmosphere, in turn, results into increased precipitation amounts (Trenberth, 1999, 2011; Trenberth et al., 2003). Allen and Ingram (2002) and Trenberth et al. (2003) mention a global, model-based value of this precipitation amount increase of around 1$3 \%$ per Kelvin.

The water-holding capacity of the atmosphere is physically 
governed by the Clausius-Clapeyron (CC) equation. This equation is derived from the first and second law of thermodynamics and presents a relationship between saturated vapour pressure and temperature in moist air. We will elaborate upon this equation in the context of precipitation extremes in section 6.5. When (due to climate change) the temperature of the atmosphere increases, its water-holding capacity will also increase. This increase is about $7 \%$ per Kelvin. As model results show that changes in relative humidity are modest, the increase of the actual moisture content of the atmosphere should also be about 7\% per Kelvin, which is confirmed by observations. Though this value might hold globally, in reality moisture changes are not uniform, despite the rather uniform increase of temperature along the globe. A larger increase in moisture at lower latitudes will occur in spite of a larger increase in temperature at higher latitudes. This non-uniform increase in moisture on the globe is caused by the non-linearity of the CC equation. In this respect, also the dynamics of the atmosphere (global atmospheric circulation) play a significant role as these dynamics influence the position and strength of storm tracks as well as those of the atmospheric high- and low- pressure regions with their subsidence and convergence (Trenberth et al., 2003; Trenberth, 2011).

Because of energy balance constraints, the disparity between moisture increase and precipitation increase (7\% and $1-3 \%$ per Kelvin, respectively) has major implications for the frequency of precipitation and the precipitation efficiency (Trenberth, 1998, 1999, 2011). To restrict the precipitation amounts, the frequency of precipitation events should decrease. Though the influence of climate change on precipitation efficiency is not clear, it is supposed that more moisture remains in the atmosphere when the water-holding capacity of the atmosphere increases and the relative humidity remains more or less unchanged. As more moisture remains in the atmosphere, precipitation cannot increase in direct proportion to the available moisture (Trenberth, 1998). Another consequence of this disparity can be the greater distance between separate events: the spatial distribution of storms becomes more spotty (Trenberth, 1999, 2011; Trenberth et al., 2003) and has been corroborated by the simulation experiment of Loriaux et al. (2017).

As discussed in chapter 4 and section 6.3, heavy precipitation events strongly depend on the convergence of available low-level moisture on the scale of the system. Accompanying precipitation rates greatly exceed the evaporation rate or the locally available moisture in the atmosphere. If (due to climate change) the atmospheric moisture content increases conform the CC equation, the moisture convergence should increase by the same amount as the precipitation. Due to this dependency the atmospheric moisture directly affects precipitation rates (Trenberth, 1999). Actually, the increase of the rate of individual precipitation storms can even exceed the rate of increase according to the CC equation. The extra available moisture causes the release of additional heat that feeds back and invigorates the storm, thereby further enhancing the convergence of moisture and so the precipitation rate. The consequence of it is that precipitation rates changes faster than changes in total precipitation amounts. The implication of this disparity is that there must be a decrease in light and moderate precipitation events and/or a decrease in the frequency or duration of heavy precipitation events, as it takes longer to recharge the atmosphere with moisture. Hence, the expectation is in general a fewer and farther between, but more intense precipitation events. This pattern of more intense precipitation events is observed in many parts of the world, even when mean precipitation amounts don't increase (Allen and Ingram, 2002; Fischer and Knutti, 2016; Trenberth, 2011; Wang et al., 2017) and is associated with fewer rainy days due to increased frequency and persistence of sub-tropical anticyclones (Alpert et al., 2002). According to Trenberth et al. (2003) and Allan and Soden (2008) precipitation intensity might increase even further when the precipitation amounts increase.

From the foregoing it can be concluded that in the context of climate change intensity and frequency of precipitation are as important as its amount (or duration) and size in understanding what is happening with precipitation under a changing climate and its consequences like flooding (Nissen and Ulbrich, 2017; Trenberth, 1999; Trenberth et al., 2003). The rationale of the changes in the hydrological cycle along with the resulting changing character of precipitation is depicted in Fig. 11. This conceptual picture tells what locally can (and not what should) happen with precipitation due to climate change as an overall global average (Trenberth, 1999). It shows the factors involved in increasing moisture content of the atmosphere (upper part) and how this alters precipitation rates as all precipitating systems feed on the available moisture within reach of the storm-scale circulation, leading to increases in precipitation rates and feedbacks (lower part).

So far, precipitation has been seen as rain. Nonetheless, precipitation also can occur in the form of snow and snowfall also can increase the risk of flooding (Trenberth, 1999). Therefore, attention should be paid to it as well. Due to climate change however, higher temperatures are expected in winter, causing more precipitation to fall as rain rather than as snow. In addition, snowmelt in spring will fasten and snow evaporation and ablation will be greater. These factors together culminate into a smaller snowpack. Consequently, the local hydrological cycle will change by changes in soil moisture and runoff (Madsen et al., 2014; Trenberth, 1999, 2011; Trenberth et al., 2003).

This section will be finalised with the impact of climate change on sea surface temperature and tropical cyclones whose existence strongly depends on it. The increase of sea surface temperature (due to climate change) will produce more intense cyclones with larger peak winds and more heavy precipitation (Knutson et al., 2010; Zhang et al., 2018) and is therefore related to the El Niño-Southern Oscillation (Khouakhi et al., 2017; Aryal et al., 2018). The subtraction of a larger amount of heat on the ocean by these stronger cyclones can lead to a (globally averaged) lower frequency of this storm system as do possible increases in static stability (Trenberth, 2011). However, the frequency of most intense tropical cyclones and their precipitation intensity within 100 $\mathrm{km}$ of cyclone's centre increase considerably (Knutson et al., 2010). In a study on the contribution of cyclones to extreme precipitation in southeastern US, Knight and Davis (2009) attributed the rise in cyclone contribution to an increase precipitation amount and frequency of the cyclones. Apparently, other factors than the heat subtraction by a cyclone (presumably meteorological ones) are more important for the determination of its frequency.

\subsection{Precipitation change induced by climate change - considerations about space and time scale}

In section 6.2, general considerations are sketched about precipitation changes that are induced by climate changes. Though these precipitation changes mostly concern overall global averages and mostly deal with daily precipitation values (daily mean amounts), they roughly agree with observations and model results (Trenberth, 2011). However, what actually happens locally is not clear from what happens at global space scale and daily time scale. To understand what locally happens with precipitation due to climate change, it is important to simultaneously study moisture content of the air, precipitation rate and frequency, and how they change with climate change (see also Fig. 11) and not only to study precipitation amounts (Trenberth, 1999). In this context, it is important to remember from 6.2 that local precipitation change is not only driven by changes in the atmospheric moisture content, but also by changes in other factors - both on global scale, mesoscale and local scale (Trenberth, 2011). Factors that relate to moisture supply are dealt with in the context of the hydrological cycle (6.2), other factors will be discussed in 6.5.

In the beginning, precipitation data analysis was mainly based on daily means. To increase the understanding of the processes behind changes in precipitation by climate change, hourly or higher frequency data are required. Hourly precipitation data provide a much more truthful picture of real precipitation than daily data do. They facilitate detailed data analyses that is impossible with daily rainfall amounts, 
e.g. the analysis of the diurnal cycles. While it is known that increased moisture content increases the rate of heavy precipitation locally (because atmospheric moisture directly affects rain intensities, see section 6.2 ), it is less clear what happens with the total amount of precipitation, as the duration of storms may be shortened and/or the frequency may be reduced. These changes occur because it takes longer to recharge the atmosphere with moisture. Hourly data also provide the opportunity to investigate the variability of heavy precipitation (in terms of rate and frequency) across various (climate) regions of the world. These data have the advantage that they are compatible with the lifetime of the main precipitation systems. This is highly recommended because most of the time it does not precipitate and only on rare occasions rain will fall during an entire day. Therefore, precipitation data collection -conditional on when rain is falling- and accompanying determination of the precipitation frequency is of substantial importance and highly needed (Trenberth, 1998, 1999, 2011; Trenberth et al., 2003). Finally, hourly time scales are more relevant for scientific studies and practical applications concerning hydrological extremes than daily and multi-day data are (Kyselý et al., 2012). The same holds for small spatial scales (Gregersen et al., 2013).

\subsection{Precipitation extremes and climate change}

In section 6.2 and 6.3 we have - in general terms and at global scale - spoken about (heavy) precipitation and in 6.4 we have stressed the importance of local scale and hourly data. In this section we want to focus on heavy precipitation events more specifically by paying attention to several aspects of these events, which are often referred to as 'precipitation extremes' in literature. Precipitation extremes are manifold connected with climate change and they frequently form the subject of ongoing research and public debate in the context of climate change. From a modelling point of view, they appear to be highly sensitive to the magnitude of future global warming (Zhang and Villarini, 2017).

Recalling from 6.3, the CC equation describes the rate of increase in the water-holding capacity of the atmosphere (in terms of saturated water vapour pressure) as function of surface temperature. This way, a scale can be set for changes in precipitation extremes with temperature change. This scale setting is based upon three assumptions that approximately hold at a large scale (Lenderink and Van Meijgaard, 2008). First, the relative humidity remains nearly constant at climate change by which the actual amount of moisture in the atmosphere will scale with the water holding capacity. Second, in extreme precipitation events precipitation is mainly determined by the moisture already available in the atmosphere (nearly all available water is converted into rain). Third, the change in atmospheric circulation that determines vertical motions responsible for the formation of rain, is negligible. This third assumption does not always hold (Lenderink and Van Meijgaard, 2008). Basically spoken, the primary cause of the increase of precipitation extremes by global warming is the increase of the amount of atmospheric moisture (a change primarily in atmospheric thermodynamics) (Loriaux et al., 2016; Lenderink et al., 2017). The physical principle behind this is the simple fact that a warmer atmosphere can hold more moisture (Berg et al., 2013; Held and Soden, 2006; Kendon et al., 2014; Lenderink and Van Meijgaard, 2008, 2010; Teufel et al., 2017) and the expectation that precipitation should follow accordingly (Berg et al., 2009; Loriaux et al., 2017). As dew point is a more immediate measure of the available moisture, CC scaling with dew point better captures the influence of climate change on heavy precipitation than temperature does (Lenderink and Van Meijgaard, 2010; Lenderink et al., 2017; Lochbihler et al., 2017; Schroeer and Kirchengast, 2018).

The arguments given above are mentioned explicitly to make clear that the CC equation doesn't necessarily sufficiently hold at the local scale. Apparently, at this scale other factors and processes than the local availability of moisture play a role in the significant deviation from the relation between the precipitation extremes and local temperature that was expected considering just the CC equation (Donat et al., 2016; Frei et al., 2000; Trenberth et al., 2003; Wang et al., 2017). Besides the thermodynamic factors (given by the CC equation), dynamic factors and precipitation efficiency also are important to consider for changes in precipitation extremes in response to climate change (Haerter et al., 2010; O'Gorman, 2015). They can cause a strengthening or a weakening of the CC scaling or both, showing the topic of competing factors or processes. An example of both strengthening and weakening is the change in global circulation or atmospheric dynamics (O'Gorman, 2015). Subtle shifts in large-scale atmospheric circulation can affect local precipitation to a much greater extent than the thermodynamic processes related to the atmospheric moisture content (Allan, 2011). In the context of deviations of CC scaling it is important to mention that changes in temperature may also affect other quantities than (changes in) the atmospheric moisture content (). An example of it is the temperature induced change of the moist adiabatic lapse rate that affects the condensation rate of moisture and so the rain intensity.

Another example concerns the areal rainfall, size and organisation of clouds. Peleg et al. (2018) observed that the convective areal rainfall increases with higher temperatures while the non-convective areal rainfall and storm area decrease. This points to a redistribution of moisture (or enhanced moisture convergence) from the entire storm toward the convective rain cells, caused by an enhanced convective intensity of these cells at higher temperatures. Consequently, the total rainfall amount in the entire storm area decreases. Cloud sizes and precipitation intensities increase by merging and splitting of convective cells and this property becomes likely at higher dew point temperatures (Lochbihler et al., 2017) and if clouds are organised in a cloud system, also the temperature dependency of cloud-cloud interactions, like the collision of cold pool boundaries, have to be considered (instead of focusing on a single cloud system) (Moseley et al., 2016). Consequently, larger rain cells follow super CC scaling while small rain cells do not. Remarkably, rain cell size has to increase to maintain super CC scaling and rain cell size increases strongly with dew point temperature. Therefor higher rain intensities are accompanied by larger rain cells and larger rainfall areas (Lochbihler et al., 2017). This is in contradiction to Wasko et al. (2016) who obtained smaller rain cells within Australian storms with increasing air temperature (with a redistribution of moisture towards the storm's centre). In addition, in these storms Wasko et al. (2015) observed steeper temporal distributions of precipitation intensity with higher peak intensities at increasing air temperatures. Though CC scaling is widely considered as a guide for quantifying the increase of precipitation extremes (Wang et al., 2017), it apparently must be used with caution: "while moisture increases in the atmosphere may be closely related to temperature increases, we emphasize that such simple relations do not apply for precipitation" (Haerter et al., 2010).

In addition to the factors and processes discussed, the CC scaling also depends on the time scale or duration and frequency of the precipitation extremes: the scaling decreases with increasing event duration and frequency (Hardwick Jones et al., 2010; Panthou et al., 2014; Wasko et al., 2015). On average, sub-daily precipitation extremes scale with temperature at higher rates than daily, multi-daily and seasonal precipitation extremes do (Berg et al., 2013; Fischer and Knutti, 2016; Kendon et al., 2014; Kyselý et al., 2012; Lenderink and Van Meijgaard, 2008; O'Gorman and Schneider, 2009; Panthou et al., 2014; Utsumi et al., 2011) at which daily precipitation extremes roughly commensurate with the CC rate (or below, Haerter et al., 2010) and the sub-daily extremes with rates higher (Fischer and Knutti, 2016) or about twice this rate (Ban et al., 2014), also called super CC scaling (Lenderink and Van Meijgaard, 2010). This has been verified in high and mid-latitude as well tropical regions (Utsumi et al., 2011; Berg et al., 2013; Fischer and Knutti, 2016) and in winter and summer seasons, together with a higher frequency of extreme precipitation events in summer (Kendon et al., 2014). These higher rates can even occur in regions and seasons in which mean precipitation declines (Kyselý et al., 
2012). The less pronounced scaling behaviour of daily extremes suggests that precipitation does not only depend on the local available moisture but also on the moisture advected from the surrounding regions suggesting/pointing to synoptic events (Panthou et al., 2014). It also suggests that the processes involved at daily scale are more complicated than those at hourly scale (Lenderink and Van Meijgaard, 2008). Examples are precipitation extremes with a clear daily cycle that show increases in these extremes due to temperature increases by global warming. This typical behaviour is related to the supply and build-up of moisture and convective energy together with the cloud formation processes. Thanks to this behaviour, changes in precipitation extremes may be caused by both temperature changes and changes in this supply of build-up and the cloud formation processes - changes as induced by global warming (Berg et al., 2013).

In a study on summertime afternoon precipitation events by Lenderink et al. (2017), the hourly peak precipitation intensities of these events show a super CC scaling with the surface humidity (i.c. surface dew point temperature). The atmospheric instability/CAPE (showing local cloud dynamics) and the maximum cloud depth increase with increasing surface humidity while relative humidity and dry lapse rate do not, pointing to the response of convection to increasing surface humidity as potential cause of the super CC scaling. The release of latent heat by this response enhances buoyancy and vertical velocities by which next low-level moisture convergence also enhances and so the precipitation (positive feedback) (Trenberth et al., 2003; Loriaux et al., 2013; Lenderink et al., 2017). Also the increase of CAPE with air temperature is responsible for the super CC scaling (Panthou et al., 2014). In addition, hourly peak precipitation intensities are commonly associated with high large-scale vertical velocities causing substantial large-scale moisture convergence (showing large-scale cloud dynamics), in turn causing larger event sizes. The high large-scale velocities don't only point to synoptic scale circulation but also to a positive feedback due to convection (large-scale uplift triggers convective updraft, Loriaux et al., 2017). The event size increases considerably at higher surface humidity, hinting at an increased occurrence of larger cloud systems at those high humidity values. This points to the necessary role of large-scale circulation in providing substantial moisture to the developing clouds.

Ban et al. (2014) discovered in their study that precipitation extremes in summer on hourly and daily scales become more frequent and more intense, but not as pronounced as those in the studies of Lenderink and Van Meijgaard, 2008 and of Kendon et al. (2014): precipitation extremes at daily and hourly time scales increase with the CC rate (and not faster). They attributed this inconsistency to changes in the fraction of wet hours. This study shows that extrapolation from present-day super CC scaling into the future doesn't hold as was already questioned by Singh and O'Gorman (2014), Ban et al. (2015) and Donat et al. (2016).

Berg et al. (2009) found a seasonality in the temperature dependence of the intensity of precipitation extremes, with a general increase in winter and a decrease in summer. This increase can be explained by the dominance of large-scale precipitation in the winter season. Because of a relative low air temperature in winter, it is readily saturated by the advected moisture. Hence, the CC scaling can describe the change of precipitation with temperature in this season. The decrease in summer can be explained by the temperature dependent contribution of largescale precipitation and convective precipitation at which - at increasing temperatures - convective precipitation increasingly dominates the temperature dependent behaviour. In summer the intensities of largescale precipitation show a decrease with temperature due to a lack of saturation at this scale. Intensities of convective precipitation, however, show a season-dependent peak behaviour because the convection process itself is temperature dependent. Due to higher temperatures in summer the atmosphere can hold more moisture but it becomes less readily saturated because there is a decrease in relative humidity with temperature (Berg et al., 2013). Together with the lower supply due to a more local character of moisture transport because of the convective nature of precipitation, the moisture availability can become limited in summer. Hence, in summer the moisture availability rather than moisture content mainly controls the precipitation behaviour with a decrease of intensities with temperature.

The differences in scaling between daily and hourly extreme precipitation have been related to differences in the type of precipitation. On a sub-daily timescale precipitation extremes are usually related to convective showers or downpours and on a daily time-scale to largescale stratiform precipitation. Four factors can be distinguished that may affect the temperature scaling of precipitation extremes. First, temperature change induced changes in the physics of the convective showers themselves. These changes can be explained by the latent heat released within storms invigorating vertical motion that leads to greater increase in precipitation intensity (see also 6.2) (Kendon et al., 2014). Second, changes in temperature can coincide with changes in (the portion of different) precipitation types. Changes from lower to higher temperature involve a change from predominantly large-scale (frontal/ cyclonal) precipitation to local scale (convective) precipitation. While large-scale precipitation commonly is limited by the moisture holding capacity of the atmosphere (i.e. CC scaling), small-scale precipitation is limited by the moisture availability at which super CC scaling can occur (Berg et al., 2009; Lenderink and Van Meijgaard, 2008) if sufficient moisture is supplied to convective storms by mesoscale atmospheric motion from the surrounding atmosphere (Attema et al., 2014; Berg et al., 2013). Third, changes in small-scale dynamics of cloud and sub-cloud layer, cloud and precipitation microphysics and in cloud sizes may influence the production of rain (Lenderink and Van Meijgaard, 2008; Attema et al., 2014; Singh and O'Gorman, 2014). In this context Singh and O'Gorman (2014) remark that the fall speed of hydrometeors is determinant for the intensity of convective precipitation extremes in short showers. Precipitation intensity increases when the fall speed increases because of changes in the efficiency with which net-condensation is translated into precipitation. The mean fall speed increases with temperature increase as the fraction of frozen hydrometeors decreases. Fourth, differences in scaling can also result from changes in the atmospheric vertical temperature or instability. Higher surface temperatures lead to an increase in instability and therefore to an invigoration of convection (Lenderink and Van Meijgaard, 2010; Trenberth, 1999; Westra et al., 2014).

Besides seasonal daily cycle and diurnal differences in precipitation extremes also regional differences exist in the scaling of precipitation extremes with temperature. This scaling of daily precipitation extremes varies with latitude and is generally not equal to CC scaling (O'Gorman and Schneider, 2009). Regional patterns of changes in precipitation extremes due to global warming can be understood from geographic variations in the changes of the strength of factors and processes (as mentioned above in this section) influencing the production of rain. Though these factors and processes result into a complex pattern of changes in regional precipitation extremes, studies remarkably enough show an increase of daily precipitation extremes over most regions in the world (Fischer and Knutti, 2016). These increases occur in both dry and wet regions and in both tropical and extratropical regions (Donat et al., 2016) and in coastal and inland regions (Panthou et al., 2014). In dry regions, the increases of daily precipitation extremes are linearly related to global temperature changes. In mid- to high latitudes (extratropics) daily precipitation extremes often scale with local to regional temperatures at rates close to CC scaling (Fischer and Knutti, 2016). Though in these latitudes, the upward velocity to a greater extent is controlled by large-scale vertical processes than in the low latitudes, their contribution might not change greatly under climate change. The changes in the moist adiabatic lapse rate mainly determine the rate of increase of precipitation extremes in these latitudes. Or stated otherwise, the thermodynamic contribution from changes in the moist lapse rate are larger than the dynamical contributions from changes in vertical velocities. In low latitudes ((sub-)tropics) however, 
daily precipitation extremes generally are more sensitive to global warming and vertical velocities are more influenced by convection than the precipitation extremes in the extratropics (Davies et al., 2013; Emori and Brown, 2005). This larger sensitivity might be caused by a more positive dynamical contribution from changes in the vertical velocities than in the extratropics at which these contributions can be either positive or negative, depending on season and hemisphere (O'Gorman and Schneider, 2009; O'Gorman, 2015). However the negative CC-scaling obtained in the tropics (due to limited moisture availability), can be positive if the CC scaling is based on individual storm durations instead of a given duration (with an aggregation of several events) (Wasko et al., 2015). Coastal regions across Canada exhibit a CC-scaling and inland regions exhibit a super CC-scaling (for short event durations). This difference is mainly related to the difference in the main driver of the precipitation system, synoptic and convective system respectively (Panthou et al., 2014). According to Panthou et al. (2014), Shaw et al. (2011) and Utsumi et al. (2011) the geographical region with its hydro-climatology (i.c. moisture availability) is one of the most important factors affecting the CC scaling. Though regional differences in climate change mediated precipitation extremes are projected by climate models (and are observed, e.g. O'Gorman, 2015), large uncertainties exist in these projections (Lenderink and Fowler, 2017).

Temperature itself also influences the precipitation scaling in multiple perspectives. It matters how the vertical atmospheric temperature profile is disturbed (Singh and O'Gorman, 2014). Loriaux et al. (2013) mention a scaling behaviour close to CC if the profile is perturbed according to a moist adiabatic and a super CC scaling if the profile is perturbed vertically uniform. Such a moist adiabatic perturbation is considered more representative for the tropics, while a vertically uniform temperature perturbation is more representative for the extratropics (Attema et al., 2014). Besides vertical changes in temperature also changes in the moisture profile might influence the precipitation scaling (Böing et al., 2012).

A second topic in this respect concerns the applicability of CC scaling at (very) high temperatures. According to Lenderink and Van Meijgaard, 2008 and Wang et al., 2017 daily precipitation extremes generally show a decrease when local surface temperature exceeds a certain threshold (a negative scaling behaviour) and these extremes therefore peak at this threshold. This decrease appears to be a robust characteristic across climate regimes and can occur even without a decrease in the absolute moisture content (Wang et al., 2017). Two mechanisms that work together are primarily held responsible for this decrease and the dominance of them is probably region dependent (Wang et al. (2017)). First, less precipitation as a result of moisture limitation at (very) high temperatures. In this case the saturation deficit (difference between the maximum and absolute moisture content) can be large, probably inhibiting deep convection and therefore extreme precipitation. Second, the temperature response to (decreased or increased) precipitation. In conditions of large-scale subsidence, convection and therefore precipitation become suppressed, leading to more sunshine, lighter winds and less evaporation, and therefore to higher surface atmospheric temperatures than without large-scale influences. In cases of extreme precipitation, conversely strong latent heat fluxes of falling rain droplets contribute significantly to the cooling of the surface atmosphere and accompanying lowering of atmospheric temperatures. However, the negative scaling at high temperature does not refute the relevance of CC scaling if it is considered when CC scaling is applicable (see the arguments before). When temperature increases, the increase of moisture slows down and CC scaling becomes inapplicable (because moisture is limited or the relative humidity is not constant at (very) high temperatures), precipitation cannot increase anymore and reaches a peak value (the condition at the peak of extreme precipitation is the closest for the CC scaling to be applicable). The merits of the CC scaling lies in the fact that the peak of extreme precipitation and the accompanying temperature can be established. This accompanying temperature then remains behind the local mean temperature and should not be confused with each other. The scaling of peak extreme precipitation with peak temperature is conform to CC scaling in the mid- and high latitudes and to super CC scaling in the tropics.

Another topic deals with the temperature dependence of the main precipitation types, convective and stratiform precipitation. While convective precipitation has a peak-like structure in temperature dependence, independent of the mean local temperature, contrary to stratiform precipitation which has a monotonic increase in temperature dependence (Berg et al., 2009).

Finally, when temperatures increase extreme precipitation event durations decrease (Haerter et al., 2010). This decrease relates to precipitation efficiency. According to Singh and O'Gorman (2014) and O'Gorman (2015), for temperatures below $295 \mathrm{~K}$, the precipitation efficiency can increase substantially with global warming and the scaling of precipitation extremes with temperature then becomes dependent on the duration of the precipitation event. As a consequence of the decrease of event duration, the total precipitation amount of an event increases less pronounced than the mean precipitation intensity of an event (Haerter et al., 2010).

Increases in precipitation extremes with increasing temperature are probably more robust than changes in mean precipitation (Hegerl et al., 2004) and in total precipitation (Trenberth et al., 2003; Haerter et al., 2010). In case of mean precipitation, this is due to the fact that increasing moisture with global warming more strongly influences precipitation intensity than precipitation occurrence or frequency (Kendon et al., 2009) and in case of total precipitation this is due to a reduction in the duration of the precipitation event (Haerter et al., 2010) or a reduction of both duration and frequency (Trenberth, 2011). Mean precipitation is mainly controlled by large-scale dynamics and the energy budget of the atmosphere, extreme precipitations by the budget of available moisture (Allen and Ingram, 2002; Haerter et al., 2010). These differences underpin yet that precipitation characteristics like frequency and duration are just as of vital importance as its amount (Trenberth et al., 2003).

\subsection{Conclusion}

The response of precipitation extremes to climate change has been investigated from literature with a focus on the physical factors and processes that control this response. In addition to the moisture content of the atmosphere, the nature of this response depends on many additional factors that should be considered together: a complex relationship exists between precipitation extremes and these factors (Pendergrass, 2018). Studies encompassing both theory, modelling and observations show that precipitation extremes intensify and occur more frequently due to climate change in different regions of the world. Both carefully constructed high resolution monitoring systems and high-resolution modelling studies collectively are required to increase our understanding of the response of precipitation extremes to climate change and of the processes that might cause precipitation extremes to change by climate change and of the processes that are responsible for this response. Especially the climate change mediated influences of mesoscale convective organisation on precipitation extremes serves much attention. This high resolution monitoring and modelling are particularly important because precipitation extremes are inherently local and of short duration and just these precipitation extremes are expected to change due to climate change. This increased knowledge is urgently needed to be able to more accurately predict precipitation extremes and adequately respond to changes in the risk of floods because they are principally caused by these precipitation extremes (Allan, 2011; Fischer and Knutti, 2016; Frei et al., 2000; O'Gorman, 2015; Panthou et al., 2014; Trenberth et al., 2003; Westra et al., 2014). 


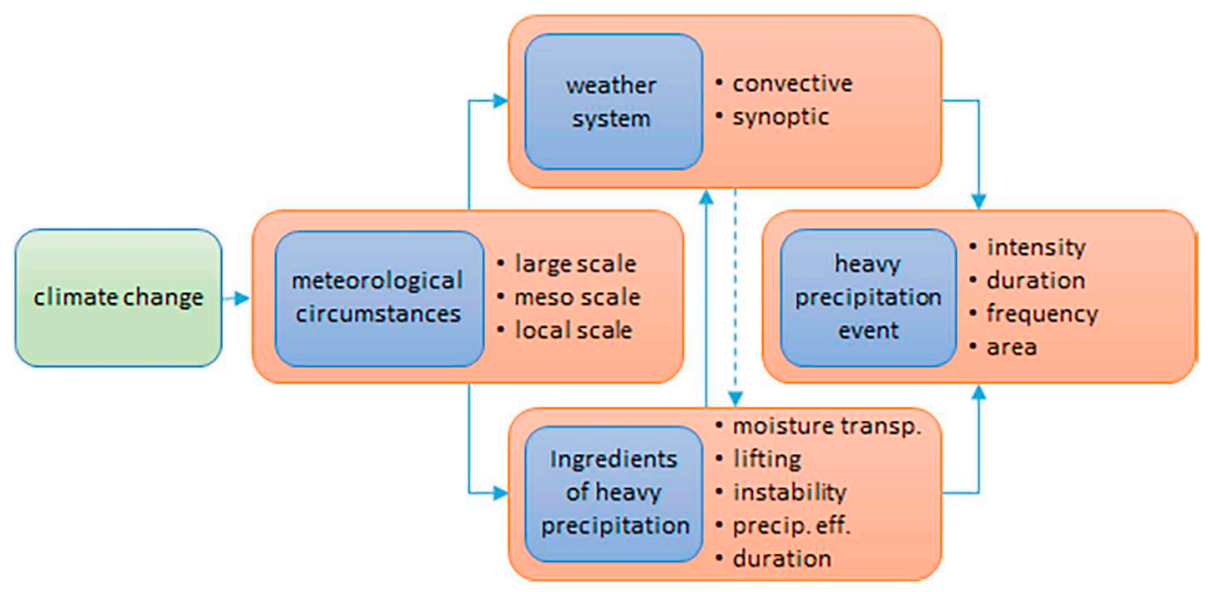

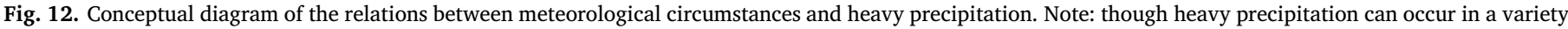

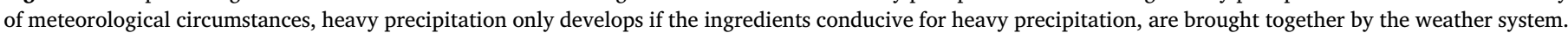

\section{Summarizing conclusions}

This paper attempts to present an overview of the processes and circumstances that play a role in the generation of heavy precipitation events. To understand and predict the occurrence of such a heavy precipitation event, it is essential to know under which meteorological circumstances a heavy precipitation event can develop or can be expected, meaning practically when (at which periods of time) and where (at which locations) a certain minimum hazardous amount of precipitation (e.g. $50 \mathrm{~mm}$ in an hour) will occur. It becomes clear that a heavy precipitation event can only be expected at certain specific meteorological conditions at which both large-scale, mesoscale and local scale conditions do matter and these conditions can differ greatly with location and time (Renard, 2017; Ricard et al., 2012). Inherent to it is that a heavy precipitation event is coupled to a specific location and time. These circumstances go together with weather systems (section 5.3 and 5.4) that deliver and bring together the necessary ingredients (section 4.2) for the production of heavy precipitation (Schumacher et al., 2013). The relations between meteorological circumstances and heavy precipitation are conceptualised in Fig. 12. It is the task of regional meteorological services to thoroughly know and understand when and where these weather storms might be expected. They have to communicate about them with local water and flood authorities in order to take timely and location-specific effective counter measures. Though, from a climatological point of view, some common meteorological circumstances responsible for production of heavy precipitation at a certain location will be known, it is emphasised that actual heavy precipitation expectations (or heavy precipitation potential) still have to be made. The actual meteorological circumstances certainly will differ from the climatological ones. Each heavy precipitation event is unique (section 4.3). In addition, it is important to realize that a heavy precipitation potential doesn't imply the real occurrence of a heavy precipitation event at a particular location and time.

In this paper we want to emphasize the complexity of the meteorology of a heavy precipitation event and the diversity in the corresponding weather systems. This finds its repercussions in the difficulty to accurately model this meteorology. According to Lin et al. (2001) and Schumacher and Johnson (2008) -to name a few- quantitative prediction of precipitation is one of the most challenging and most difficult problems in numeral weather prediction. The prediction of the amount of precipitation is more difficult than the prediction of its occurrence, but "it is the amount of precipitation that transforms an otherwise ordinary precipitation into an extra-ordinary situation" (Doswell et al., 1996). It is also difficult to accurately predict the location of a storm system as well as to understand why a storm system becomes paroxysmal (Ricard et al., 2012). The problems in modelling precipitation basically stem from incomplete knowledge of the localscale processes (convection, turbulence, microphysics), the non-linear process interactions among different scales and the insufficient density of observations at meso- and local scales (Schumacher et al., 2013; Ducrocq et al., 2014). In addition, modelling of organisational aspects of heavy precipitation is also not straightforward.

Closely related to the foregoing is the interest in the relation between the ingredients responsible for a heavy precipitation event (section 4.2) and its characteristics (section 3.1) and how this relation will be altered by climate change (section 6.5 ). Of particular interest is the quantification of the relation between ingredients and characteristics because of the strong need on quantitative numbers. The number of investigations that specifically focus on this quantification however is relatively limited and they mainly deal with precipitation intensity to characterize a heavy precipitation event (e.g. Doswell et al., 1996; Lin et al., 2001; Lenderink and Van Meijgaard, 2008; Utsumi et al., 2011; Ricard et al., 2012; Lepore et al., 2016; Loriaux et al., 2016). Though positive relationships exist between ingredients and the peak intensity, generally no quantitative physically process wise expressions can be derived. In addition, there is no one-to-one correspondence between the ingredients and heavy precipitation, by which no quantitative indicators can be derived (Loriaux et al., 2016; Lenderink et al., 2017). Generally, it can be remarked that the higher the value of the ingredient (or the stronger the mechanism) and the more ingredients working together (also the more types of one ingredient, like multiple lifting mechanisms), the heavier the precipitation event. In addition, the mutual relationship (i.e. the organisation of the ingredients in favourable space and time) will change the intensity of the precipitation event as well (Yang et al., 2017b).

To conclude: it is important to know which meteorological circumstances (when and where) can lead to a heavy precipitation event. Or, more specifically, which ingredients, brought together by the storm systems distinguished, can result into a heavy precipitation event. The valuation of a precipitation event as heavy depends on the classification system and the accompanying characteristics used. A precipitation event with a precipitation intensity of $50 \mathrm{~m} / \mathrm{h}$ is often valuated as 'heavy'.

Knowledge of heavy precipitation is important as these events are one of the main causes of floods. The most dangerous flood-responsible storm systems combine a strong uplift with near-stationarity. In addition, it is also important to know what the values belonging to the characteristics of the real precipitation event are which implies that measurement of these characteristics (intensity, duration) in a catchment always remain necessary. The generation and development of a flood doesn't only depend on the intensity and duration of 
precipitation, it also depends on their spatiotemporal variability and the characteristics (like motion speed and direction) of the storm system itself. However, many other factors also contribute to the generation and development of a flood, such as the characteristics of soil, land use and land surface. These hydrological aspects, being equally important in determining flood potential (Doswell, 1997), are the subject of a follow-up paper.

\section{Declaration of Competing Interest}

The authors declare that they have no known competing financial interests or personal relationships that could have appeared to influence the work reported in this paper.

\section{References}

Acreman, M.C., 1990. A simple stochastic model of hourly rainfall for Farnborough, England. Hydrol. Sci. J. 35, 119-148.

Allan, R.P., 2011. Human influence on rainfall. Nature 470, 344.

Allan, R.P., Soden, B.J., 2008. Atmospheric warming and the amplification of precipitation extremes. Science 321, 1481-1484.

Allen, M.R., Ingram, W.J., 2002. Constraints on future changes in climate and the hydrologic cycle. Nature 419, 224.

Alpert, P., Ben-Gai, T., Baharad, A., Benjamini, Y., Yekutieli, D., Colacino, M., Diodato, L. Ramis, C., Homar, V., Romero, R., Michaelides, S., Manes, A., 2002. The paradoxical increase of Mediterranean extreme daily rainfall in spite of decrease in total values. Geophys. Res. Lett. 29 31-31-31-34.

Al-Rawas, G.A., Valeo, C., 2009. Characteristics of rainstorm temporal distributions in arid mountainous and coastal regions. J. Hydrol. 376, 318-326.

Archambault, H.M., Bosart, L.F., Keyser, D., Cordeira, J.M., 2013. A climatological analysis of the extratropical flow response to recurving western north pacific tropical cyclones. Mon. Weather Rev. 141, 2315-2346.

Aryal, Y.N., Villarini, G., Zhang, W., Vecchi, G.A., 2018. Long term changes in flooding and heavy rainfall associated with North Atlantic tropical cyclones: Roles of the North Atlantic Oscillation and El Niño-Southern Oscillation. J. Hydrol. 559, 698-710.

Atallah, E.H., Bosart, L.F., 2003. The extratropical transition and precipitation distribution of Hurricane Floyd (1999). Mon. Weather Rev. 131, 1063-1081.

Atallah, E., Bosart, L.F., Aiyyer, A.R., 2007. Precipitation distribution associated with landfalling tropical cyclones over the Eastern United States. Mon. Weather Rev. 135, 2185-2206.

Attema, J.J., Loriaux, J.M., Lenderink, G., 2014. Extreme precipitation response to climate perturbations in an atmospheric mesoscale model. Environ. Res. Lett. 9, 1-12.

Aylward, R.P., Dyer, J.L., 2010. Synoptic environments associated with the training of convective cells. Weather Forecast. 25, 446-464.

Azorin-Molina, C., Tijm, S., Ebert, E.E., Vicente-Serrano, S.M., Estrela, M.J., 2015. High resolution HIRLAM simulations of the role of low-level sea-Breeze convergence in initiating deep moist convection in the Eastern Iberian Peninsula. Bound.-Layer Meteorol. 154, 81-100.

Baek, E.H., Kim, J.H., Kug, J.S., Lim, G.H., 2013. Favorable versus unfavorable synoptic backgrounds for indirect precipitation events ahead of tropical cyclones approaching the korean peninsula: a comparison of two cases. Asia-Pac. J. Atmos. Sci. 49, $333-346$.

Baek, E.H., Lim, G.H., Kim, J.H., Kug, J.S., 2014. Antecedent mid-tropospheric frontogenesis caused by the interaction between a tropical cyclone and midlatitude trough: a case study of Typhoon Rusa (2002). Theor. Appl. Climatol. 118, 9-24.

Baldwin, J.W., Vecchi, G.A., Bordoni, S., 2019. The direct and ocean-mediated influence of Asian orography on tropical precipitation and cyclones. Clim. Dyn. 53, 805-824.

Ban, N., Schmidli, J., Schär, C., 2014. Evaluation of the convection-resolving regional climate modeling approach in decade-long simulations. J. Geophys. Res.-Atmos. 119, 7889-7907.

Ban, N., Schmidli, J., Schär, C., 2015. Heavy precipitation in a changing climate: does short-term summer precipitation increase faster? Geophys. Res. Lett. 42, 1165-1172.

Bao, X., Davidson, N.E., Yu, H., Hankinson, M.C.N., Sun, Z., Rikus, L.J., Liu, J., Yu, Z., Wu, D., 2015. Diagnostics for an extreme rain event near Shanghai during the Landfall of Typhoon Fitow (2013). Mon. Weather Rev. 143, 3377-3405.

Barton, Y., Giannakaki, P., von Waldow, H., Chevalier, C., Pfahl, S., Martius, O., 2016. Clustering of regional-scale extreme precipitation events in Southern Switzerland. Mon. Weather Rev. 144, 347-369.

Bennett, L.J., Browning, K.A., Blyth, A.M., Parker, D.J., Clark, P.A., 2006. A review of the initiation of precipitating convection in the United Kingdom. Q. J. R. Meteorol. Soc. $132,1001-1020$.

Berg, P., Haerter, J.O., Thejll, P., Piani, C., Hagemann, S., Christensen, J.H., 2009. Seasonal characteristics of the relationship between daily precipitation intensity and surface temperature. J. Geophys. Res.-Atmos. 114, 1-9.

Berg, P., Moseley, C., Haerter, J.O., 2013. Strong increase in convective precipitation in response to higher temperatures. Nat. Geosci. 6, 181.

Berry, G., Reeder, M.J., Jakob, C., 2011. A global climatology of atmospheric fronts. Geophys. Res. Lett. 38, 1-5.

Billings, J.M., Parker, M.D., 2012. Evolution and maintenance of the 22-23 June 2003 nocturnal convection during BAMEX. Weather Forecast. 27, 279-300.
Blanchard, D.O., 1990. Mesoscale convective patterns of the southern high plains. Bull. Am. Meteorol. Soc. 71, 994-1005.

Boers, N., Bookhagen, B., Marwan, N., Kurths, J., 2016. Spatiotemporal characteristics and synchronization of extreme rainfall in South America with focus on the Andes Mountain range. Clim. Dyn. 46, 601-617.

Böing, S.J., Jonker, H.J.J., Siebesma, A.P., Grabowski, W.W., 2012. Influence of the subcloud layer on the development of a deep convective ensemble. J. Atmos. Sci. 69, 2682-2698.

Borga, M., Boscolo, P., Zanon, F., Sangati, M., 2007. Hydrometeorological analysis of the 29 August 2003 flash flood in the Eastern Italian Alps. J. Hydrometeorol. 8, 1049-1067.

Bosart, L.F., Cordeira, J.M., Galarneau, T.J., Moore, B.J., Archambault, H.M., 2012. An analysis of multiple predecessor rain events ahead of tropical cyclones Ike and Lowell: 10-15 September 2008. Mon. Weather Rev. 140, 1081-1107.

Bouin, M.N., Redelsperger, J.L., Lebeaupin Brossier, C., 2017. Processes leading to deep convection and sensitivity to sea-state representation during HyMeX IOP8 heavy precipitation event. Q. J. R. Meteorol. Soc. 143, 2600-2615.

Bracken, L.J., Cox, N.J., Shannon, J., 2008. The relationship between rainfall inputs and flood generation in south-east Spain. Hydrol. Process. 22, 683-696.

Bradley, A.A., Smith, J.A., 1994. The hydrometeorological environment of extreme rainstorms in the Southern Plains of the United States. J. Appl. Meteorol. 33, 1418-1431.

Bresson, E., Ducrocq, V., Nuissier, O., Ricard, D., de Saint-Aubin, C., 2012. Idealized numerical simulations of quasi-stationary convective systems over the Northwestern Mediterranean complex terrain. Q. J. R. Meteorol. Soc. 138, 1751-1763.

Brommer, D.M., Cerveny, R.S., Balling, R.C., 2007. Characteristics of long-duration precipitation events across the United States. Geophys. Res. Lett. 34 L22712.

Browning, K.A., 1990. Organization of clouds and precipitation in extratropical cyclones. In: Newton, C.W., Holopainen, E.O. (Eds.), Extratropical Cyclones: The Erik Palmén Memorial Volume. American Meteorological Society, pp. 129-153.

Browning, K.A., Hill, F.F., 1984. Structure and evolution of a mesoscale convective system near the British Isles. Q. J. R. Meteorol. Soc. 110, 897-913.

Browning, K.A., Roberts, N.M., 1996. Variation of frontal and precipitation structure along a cold front. Q. J. R. Meteorol. Soc. 122, 1845-1872.

Bryan, G.H., Knievel, J.C., Parker, M.D., 2006. A multimodel assessment of RKW theory's relevance to Squall-line characteristics. Mon. Weather Rev. 134, 2772-2792.

Budikova, D., Coleman, J.S.M., Strope, S.A., Austin, A., 2010. Hydroclimatology of the 2008 Midwest floods. Water Resour. Res. 46, 1-16.

Buytaert, W., Celleri, R., Willems, P., De Bievre, B., Wyseure, G., 2006. Spatial and temporal rainfall variability in mountainous areas: A case study from the south Ecuadorian Andes. J. Hydrol. 329, 413-421.

Buzzi, A., Davolio, S., Malguzzi, P., Drofa, O., Mastrangelo, D., 2014. Heavy rainfal episodes over Liguria in autumn 2011: Numerical forecasting experiments. Nat. Hazards Earth Syst. Sci. 14, 1325-1340.

Caracena, F., Maddox, R.A., Hoxit, L.R., Chappell, C.F., 1979. Mesoanalysis of the Big Thompson Storm. Mon. Weather Rev. 107, 1-17.

Carrió, D.S., Homar, V., Jansa, A., Romero, R., Picornell, M.A., 2017. Tropicalization process of the 7 November 2014 Mediterranean cyclone: numerical sensitivity study. Atmos. Res. 197, 300-312.

Caruso, S.J., Businger, S., 2006. Subtropical cyclogenesis over the central North Pacific. Weather Forecast. 21, 193-205.

Casas, M.C., Codina, B., Redaño, A., Lorente, J., 2004. A methodology to classify extreme rainfall events in the western Mediterranean area. Theor. Appl. Climatol. 77, $139-150$.

Casas, M.C., Rodríguez, R., Redaño, Á., 2010. Analysis of extreme rainfall in Barcelona using a microscale rain gauge network. Meteorol. Appl. 17, 117-123.

Catto, J.L., Pfahl, S., 2013. The importance of fronts for extreme precipitation. J. Geophys. Res.-Atmos. 118, 10,791-710,801.

Catto, J.L., Jakob, C., Berry, G., Nicholls, N., 2012. Relating global precipitation to atmospheric fronts. Geophys. Res. Lett. 39, 1-6.

Cavicchia, L., von Storch, H., Gualdi, S., 2014a. Mediterranean tropical-like cyclones in present and future climate. J. Clim. 27, 7493-7501.

Cavicchia, L., von Storch, H., Gualdi, S., 2014b. A long-term climatology of medicanes. Clim. Dyn. 43, 1183-1195.

Cavicchia, L., Dowdy, A., Walsh, K., 2018. Energetics and dynamics of subtropical Australian East Coast cyclones: two contrasting cases. Mon. Weather Rev. 146, 1511-1525.

Chaboureau, J.P., Pantillon, F., Lambert, D., Richard, E., Claud, C., 2012. Tropical transition of a Mediterranean storm by jet crossing. Q. J. R. Meteorol. Soc. 138, 596-611.

Chappell, C.F., 1986. Quasi-stationary convective events. In: Ray, P.S. (Ed.), Mesoscale Meteorology and Forecasting. American Meteorological Society, Boston, MA.

Chen, T.-C., Wu, C.-C., 2016. The Remote Effect of Typhoon Megi (2010) on the Heavy Rainfall over Northeastern Taiwan. Mon. Weather Rev. 144, 3109-3131.

Chen, C.-S., Chen, W.-C., Tao, W.-K., 2004. Characteristics of heavy summer rainfall in Southwestern Taiwan in relation to orographic effects. J. Meteorol. Soc. Jpn. 82, 1521-1543.

Chen, L.S., Li, Y., Cheng, Z.Q., 2010. An overview of research and forecasting on rainfall associated with landfalling tropical cyclones. Adv. Atmos. Sci. 27, 967-976.

Choi, H.Y., Ha, J.H., Lee, D.K., Kuo, Y.H., 2011. Analysis and Simulation of Mesoscale Convective Systems Accompanying Heavy Rainfall: The Goyang Case. Asia-Pacific Journal of Atmospheric Sciences 47, 265-279.

Claud, C., Alhammoud, B., Funatsu, B.M., Chaboureau, J.P., 2010. Mediterranean hurricanes: large-scale environment and convective and precipitating areas from satellite microwave observations. Nat. Hazards Earth Syst. Sci. 10, 2199-2213.

Cohuet, J.B., Romero, R., Homar, V., Ducrocq, V., Ramis, C., 2011. Initiation of a severe thunderstorm over the Mediterranean Sea. Atmos. Res. 100, 603-620. 
Couto, F.T., Salgado, R., Costa, M.J., 2012. Analysis of intense rainfall events on Madeira Island during the 2009/2010 winter. Nat. Hazards Earth Syst. Sci. 12, 2225-2240.

Curtis, M.B., 2017. A Synoptic and Mesoscale Analysis of Heavy Rainfall at Portland, Maine, 13-14 August 2014. 5. pp. 78-86.

Dairaku, K., Emori, S., Oki, T., 2004. Rainfall amount, intensity, duration, and frequency relationships in the Mae Chaem Watershed in Southeast Asia. J. Hydrometeorol. 5, 458-470.

Davies, L., Jakob, C., May, P., Kumar, V.V., Xie, S., 2013. Relationships between the largescale atmosphere and the small-scale convective state for Darwin, Australia. J. Geophys. Res.-Atmos. 118, 11534-11545.

Davis, C.A., 2010. Simulations of subtropical cyclones in a baroclinic channel model. J. Atmos. Sci. 67, 2871-2892.

Davis, C.A., Bosart, L.F., 2003. Baroclinically induced tropical cyclogenesis. Mon. Weather Rev. 131, 2730-2747.

Davis, C.A., Lee, W.-C., 2012. Mesoscale analysis of heavy rainfall episodes from SoWMEX/TiMREX. J. Atmos. Sci. 69, 521-537.

Davolio, S., Volonté, A., Manzato, A., Pucillo, A., Cicogna, A., Ferrario, M.E., 2016. Mechanisms producing different precipitation patterns over north-eastern Italy: insights from HyMeX-SOP1 and previous events. Q. J. R. Meteorol. Soc. 142, 188-205.

Dayan, U., Nissen, K., Ulbrich, U., 2015. Review Article: atmospheric conditions inducing extreme precipitation over the eastern and western Mediterranean. Nat. Hazards Earth Syst. Sci. 15, 2525-2544.

De Lannoy, G., 2001. Ruimtelijke en temporele karakteristieken van neerslag bepaald met radarbeelden. In: PhD Thesis. Gent University $177 \mathrm{p}$.

De Ploey, J., Kirkby, M.J., Ahnert, F., 1991. Hillslope erosion by rainstorms-a magnitudefrequency analysis. Earth Surf. Process. Landf. 16, 399-409.

De Vries, A.J., Feldstein, S.B., Riemer, M., Tyrlis, E., Sprenger, M., Baumgart, M., Fnais, M., Lelieveld, J., 2016. Dynamics of tropical-extratropical interactions and extreme precipitation events in Saudi Arabia in autumn, winter and spring. Q. J. R. Meteorol. Soc. $142,1862-1880$.

DeHart, J.C., Houze, R.A., 2017. Orographic modification of precipitation processes in Hurricane Karl (2010). Mon. Weather Rev. 145, 4171-4186.

Delrieu, G., Nicol, J., Yates, E., Kirstetter, P.-E., Creutin, J.-D., Anquetin, S., Obled, C., Saulnier, G.-M., Ducrocq, V., Gaume, E., Payrastre, O., Andrieu, H., Ayral, P.-A., Bouvier, C., Neppel, L., Livet, M., Lang, M., du-Châtelet, J.P., Walpersdorf, A., Wobrock, W., 2005. The catastrophic flash-flood event of 8-9 September 2002 in the Gard Region, France: a first case study for the Cévennes-Vivarais Mediterranean hydrometeorological observatory. J. Hydrometeorol. 6, 34-52.

Demirtaş, M., 2016. The October 2011 devastating flash flood event of Antalya: triggering mechanisms and quantitative precipitation forecasting. Q. J. R. Meteorol. Soc. 142, 2336-2346.

Dimri, A.P., Chevuturi, A., Niyogi, D., Thayyen, R.J., Ray, K., Tripathi, S.N., Pandey, A.K., Mohanty, U.C., 2017. Cloudbursts in Indian Himalayas: a review. Earth Sci. Rev. 168, $1-23$.

Dodla, V.B.R., Ratna, S.B., 2010. Mesoscale characteristics and prediction of an unusual extreme heavy precipitation event over India using a high resolution mesoscale model. Atmos. Res. 95, 255-269.

Donat, M.G., Lowry, A.L., Alexander, L.V., O’Gorman, P.A., Maher, N., 2016. More extreme precipitation in the world's dry and wet regions. Nat. Clim. Chang. 6, 508.

Dong, M., Chen, L., Li, Y., Lu, C., 2010. Rainfall reinforcement associated with landfalling tropical cyclones. J. Atmos. Sci. 67, 3541-3558.

Doswell, C.A., 1987. The distinction between large-scale and mesoscale contribution to severe convection: a case study example. Weather Forecast. 2, 3-16.

Doswell, C.A., 1997. Flash Flood Forecasting - Techniques and Limitations. Preprints, Jornades de Meteorologia Eduard Fontsere. Barcelona, Catalan Meteorological Society.

Doswell, C.A., Brooks, H.E., Maddox, R.A., 1996. Flash flood forecasting: an ingredientsbased methodology. Weather Forecast. 11, 560-581.

Doswell, C.A., Ramis, C., Romero, R., Alonso, S., 1998. A diagnostic study of three heavy precipitation episodes in the Western Mediterranean region. Weather Forecast. 13, 102-124.

Ducrocq, V., Nuissier, O., Ricard, D., Lebeaupin, C., Thouvenin, T., 2008. A numerical study of three catastrophic precipitating events over southern France. II: Mesoscale triggering and stationarity factors. Q. J. R. Meteorol. Soc. 134, 131-145.

Ducrocq, V., Braud, I., Davolio, S., Ferretti, R., Flamant, C., Jansa, A., Kalthoff, N. Richard, E., Taupier-Letage, I., Ayral, P.-A., Belamari, S., Berne, A., Borga, M. Boudevillain, B., Bock, O., Boichard, J.-L., Bouin, M.-N., Bousquet, O., Bouvier, C., Chiggiato, J., Cimini, D., Corsmeier, U., Coppola, L., Cocquerez, P., Defer, E., Delanoë, J., Girolamo, P.D., Doerenbecher, A., Drobinski, P., Dufournet, Y., Fourrié, N., Gourley, J.J., Labatut, L., Lambert, D., Coz, J.L., Marzano, F.S., Molinié, G., Montani, A., Nord, G., Nuret, M., Ramage, K., Rison, W., Roussot, O., Said, F., Schwarzenboeck, A., Testor, P., Baelen, J.V., Vincendon, B., Aran, M., Tamayo, J., 2014. HyMeX-SOP1: the field campaign dedicated to heavy precipitation and flash flooding in the Northwestern Mediterranean. Bull. Am. Meteorol. Soc. 95, 1083-1100.

Duda, J.D., Gallus Jr., W.A., 2010. Spring and Summer Midwestern Severe Weather Reports in Supercells Compared to Other Morphologies. Weather Forecast. 25, 190-206.

Dunkerley, D., 2008a. Identifying individual rain events from pluviograph records: a review with analysis of data from an Australian dryland site. Hydrol. Process. 22, 5024-5036.

Dunkerley, D., 2008b. Rain event properties in nature and in rainfall simulation experiments: a comparative review with recommendations for increasingly systematic study and reporting. Hydrol. Process. 22, 4415-4435.

Dunkerley, D.L., 2010. How do the rain rates of sub-event intervals such as the maximum 5- and 15-min rates (I5 or I30) relate to the properties of the enclosing rainfall event?
Hydrol. Process. 24, 2425-2439.

Dunkerley, D., 2015. Intra-event intermittency of rainfall: an analysis of the metrics of rain and no-rain periods. Hydrol. Process. 29, 3294-3305.

Easterling, D.R., Meehl, G.A., Parmesan, C., Changnon, S.A., Karl, T.R., Mearns, L.O., 2000. Climate extremes: observations, modeling, and impacts. Science 289 , 2068-2074.

Emanuel, K., 2005. Genesis and maintenance of "Mediterranean hurricanes". Adv. Geosci. 2, 217-220.

Emori, S., Brown, S.J., 2005. Dynamic and thermodynamic changes in mean and extreme precipitation under changed climate. Geophys. Res. Lett. 32, 1-5.

Eshel, G., Farrell, B.F., 2000. Mechanisms of eastern Mediterranean rainfall variability. J. Atmos. Sci. 57, 3219-3232.

Evans, J.L., Braun, A., 2012. A climatology of subtropical cyclones in the South Atlantic. J. Clim. 25, 7328-7340.

Evans, J.L., Guishard, M.P., 2009. Atlantic Subtropical Storms. Part I: Diagnostic criteria and composite analysis. Mon. Weather Rev. 137, 2065-2080.

Fassnacht, S.R., Recrods, R.M., 2015. Large snowmelt versus rainfall events in the mountains. J. Geophys. Res.-Atmos. 120, 2375-2381.

Field, P.R., Wood, R., 2007. Precipitation and cloud structure in midlatitude cyclones. J. Clim. 20, 233-254.

Fiori, E., Comellas, A., Molini, L., Rebora, N., Siccardi, F., Gochis, D.J., Tanelli, S., Parodi, A., 2014. Analysis and hindcast simulations of an extreme rainfall event in the Mediterranean area: The Genoa 2011 case. Atmos. Res. 138, 13-29.

Fiori, E., Ferraris, L., Molini, L., Siccardi, F., Kranzlmueller, D., Parodi, A., 2017. Triggering and evolution of a deep convective system in the Mediterranean Sea: modelling and observations at a very fine scale. Q. J. R. Meteorol. Soc. 143, 927-941.

Fischer, E.M., Knutti, R., 2016. Observed heavy precipitation increase confirms theory and early models. Nat. Clim. Chang. 6, 986.

Fita, L., Flaounas, E., 2018. Medicanes as subtropical cyclones: the December 2005 case from the perspective of surface pressure tendency diagnostics and atmospheric water budget. Q. J. R. Meteorol. Soc. 142, 275-286.

Fita, L., Romero, R., Ramis, C., 2006. Intercomparison of intense cyclogenesis events over the Mediterranean basin based on baroclinic and diabatic influences. Adv. Geosci. 7, 333-342.

Fita, L., Romero, R., Luque, A., Emanuel, K., Ramis, C., 2007. Analysis of the environments of seven Mediterranean tropical-like storms using an axisymmetric, non-hydrostatic, cloud resolving model. Nat. Hazards Earth Syst. Sci. 7, 41-56.

Flaounas, E., Raveh-Rubin, S., Wernli, H., Drobinski, P., Bastin, S., 2015. The dynamical structure of intense Mediterranean cyclones. Clim. Dyn. 44, 2411-2427.

Flaounas, E., Lagouvardos, K., Kotroni, V., Claud, C., Delanoë, J., Flamant, C., Madonna, E., Wernli, H., 2016. Processes leading to heavy precipitation associated with two Mediterranean cyclones observed during the HyMeX SOP1. Q. J. R. Meteorol. Soc. $142,275-286$.

Flaounas, E., Kotroni, V., Lagouvardos, K., Gray, S.L., Rysman, J.F., Claud, C., 2018. Heavy rainfall in Mediterranean cyclones. Part I: contribution of deep convection and warm conveyor belt. Clim. Dyn. 50, 2935-2949.

Flaounas, E., Lluis, F., Lagouvardos, K., Kotroni, V., 2019. Heavy rainfall in Mediterranean cyclones, Part II: water budget, precipitation efficiency and remote water sources. Clim. Dyn. 53, 2539-2555.

Fragoso, M., Tildes Gomes, P., 2008. Classification of daily abundant rainfall patterns and associated large-scale atmospheric circulation types in Southern Portugal. Int. J. Climatol. 28, 537-544.

Fragoso, M., Trigo, R.M., Pinto, J.G., Lopes, S., Lopes, A., Ulbrich, S., Magro, C., 2012. The 20 February 2010 Madeira flash-floods: synoptic analysis and extreme rainfall assessment. Nat. Hazards Earth Syst. Sci. 12, 715-730.

Frei, C., Davies, H.C., Gurtz, J., Schär, C., 2000. Climate dynamics and extreme precipitation and flood events in Central Europe. Integr. Assess. 1, 281-300.

Fritsch, J.M., Kane, R.J., Chelius, C.R., 1986. The contribution of mesoscale convective weather systems to the warm-season precipitation in the United States. J. Clim. Appl. Meteorol. 25, 1333-1345.

Fritz, C., Wang, Z., 2014. Water vapour budget in a developing tropical cyclone and its implication for tropical cyclone formation. J. Atmos. Sci. 71, 4321-4332.

Funatsu, B.M., Waugh, D.W., 2008. Connections between potential vorticity intrusions and convection in the Eastern Tropical Pacific. J. Atmos. Sci. 65, 987-1002.

Funatsu, B.M., Claud, C., Chaboureau, J.P., 2008. A 6-year AMSU-based climatology of upper-level troughs and associated precipitation distribution in the Mediterranean region. J. Geophys. Res.-Atmos. 113 n/a-n/a.

Funatsu, B.M., Claud, C., Chaboureau, J.-P., 2009. Comparison between the large-scale environments of moderate and intense precipitating systems in the Mediterranean Region. Mon. Weather Rev. 137, 3933-3959.

Gaál, L., Molnar, P., Szolgay, J., 2014. Selection of intense rainfall events based on in tensity thresholds and lightning data in Switzerland. Hydrol. Earth Syst. Sci. 18, 1561-1573.

Galarneau, T.J., Bosart, L.F., Schumacher, R.S., 2010. Predecessor rain events ahead of tropical cyclones. Mon. Weather Rev. 138, 3272-3297.

Gao, S., Meng, Z., Zhang, F., Bosart, L.F., 2009. Observational analysis of heavy rainfall mechanisms associated with severe tropical storm Bilis (2006) after its landfall. Mon. Weather Rev. 137, 1881-1897.

Garde, L.A., Pezza, A.B., Bye, J.A.T., 2010. Tropical transition of the 2001 Australian Duck. Mon. Weather Rev. 138, 2038-2057.

Ge, X., Li, T., Zhang, S., Peng, M., 2010. What causes the extremely heavy rainfall in Taiwan during Typhoon Morakot (2009)? Atmos. Sci. Lett. 11, 46-50.

Gimeno, L., Dominguez, F., Nieto, R., Trigo, R., Drumond, A., Reason, C.J.C., Taschetto, A., Ramos, A.M., Kumar, R., Marengo, J., 2016. Major mechanism of atmospheric moisture transport and their role in extreme precipitation events. Annu. Rev. Environ. Resour. 41, 117-141. 
Gochis, D.J., Brito-Castillo, L., Shuttleworth, W.J., 2006. Hydroclimatology of the North American Monsoon region in northwest Mexico. J. Hydrol. 316, 53-70.

Grams, C.M., Wernli, H., Böttcher, M., Čampa, J., Corsmeier, U., Jones, S.C., Keller, J.H., Lenz, C.-J., Wiegand, L., 2011. The key role of diabatic processes in modifying the upper-tropospheric wave guide: a North Atlantic case-study. Q. J. R. Meteorol. Soc $137,2174-2193$.

González-Alemán, J.J., Valero, F., Martin-Leon, F., Evans, J.L., 2015. Classification and Synoptic Analysis of Subtropical Cyclones within the Northeastern Atlantic Ocean. Journal of Climate 28, 3331-3352.

Grams, C.M., Binder, H., Pfahl, S., Piaget, N., Wernli, H., 2014. Atmospheric processes triggering the central European floods in June 2013. Nat. Haz.aEarth Sci. 14, 1691-1702.

Gregersen, I.B., Sørup, H.J.D., Madsen, H., Rosbjerg, D., Mikkelsen, P.S., ArnbjergNielsen, K., 2013. Assessing future climatic changes of rainfall extremes at small spatio-temporal scales. Clim. Chang. 118, 783-797.

Guishard, M.P., Evans, J.L., Hart, J.L., 2009. Atlantic subtropical storms. Part II: Climatology. J. Clim. 22, 3574-3594.

Guo, X., Fu, D., Wang, J., 2006. Mesoscale convective precipitation system modified by urbanization in Beijing City. Atmos. Res. 82, 112-126.

Haerter, J.O., Berg, P., Hagemann, S., 2010. Heavy rain intensity distributions on varying time scales and at different temperatures. J. Geophys. Res.-Atmos. 115 n/a-n/a.

Hai, O.S., Samah, A.A., Chenoli, S.N., Subramaniam, K., Ahmad Mazuki, M.Y., 2017. Extreme rainstorms that caused devastating flooding across the East Coast of Peninsular Malaysia during November and December 2014. Weather Forecast. 32, 849-872.

Haile, A.T., Rientjes, T.H.M., Habib, E., Jetten, V., Gebremichael, M., 2011. Rain event properties at the source of the Blue Nile River. Hydrol. Earth Syst. Sci. 15, 1023-1034.

Hand, W.H., Fox, N.I., Collier, C.G., 2004. A study of twentieth-century extreme rainfall events in the United Kingdom with implications for forecasting. Meteorol. Appl. 11, 15-31.

Hanel, M., Máca, P., 2014. Spatial variability and interdependence of rain event characteristics in the Czech Republic. Hydrol. Process. 28, 2929-2944.

Harats, N., Ziv, B., Yair, Y., Kotroni, V., Dayan, U., 2010. Lightning and rain dynamic indices as predictors for flash floods events in the Mediterranean. Adv. Geosci. 23, 57-64.

Hardwick Jones, R., Westra, S., Sharma, A., 2010. Observed relationships between extreme sub-daily precipitation, surface temperature, and relative humidity. Geophysical Research Letters 37, 1-5.

Harpold, A.A., Kohler, M., 2017. Potential for changing extreme snowmelt and rainfall events in the mountains of the Western United States. J. Geophys. Res.-Atmos. 122, 13219-13228.

Hart, R.E., 2003. A cyclone phase space derived from thermal wind and thermal asymmetry. Mon. Weather Rev. 131, 585-616.

Hart, R.E., Evans, J.L., 2001. A climatology of the extratropical transition of Atlantic tropical cyclones. J. Clim. 14, 546-564.

Hart, R.E., Evans, J.L., Evans, C., 2006. Synoptic composites of the extratropical transition life cycle of north atlantic tropical cyclones: factors determining posttransition evolution. Mon. Weather Rev. 134, 553-578.

Hawcroft, M.K., Shaffrey, L.C., Hodges, K.I., Dacre, H.F., 2012. How much Northern Hemisphere precipitation is associated with extratropical cyclones? Geophys. Res. Lett. 39, 1-7.

He, Z., Zhang, Q., Bai, L., Meng, Z., 2017. Characteristics of mesoscale convective systems in central East China and their reliance on atmospheric circulation patterns. Int. J. Climatol. 37, 3276-3290.

Hegerl, G.C., Zwiers, F.W., Stott, P.A., Kharin, V.V., 2004. Detectability of anthropogenic changes in annual temperature and precipitation extremes. J. Clim. 17, 3683-3700.

Held, I.M., Soden, B.J., 2006. Robust responses of the hydrological cycle to global warming. J. Clim. 19, 5686-5699.

Hellström, C., 2005. Atmospheric conditions during extreme and non-extreme precipitation events in Sweden. Int. J. Climatol. 25, 631-648.

Heo, K.-Y., Seo, Y.W., Ha, K.J., Park, K.S., Kim, J., Choi, J.W., Jun, K., Jeong, J.Y., 2015. Development mechanisms of an explosive cyclone over East Sea on 3-4 April 2012. Dyn. Atmos. Oceans 70, 30-46.

Heo, K.Y., Ha, K.J., Ha, T., 2019. Explosive Cyclogenesis around the Korean Peninsula in May 2016 from a potential vorticity perspective: case study and numerical simulations. Atmosphere 10, 1-19.

Hernández Ayala, J.J., Matyas, C.J., 2016. Tropical cyclone rainfall over Puerto Rico and its relations to environmental and storm-specific factors. Int. J. Climatol. 36, 2223-2237.

Hitchens, N.M., Brooks, H.E., 2013. Preliminary investigation of the contribution of supercell thunderstorms to the climatology of heavy and extreme precipitation in the United States. Atmos. Res. 123, 206-210.

Hitchens, N.M., Brooks, H.E., Schumacher, R., 2013. Spatial and Temporal Characteristics of Heavy Hourly Rainfall in the United States. Monthly Weather Review 141, 4564-4575.

Homar, V., Ramis, C., Alonso, S., 2002. A deep cyclone of African origin over the Western Mediterranean: diagnosis and numerical simulation. Ann. Geophys. 20, 93-106.

Homar, V., Romero, R., Stensrud, D., Ramis, C., Alonso, S., 2003. Numerical diagnosis of a small, quasi-tropical cyclone over the western Mediterranean: Dynamical vs. boundary factors. Q. J. R. Meteorol. Soc. 129, 1469-1490.

Horgan, K.L., Schultz, D.M., Hales, J.E., Cordifi, S.F., Johns, R.H., 2007. A five-year climatology of elevated severe convective storms in the United States East of the Rocky Mountains. Weather Forecast. 22, 327-347.

Houze, R.A., 1993. Cloud Dynamics. Academic, San Diego, California, pp. 534.

Huang, H.L., Yang, M.J., Sui, C.H., 2014. Water budget and precipitation efficiency of typhoon Morakat (2009). J. Atmos. Sci. 71, 112-129.

Huff, F.A., 1967. Time distribution of rainfall in heavy storms. Water Resour. Res. 3, 1007-1019.

Ivančan-Picek, B., Glasnović, D., Jurčec, V., 2003. Analysis and Aladin prediction of a heavy precipitation event on the Eastern side of the Alps during Map IOP 5. Meteorol. Z. 12, 103-112.

Ivančan-Picek, B., Horvath, K., Mahović, N.S., Gajić-Čapka, M., 2014. Forcing mechanisms of a heavy precipitation event in the south-eastern Adriatic area. Nat. Hazards $72,1231-1252$.

Iwai, H., Ishii, S., Kawamura, S., Sato, E., Kusunoki, K., 2018. Case study on convection initiation associated with an isolated convective storm developed over flat terrain during TOMACS. J. Meteorol. Soc. Jpn. II 96A, 3-23.

James, P., Stohl, A., Spichtinger, N., Eckhart, S., Forster, C., 2004. Climatological aspects of the extreme European rainfall of August 2002 and a trajectory method for estimating the associated evaporative source regions. Nat. Haz. Earth Sci. 4, 733-746.

Javier Julie Rose, N., Smith James, A., Baeck Mary, L., Villarini, G., 2010. Flash flooding in the Philadelphia metropolitan region. J. Hydrol. Eng. 15, 29-38.

Javier, J.R.N., Smith, J.A., England, J., Baeck, M.L., Steiner, M., Ntelekos, A.A., 2007. Climatology of extreme rainfall and flooding from orographic thunderstorm systems in the upper Arkansas River basin. Water Resources Research 43, n/a-n/a.

Jeong, J.H., Lee, D.I., Wang, C.C., Jang, S.M., You, C.H., Jang, M., 2012. Environment and morphology of mesoscale convective systems associated with the Changma front during 9-10 July 2007. Ann. Geophys. 30, 1235-1248.

Jeong, J.-H., Lee, D.-I., Wang, C.-C., Jang, S.-M., Park, S.-H., Jung, S.-A., 2014a. Structure and evolution of line-shaped convective systems associated with Changma front during GRL PHONE-09: 6 July 2009 case. Meteorol. Appl. 21, 786-794.

Jeong, D., Min, K.H., Lee, G., Kim, K.E., 2014b. A case study of mesoscale convective band (MCB) development and evolution along a quasi-stationary front. Adv. Atmos. Sci. 31, 901-915.

Jeong, J.-H., Lee, D.-I., Wang, C.-C., 2016a. Impact of the cold pool on mesoscale convective system-produced extreme rainfall over Southeastern South Korea: 7 July 2009. Mon. Weather Rev. 144, 3985-4006.

Jeong, J.H., Lee, D.I., Wang, C.C., Han, I.S., 2016b. Characteristics of mesoscale-convective-system-produced extreme rainfall over southeastern South Korea: 7 July 2009. Nat. Hazards Earth Syst. Sci. 16, 927-939.

Jessup, S.M., Colucci, S.J., 2012. Organization of flash-flood-producing precipitation in the Northeast United States. Weather Forecast. 27, 345-361.

Jiang, H., Halverson, J.B., Zipser, E.J., 2008. Influence of environmental moisture on TRMM-derived tropical cyclone precipitation over land and ocean. Geophys. Res. Lett. 35, 1-6.

Jiang, X., Ren, F., Li, Y., Qiu, W., Ma, Z., Cai, Q., 2018. Characteristics and preliminary causes of tropical cyclone extreme rainfall events over Hainan Island. Adv. Atmos. Sci. 35, 580-591.

Jung, W., Lee, T.Y., 2013. Formation and evolution of mesoscale convective systems that brought the heavy rainfall over Seoul on September 21, 2010. Asia-Pac. J. Atmos. Sci. 49, 635-647.

Kahana, R., Ziv, B., Enzel, Y., Dayan, U., 2002. Synoptic climatology of major floods in the Negev Desert, Israel. Int. J. Climatol. 22, 867-882.

Kane Jr., R.J., Chelius, C.R., Fritsch, J.M., 1987. Precipitation characteristics of mesoscale convective weather systems. J. Clim. Appl. Meteorol. 26, 1345-1357.

Kašpar, M., Müller, M., 2014. Combinations of large-scale circulation anomalies conducive to precipitation extremes in the Czech Republic. Atmospheric Research 138, 205-212.

Kastman, J.S., Market, P.S., Fox, N.I., Foscato, A.L., Lupo, A.R., 2017a. Lightning and rainfall characteristics in elevated vs. surface based convection in the midwest that produce heavy rainfall. Atmosphere 8, 1-17.

Kastman, J.S., McCoy, L.D., Market, P.S., Fox, N.I., 2017b. An example of synergistic coupling of upper- and lower-level jets associated with flash flooding. Meteorol. Appl. 24, 206-210.

Kendon, E.J., Rowell, D.P., Jones, R.G., 2009. Mechanisms and reliability of future projected changes in daily Precipitation. Clim. Dyn. 40, 1-21.

Kendon, E.J., Roberts, N.M., Fowler, H.J., Roberts, M.J., Chan, S.C., Senior, C.A., 2014 Heavier summer downpours with climate change revealed by weather forecast resolution model. Nat. Clim. Chang. 4, 570.

Khouakhi, A., Villarini, G., Vecchi, G.A., 2017. Contribution of tropical cyclones to rainfall at the global scale. J. Clim. 30, 359-372.

Klein, P.M., Harr, P.A., Elsberry, R.L., 2000. Extratropical transition of Western North Pacific tropical cyclones: an overview and conceptual model of the transformation stage. Weather Forecast. 15, 373-395.

Knight, D.B., Davis, R.E., 2009. Contribution of tropical cyclones to extreme rainfal events in the southeastern United States. J. Geophys. Res.-Atmos. 114 n/a-n/a.

Knutson, T.R., McBride, J.L., Chan, J., Emanuel, K., Holland, G., Landsea, C., Held, I., Kossin, J.P., Srivastava, A.K., Sugi, M., 2010. Tropical cyclones and climate change. Nat. Geosci. 3, 157-163.

Konrad, C.E., 1997. Synoptic-scale features associated with warm season heavy rainfall over the interior Southeastern United States. Weather Forecast. 12, 557-571.

Konrad, C.E., 2001. The most extreme precipitation events over the Eastern United States from 1950 to 1996: considerations of scale. J. Hydrometeorol. 2, 309-325.

Konrad, C.E., Perry, L.B., 2010. Relationships between tropical cyclones and heavy rainfall in the Carolina region of the USA. Int. J. Climatol. 30, 522-534.

Kotal, S.D., Tyagi, A., Bhowmik, S.K.R., 2012. Potential vorticity diagnosis of rapid intensification of a very severe cylone GIRI (2010) over the Bay of Bengal. Nat. Hazards $60,461-484$.

Kouroutzoglou, J., Flocas, H.A., Simmonds, I., Keay, K., Hatzaki, M., 2011. Climatological aspects of explosive cyclones in the Mediterranean. Int. J. Climatol. 31, 1785-1802.

Kouroutzoglou, J., Flocas, H.A., Keay, K., Simmonds, I., Hatzaki, M., 2012. On the vertical 
structure of Mediterranean explosive cyclones. Theor. Appl. Climatol. 110, 155-176.

Kouroutzoglou, J., Flocas, H.A., Hatzaki, M., Keay, K., Simmonds, I., 2014. A high-resolution climatological study on the comparison between surface explosive and ordinary cyclones in the Mediterranean. Reg. Environ. Chang. 14, 1833-1846.

Kozaric, T., Ivančan-Picek, B., 2006. Meteorological features of extreme precipitation in the northern Adriatic. Croat. Meteorl. J. 41, 53-67.

Kyselý, J., Beguería, S., Beranová, R., Gaál, L., López-Moreno, J.I., 2012. Different patterns of climate change scenarios for short-term and multi-day precipitation extremes in the Mediterranean. Glob. Planet. Chang. 98-99, 63-72.

Lackmann, G.M., Gyakum, J.R., 1999. Heavy Cold-Season Precipitation in the Northwestern United States: Synoptic Climatology and an Analysis of the Flood of 17 18 january 1986. Weather Forecast. 14, 687-700.

Lagouvardos, K., Kotroni, V., Defer, E., 2007. The 21-22 January 2004 explosive cyclogenesis over the Aegean Sea: observations and model analysis. Q. J. R. Meteorol. Soc. 133, 1519-1531.

Laing, A.G., 2004. Cases of heavy precipitation and flash floods in the caribbean during El Niño winters. J. Hydrometeorol. 5, 577-594.

Laing, A.G., Stanley, S.B., Davis, C.A., 2012. Numerical simulation of episodes of organized convection in Tropical Northern Africa. Mon. Weather Rev. 140, 2874-2886.

Lavers, D.A., Allan, R.P., Wood, E.F., Villarini, G., Brayshaw, D.J., Wade, A.J., 2011. Winter floods in Britain are connected to atmospheric rivers. Geophys. Res. Lett. $38,1-8$.

Lee, K.O., Flamant, C., Ducroca, V., Duffourg, F., Fourrié, N., Davolio, S., Bech, J., 2016. Convective initiation and maintenance processes of two back-building mesoscale convective systems leading to heavy precipitation events in Southern Italy during HyMeX IOP 13. Q. J. R. Meteorol. Soc. 142, 2623-2635.

Lee, J.Y., Kim, W., Lee, T.Y., 2017a. Physical and dynamic factors that drove the heavy rainfall event over the middle Korean Peninsula on 26-27 July 2011. Asia-Pac. J. Atmos. Sci. 53, 101-120.

Lee, K.O., Flamant, C., Ducrocq, V., Duffourg, F., Fourrié, N., Delanoë, J., Bech, J., 2017b. Initiation and development of a mesoscale convective system in the Ebro River Valley and related heavy precipitation over northeastern Spain during HyMeX IOP 15a. Q. J. R. Meteorol. Soc. 143, 942-956.

Lenderink, G., Fowler, H.J., 2017. Hydroclimate: understanding rainfall extremes. Nat Clim. Chang. 7, 391-393.

Lenderink, G., Barbero, R., Loriaux, J.M., Fowler, H.J., 2017. Super-Clausius-Clapeyron scaling of extreme hourly convective precipitation and its relation to large-scale at mospheric conditions. J. Clim. 30, 6037-6052.

Lenderink, G., Van Meijgaard, E., 2008. Increase in hourly precipitation extremes beyond expectations from temperature changes. Nat. Geosci. 1, 511.

Lenderink, G., Van Meijgaard, E., 2010. Linking increases in hourly precipitation extremes to atmospheric temperature and moisture changes. Environ. Res. Lett. 5, 1-9.

Lepore, C., Allen, J.T., Tippett, M.K., 2016. Relationships between Hourly Rainfall Intensity and Atmospheric Variables over the Contiguous United States. Journal of Climate 29, 3181-3197.

Li, Y., Szeto, K., Stewart, R.E., Thériault, J.M., Chen, L., Kochtubajda, B., Liu, A., Boodoo, S., Goodson, R., Mooney, C., Kurkute, S., 2017. A numerical study of the June 2013 flood-producing extreme rainstorm over Southern Alberta. J. Hydrometeorol. 18, 2057-2078.

Lima, M.A., Wilson, J.W., 2008. Convective storm initiation in a moist tropical en vironment. Mon. Weather Rev. 136, 1847-1864.

Lima, K.C., Satyamurty, P., Fernández, J.P.R., 2010. Large-scale atmospheric conditions associated with heavy rainfall episodes in Southeast Brazil. Theor. Appl. Climatol. $101,121-135$.

Lin, Y.-L., Chiao, S., Wang, T.-A., Kaplan, M.L., Weglarz, R.P., 2001. Some common ingredients for heavy orographic rainfall. Weather Forecast. 16, 633-660.

Lin, C.Y., Hsu, H.M., Shengl, Y.F., Kuo, C.H., Liou, Y.A., 2011. Mesoscale processes for super heavy rainfall of typhoon Morakot (2009) over southern Taiwan. Atmos. Chem. Phys. 11, 345-361.

Lind, P., Lindstedt, D., Kjellström, E., Jones, C., 2016. Spatial and temporal characteristics of summer precipitation over Central Europe in a suite of high-resolution climate models. J. Clim. 29, 3501-3518.

Liu, C., 2011. Rainfall contributions from precipitation systems with different sizes, convective intensities, and durations over the tropics and subtropics. J. Hydrometeorol. 12, 394-412.

Liu, M., Smith, J.A., 2016. Extreme rainfall from landfalling tropical cyclones in the Eastern United States: Hurricane Irene (2011). J. Hydrometeorol. 17, 2883-2904.

Liu, G., Wu, R., 2016. Spatial and temporal characteristics of summer precipitation events spanning different numbers of days over Asia. Int. J. Climatol. 36, 2288-2302.

Llasat, M.-C., 2001. An objective classification of rainfall events on the basis of their convective features: application to rainfall intensity in the northeast of spain. Int. J. Climatol. 21, 1385-1400.

Lochbihler, K., Lenderink, G., Siebesma, A.P., 2017. The spatial extent of rainfall events and its relation to precipitation scaling. Geophys. Res. Lett. 44, 8629-8636.

Loriaux, J.M., Lenderink, G., De Roode, S.R., Pier Siebesma, A., 2013. Understanding convective extreme precipitation scaling using observations and an entraining plume model. J. Atmos. Sci. 70, 3641-3655.

Loriaux, J.M., Lenderink, G., Pier Siebesma, A., 2016. Peak precipitation intensity in relation to atmospheric conditions and large-scale forcing at midlatitudes. J. Geophys. Res.-Atmos. 121, 5471-5487.

Loriaux, J.M., Lenderink, G., Pier Siebesma, A., 2017. Large-scale controls on extreme precipitation. J. Clim. 30, 955-968.

Luo, Y., Chen, Y., 2015. Investigation of the predictability and physical mechanisms of an extreme-rainfall-producing mesoscale convective system along the Meiyu front in East China: an ensemble approach. J. Geophys. Res.-Atmos. 120, 10593-10619.

Luo, Y., Wang, H., Zhang, R., Qian, W., Luo, Z., 2013. Comparison of rainfall characteristics and convective properties of monsoon precipitation systems over South China and the Yangtze and Huai River basin. J. Clim. 26, 110-132.

Maddox, R., 1983. Large-Scale Meteorological Conditions Associated with Midlatitude, Mesoscale Convective Complexes. pp. 1475-1493.

Maddox, R.A., Chappell, C.F., Hoxit, L.R., 1979. Synoptic and meso- $\alpha$ scale aspects of flash flood events. Bull. Am. Meteorol. Soc. 60, 115-123.

Madonna, E., Wernli, H., Joos, H., Martius, O., 2014. Warm conveyor belts in the ERAInterim Dataset (1979-2010). Part I: Climatology and potential vorticity evolution. J. Clim. 27, 3-26.

Madsen, H., Lawrence, D., Lang, M., Martinkova, M., Kjeldsen, T.R., 2014. Review of trend analysis and climate change projections of extreme precipitation and floods in Europe. J. Hydrol. 519, 3634-3650.

Mahoney, K., Jackson, D.L., Neiman, P., Hughes, M., Darby, L., Wick, G., White, A. Sukovich, E., Cifelli, R., 2016. Understanding the role of atmospheric rivers in heavy precipitation in the Southeast United States. Mon. Weather Rev. 144, 1617-1632.

Martín, J.R., García, M.M., De Pablo Dávila, F., Soriano, L.R., 2013. Severe rainfall events over the western Mediterranean Sea: a case study. Atmos. Res. 127, 47-63.

Martius, O., Schwierz, Davies, H.C., 2008. Far-upstream precursors of heavy precipitation events on the Alpine south-side. Q. J. R. Meteorol. Soc. 134, 417-428.

Martius, O., Zenklusen, E., Schwierz, Davies, H.C., 2006. Episodes of Alpine heavy precipitation with an overlying elongated stratospheric intrusion: a climatology. Int. J. Climatol. 26, 1149-1164.

Martius, O., Sodemann, H., Joos, H., Pfahl, S., Winschall, A., Croci-Maspoli, M., Graf, M. Madonna, E., Mueller, B., Schemm, S., Sedláček, J., Sprenger, M., Wernli, H., 2013. The role of upper-level dynamics and surface processes for the Pakistan flood of July 2010. Q. J. R. Meteorol. Soc. 139, 1780-1797.

Massacand, A.C., Wernli, H., Davies, H.C., 1998. Heavy precipitation on the alpine southside: an upper-level precursor. Geophys. Res. Lett. 25, 1435-1438.

Massacand, A.C., Wernli, H., Davies, H.C., 2001. Influence of upstream diabatic heating upon an Alpine event of heavy precipitation. Mon. Weather Rev. 129, 2822-2828.

Mastrangelo, D., Horvath, K., Riccio, A., Miglietta, M.M., 2011. Mechanisms for convection development in a long-lasting heavy precipitation event over southeastern Italy. Atmos. Res. 100, 586-602.

Mazza, E., Ulbrich, U., Klein, R., 2017. The tropical transition of the October 1996 medicane in the western Mediterranean Sea: a warm seclusion event. Mon. Weather Rev. 145, 2575-2595.

McAnelly, R.L., Cotton, W.R., 1989. The precipitation life cycle of mesoscale convective complexes over the Central United States. Mon. Weather Rev. 117, 784-808.

McCarthy, D.T., Hathaway, J.M., Hunt, W.F., Deletic, A., 2012. Intra-event variability of Escherichia coli and total suspended solids in urban stormwater runoff. Water Res. 46, 6661-6670.

McCorkle, T.A., Williams, S.S., Pfeiffer, T.A., Basara, J.B., 2016. Atmospheric contributors to heavy rainfall events in the Arkansas-Red River Basin. Adv. Meteorol. 2016, 1-15.

McCoy, L.P., Market, P.S., Gravelle, C.M., Graves, C.E., Fox, N.I., Rochette, S.M., Kastman, J., Svoma, B., 2017. Composites of heavy rain producing elevated thunderstorms in the Central United States. Adv. Meteorol. 2017, 1-19.

Meng, W., Wang, Y., 2016a. A diagnostic study on heavy rainfall induced by landfalling typhoon utor (2013) in South China: 1. Rainfall asymmetry at landfall. J. Geophys. Res. 121 (12), 781-12,802.

Meng, W., Wang, Y., 2016b. A diagnostic study on heavy rainfall induced by landfalling typhoon utor (2013) in South China: 2. Postlandfall rainfall. J. Geophys. Res. 121 (12), 803-812,819.

Meng, Z., Yan, D., Zhang, Y., 2013. General features of squall lines in East China. Mon. Weather Rev. 141, 1629-1647.

Michaelides, S., et al., 2018. Reviews and perspectives of high impact atmospheric processes in the Mediterranean. Atmos. Res. 208, 4-44.

Miglietta, M.M., 2019. Mediterranean tropical-like cyclones (medicanes). Atmosphere $10,1-4$.

Miglietta, M.M., Rotunno, R., 2019. Development mechanisms for Mediterranean tropical-like cyclones (medicanes). Quarterly Journal of the Royal Meteorological Society 145, 1444-1460.

Miglietta, M.M., Laviola, S., Malvaldi, A., Conte, D., Levizzani, V., Price, C., 2013. Analysis of tropical-like cyclones over the Mediterranean Sea through a combined modeling and satellite approach. Geophys. Res. Lett. 40, 2400-2405.

Miglietta, M.M., Cerrai, D., Laviola, S., Cattani, E., Levizzani, V., 2017. Potential vorticity patterns in Mediterranean "hurricanes". Geophys. Res. Lett. 44, 2537-2545.

Mills, G.A., Wu, B.J., 1995. The 'Cudlee Creek' flash flood - an example of synoptic-scale forcing of a mesoscale event. Australian Meteorological Magazine 44, 201-218.

Milrad, S.M., Atallah, E.H., Gyakum, J.R., 2009a. Dynamical and precipitation structures of poleward-moving tropical cyclones in Eastern Canada, 1979-2005. Mon. Weather Rev. 137, 836-851.

Milrad, S.M., Atallah, E.H., Gyakum, J.R., 2009b. Synoptic-scale characteristics and precursors of cool-season precipitation events at St. John's, Newfoundland, 19792005. Weather Forecast. 24, 667-689.

Milrad, S.M., Atallah, E.H., Gyakum, J.R., 2010a. Synoptic typing of extreme cool-season precipitation events at St. John's, Newfoundland, 1979-2005. Weather Forecast. 25 562-586.

Milrad, S.M., Atallah, E.H., Gyakum, J.R., 2010b. A diagnostic examination of consecutive extreme cool-season precipitation events at St. John's, Newfoundland, in December 2008. Weather Forecast. 25, 997-1026.

Milrad, S.M., Atallah, E.H., Gyakum, J.R., Dookhie, G., 2014. Synoptic typing and precursors of heavy warm-season precipitation events at Montreal, Québec. Weather Forecast. 29, 419-444.

Milrad, S.M., Gyakum, J.R., Atallah, E.H., 2015. A meteorological analysis of the 2013 Alberta Flood: antecedent large-scale flow pattern and synoptic-dynamic characteristics. Mon, Weather Rev. 143, 2817-2841. 
Mohapatra, G.N., Rakesh, V., Ramesh, K.V., 2017. Urban extreme rainfall events: categorical skill of WRF model simulations for localized and non-localized events. Q. J. R. Meteorol. Soc. 143, 2340-2351.

Molini, A., Katul, G.G., Porporato, A., 2009. Revisiting rainfall clustering and intermittency across different climatic regimes. Water Resour. Res. 45 W11403.

Molini, A., Katul, G.G., Porporato, A., 2010. Causality across rainfall time scales revealed by continuous wavelet transforms. J. Geophys. Res.-Atmos. 115 n/a-n/a.

Molini, L., Parodi, A., Rebora, N., Craig, G.C., 2011. Classifying severe rainfall events over Italy by hydrometeorological and dynamical criteria. Q. J. R. Meteorol. Soc. 137, 148-154.

Moller, A.R., Doswell, C.A., Foster, M.P., Woodall, G.R., 1994. The operational recognition of supercell thunderstorm environments and storm structures. Weather Forecast. 9, 327-347.

Moore, J.T., Glass, F.H., Graves, C.E., Rochette, S.M., Singer, M.J., 2003. The environment of warm-season elevated thunderstorms associated with heavy rainfall over the Central United States. Weather Forecast. 18, 861-878.

Moore, B.J., Neiman, P.J., Ralph, F.M., Barthold, F.E., 2012. Physical processes associated with heavy flooding rainfall in Nashville, Tennessee, and Vicinity during 1-2 May 2010: the role of an atmospheric river and mesoscale convective systems. Mon. Weather Rev. 140, 358-378.

Moore, B.J., Bosart, L.F., Keyser, D., Jurewicz, M.L., 2013. Synoptic-scale environments of predecessor rain events occurring east of the Rocky mountains in association with Atlantic Basin tropical cyclones*. Mon. Weather Rev. 141, 1022-1047.

Moore, B.J., Mahoney, K.M., Sukovich, E.M., Cifelli, R., Hamill, T.M., 2015. Climatology and environmental characteristics of extreme precipitation events in the Southeastern United States. Mon. Weather Rev. 143, 718-741.

Morin, E., Yakir, H., 2014. Hydrological impact and potential flooding of convective rain cells in a semi-arid environment. Hydrol. Sci. J. 59, 1353-1362.

Moseley, C., Hohenegger, C., Berg, P., Haerter, J.O., 2016. Intensification of convective extremes driven by cloud-cloud interaction. Nat. Geosci. 9, 748-752.

Müller, M., Kašpar, M., Matschullat, J., 2009. Heavy rains and extreme rainfall-runoff events in Central Europe from 1951 to 2002. Nat. Hazards Earth Syst. Sci. 9, 441-450.

Nastos, P.T., Karavana Papadimoua, K., Matsangouras, I.T., 2018. Mediterranean tropicallike cyclones: impacts and composite daily means and anomalies of synoptic patterns. Atmos. Res. 208, 156-166.

Neiman, P.J., Ralph, F.M., Moore, B.J., Hughes, M., Mahoney, K., Cordeira, J.M., Dettinger, M.D., 2013. The landfall and inland penetration of a flood-producing atmospheric river in Arizona. Part I: Observed synoptic-scale, orographic, and hydrometerorological characteristics. J. Hydrometeorol. 14, 460-484.

Nicolaides, K., Orphanou, A., Savvidou, K., Michaelides, S., Tsitouri, M., 2010. The cold frontal depression that affected the area of Cyprus between 28 and 29 January 2008. Nat. Hazards Earth Syst. Sci. 10, 1913-1925.

Nissen, K.M., Ulbrich, U., 2017. Increasing frequencies and changing characteristics of heavy precipitation events threatening infrastructure in Europe under climate change. Nat. Hazards Earth Syst. Sci. 17, 1177-1190.

Ntelekos, A.A., Smith, J.A., Baeck, M.L., Krajewski, W.F., Miller, A.J., Goska, R., 2008. Extreme hydrometeorological events and the urban environment: Dissecting the 7 July 2004 thunderstorm over the Baltimore MD Metropolitan Region. Water Resour. Res. $44 \mathrm{n} / \mathrm{a}-\mathrm{n} / \mathrm{a}$.

Nugent, A.D., Rios-Berrios, R., 2018. Factors leading to extreme precipitation on dominica from tropical storm Erika (2015). Mon. Weather Rev. 146, 525-541.

Nuissier, O., Ducrocq, V., Ricard, D., Lebeaupin, C., Anquetin, S., 2008. A numerical study of three catastrophic precipitating events over southern France. I: Numerical framework and synoptic ingredients. Q. J. R. Meteorol. Soc. 134, 111-130.

Nuissier, O., Joly, B., Joly, A., Ducrocq, V., Arbogast, P., 2011. A statistical downscaling to identify the large-scale circulation patterns associated with heavy precipitation events over southern France. Q. J. R. Meteorol. Soc. 137, 1812-1827.

O'Gorman, P.A., 2015. Precipitation extremes under climate change. Curr. Clim. Chang. Rep. 1, 49-59.

O'Gorman, P.A., Schneider, T., 2009. The physical basis for increases in precipitation extremes in simulations of 21st-century climate change. Proc. Natl. Acad. Sci. 106, 14773-14777.

Pan, J., Teng, D., Zhang, F., Zhou, L., Luo, L., Weng, Y., Zhang, Y., 2018. Dynamics of Local Extreme Rainfall of Super Typhoon Soudelor ( 2015 ) in East China. 61. pp. 572-594.

Pang, H., Fu, G., 2017. Case study of potential vorticity tower in three explosive cyclones over eastern Asia. J. Atmos. Sci. 74, 1445-1454.

Panthou, G., Mailhot, A., Laurence, E., Talbot, G., 2014. Relationship between surface temperature and extreme rainfalls: a multi-time-scale and event-based analysis*. J. Hydrometeorol. 15, 1999-2011.

Park, S.K., Lee, E., 2007. Synoptic features of orographically enhanced heavy rainfall on the east coast of Korea associated with Typhoon Rusa (2002). Geophys. Res. Lett. $34,1-5$.

Parker, M.D., Johnson, R.H., 2000. Organizational modes of midlatitude mesoscale convective systems. Mon. Weather Rev. 128, 3413-3436.

Pawlina, A., 2002. No Rain Intervals Within Rain Events: Some Statistics Based on Milano Radar and Rain-Gauge Data. COST Action.

Peleg, N., Morin, E., 2012. Convective rain cells: radar-derived spatiotemporal characteristics and synoptic patterns over the eastern Mediterranean. J. Geophys. Res. $117,1-17$.

Peleg, N., Marra, F., Fatichi, S., Molnar, P., Morin, E., Sharma, A., Burlando, P., 2018. Intensification of convective rain cells at Warmer temperatures observed from highresolution weather radar data. J. Hydrometeorol. 19, 715-726.

Pelletier, G., Anctil, F., Filion, M., 2009. Characterization of 1-h rainfall temporal patterns using a Kohonen neural network: a Québec City case study. Can. J. Civ. Eng. 36,
980-990.

Pendergrass, A.G., 2018. What precipitation is extreme? Science 360, 1072-1073.

Perry, L.B., Seimon, A., Andrade-Flores, M.F., Endries, J.L., Yuter, S.E., Velarde, F., Arias, S., Bonshoms, M., Burton, E.J., Winkelmann, I.R., Cooper, C.M., Mamani, G., Rado, M., Montoya, N., Quispe, N., 2017. Characteristics of precipitating storms in Glacierized Tropical Andean Cordilleras of Peru and Bolivia. Ann. Am. Assoc. Geogr. 107, 309-322.

Peters, J.M., Schumacher, R.S., 2015. Mechanisms for organization and echo training in a flash-flood-producing mesoscale convective system. Mon. Weather Rev. 143, 1058-1085.

Pfahl, S., 2014. Characterising the relationship between weather extremes in Europe and synoptic circulation features. Nat. Hazards Earth Syst. Sci. 14, 1461-1475.

Pfahl, S., Wernli, H., 2012. Quantifying the Relevance of Cyclones for Precipitation Extremes. J. Clim. 25, 6770-6780.

Pfahl, S., Madonna, E., Boettcher, M., Joos, H., Wernli, H., 2014. Warm conveyor belts in the ERA-Interim Dataset (1979-2010). Part II: Moisture origin and relevance for precipitation. J. Clim. 27, 27-40.

Piaget, N., Froidevaux, P., Giannakaki, P., Gierth, F., Martius, O., Riemer, M., Wolf, G., Grams, C.M., 2015. Dynamics of a local Alpine flooding event in October 2011: moisture source and large-scale circulation. Q. J. R. Meteorol. Soc. 141, 1922-1937.

Pinto, J.G., Ulbrich, S., Parodi, A., Rudari, R., Boni, G., Ulbrich, U., 2013. Identification and ranking of extraordinary rainfall events over Northwest Italy: the role of Atlantic moisture. J. Geophys. Res.-Atmos. 118, 2085-2097.

Pinto, J.G., Gómara, I., Masato, G., Dacre, H., Woollings, T., Caballero, R., 2014. Largescale dynamics associated with clustering of extra-tropical cyclones affecting Western Europe. Geophys. Res. Lett. 119, 13704-13719.

Piotrowski, P., 2017. Moisture and circulation conditions during heavy precipitation events in łódź. Geogr. Pol. 90, 81-92.

Piper, D., Kunz, M., Ehmele, F., Mohr, S., Mühr, B., Kron, A., Daniell, J., 2016. Exceptional sequence of severe thunderstorms and related flash floods in May and June 2016 in Germany - Part 1: Meteorological background. Nat. Hazards Earth Syst. Sci. 16, 2835-2850.

Pontrelli, M.D., Bryan, G., Fritsch, J.M., 1999. The Madison County, Virginia, Flash Flood of 27 June 1995. Weather Forecast. 14, 384-404.

Porcú, F., Caracciolo, C., Prodi, F., 2003. Cloud systems leading to flood events in Europe: an overview and classification. Meteorol. Appl. 10, 217-227.

Prat, O.P., Nelson, B.R., 2016. On the link between tropical cyclones and daily rainfall extremes derived from global satellite observations. Climate 29, 6127-6135.

Ragone, F., Mariotti, M., Parodi, A., von Hardenberg, J., Pasquero, A., 2018. A climatological study of Western Mediterranean Medicanes in numerical simulations with explicit and parameterized convection. Atmosphere 9, 1-16.

Ralph, F.M., Neiman, P.J., Wick, G.A., Gutman, S.I., Dettinger, M.D., Cayan, D.R., White, A.B., 2006. Flooding on California's Russian river: role of atmospheric rivers. Geophys. Res. Lett. 33, 1-5.

Ramis, C., Arús, J., López, J.M., Mestres, A.M., 1997. Two cases of severe weather in Catalonia (Spain): an observational study. Meteorol. Appl. 4, 207-217.

Ramis, C., Romero, R., Homar, V., Alonso, S., Alarcón, M., 1998. Diagnosis and numerical simulation of a torrential precipitation event in Catalonia (Spain). Meteorog. Atmos. Phys. 69, 1-21.

Ranade, A., Singh, N., 2014. Large-scale and spatio-temporal extreme rain events over India: a hydrometeorological study. Theor. Appl. Climatol. 115, 375-390.

Raveh-Rubin, S., Wernli, H., 2015. Large-scale wind and precipitation extremes in the Mediterranean: a climatological analysis for 1979-2012. Q. J. R. Meteorol. Soc. 141, 2404-2417.

Raveh-Rubin, S., Wernli, H., 2016. Large-scale wind and precipitation extremes in the Mediterranean: dynamical aspects of five selected cyclone events. Q. J. R. Meteorol. Soc. 142, 3097-3114.

Rebora, N., Ferraris, L., 2006. The structure of convective rain cells at mid-latitudes. Adv. Geosci. 7, 31-35.

Reif, D.W., Bluestein, H.B., 2017. A 20-year climatology of nocturnal convection initiation over the Central and Southern Great Plains during the warm season. Mon. Weather Rev. 145, 1615-1639.

Renard, F., 2017. Local influence of south-east France topography and land cover on the distribution and characteristics of intense rainfall cells. Theor. Appl. Climatol. 128, 393-405.

Ricard, D., Ducroca, V., Auger, L., 2012. A climatology of the mesoscale environment associated with heavily precipitating events over a northwestern Mediterranean area. J. Appl. Meteorol. Climatol. 51, 468-488.

Rigo, T., Llasat, M.C., 2004. A methodology for the classification of convective structures using meteorological radar: application to heavy rainfall events on the Mediterranean coast of the Iberian Peninsula. Nat. Hazards Earth Syst. Sci. 4, 59-68.

Rigo, T., Pineda, N., Bech, J., 2010. Analysis of warm season thunderstorms using an object-oriented tracking method based on radar and total lightning data. Nat. Hazards Earth Syst. Sci. 10, 1881-1893.

Rios Gaona, M.F., Villarini, G., Zhang, W., Vecchi, G.A., 2018. The added value of IMERG in characterizing rainfall in tropical cyclones. Atmos. Res. 209, 95-102.

Roberge, A., Gyakum, J.R., Atallah, E.H., 2009. Analysis of intense poleward water vapor transports into high latitudes of Western North America. Weather Forecast. 24, $1732-1747$.

Rudari, R., Entekhabi, D., Roth, G., 2005. Large-scale atmospheric patterns associated with mesoscale features leading to extreme precipitation events in Northwestern Italy. Adv. Water Resour. 28, 601-614.

Russell, A., Vaughan, G., Norton, E.G., 2012. Large-scale potential vorticity anomalies and deep convection. Q. J. R. Meteorol. Soc. 138, 1627-1639.

Ryu, Y.-H., Smith, J.A., Bou-Zeid, E., Baeck, M.L., 2016. The influence of land surface heterogeneities on heavy convective rainfall in the Baltimore-Washington 
Metropolitan area. Mon. Weather Rev. 144, 553-573.

Schlemmer, L., Hohenegger, C., 2014. The formation of wider and deeper clouds as a result of cold-pool dynamics. J. Atmos. Sci. 71, 2842-2858.

Schlemmer, L., Martius, O., Sprenger, M., Schwierz, C., Twitchett, A., 2010. Disentangling the forcing mechanisms of a heavy precipitation event along the Alpine South side using potential vorticity inversion. Mon. Weather Rev. 138, 2336-2353.

Schroeer, K., Kirchengast, G., 2018. Sensitivity of extreme precipitation to temperature: the variability of scaling factors from a regional to local presepctive. Clim. Dyn. 50, 3981-3994.

Schumacher, R.S., 2009. Mechanisms for quasi-stationary behavior in simulated heavyrain-producing convective systems. J. Atmos. Sci. 66, 1543-1568.

Schumacher, R.S., 2015. Sensitivity of precipitation accumulation in elevated convective systems to small changes in low-level moisture. J. Atmos. Sci. 72, 2507-2524.

Schumacher, R.S., Johnson, R.H., 2005. Organization and environmental properties of extreme-rain-producing mesoscale convective systems. Mon. Weather Rev. 133, 961-976.

Schumacher, R.S., Johnson, R.H., 2006. Characteristics of U.S. extreme rain events during 1999-2003. Weather Forecast. 21, 69-85.

Schumacher, R.S., Johnson, R.H., 2008. Mesoscale processes contributing to extreme rainfall in a midlatitude warm-season flash flood. Mon. Weather Rev. 136, 3964-3986.

Schumacher, R.S., Johnson, R.H., 2009. Quasi-stationary, extreme-rain-producing convective systems associated with midlevel cyclonic circulations. Weather Forecast. 24, $555-574$.

Schumacher, R.S., Peters, J.M., 2017. Near-surface thermodynamic sensitivities in simulated extreme-rain-producing mesoscale convective systems. Mon. Weather Rev. 145, 2177-2200.

Schumacher, R.S., Galarneau, T.J., Bosart, L.F., 2011. Distant effects of a recurving tropical cyclone on rainfall in a midlatitude convective system: a high-impact predecessor rain event. Mon. Weather Rev. 139, 650-667.

Schumacher, R.S., Clark, A.J., Xue, M., Kong, F., 2013. Factors influencing the development and maintenance of nocturnal heavy-rain-producing convective systems in a storm-scale ensemble. Mon. Weather Rev. 141, 2778-2801.

Shaw, S.B., Royem, A.A., Riha, S.J., 2011. The Relationship between Extreme Hourly Precipitation and Surface Temperature in Different Hydroclimatic Regions of the United States. Journal of Hydrometeorology 12, 319-325.

Shin, C., Lee, T.Y., 2005. Development mechanisms for the heavy rainfalls of 6-7 August 2002 over the middle of the Korean peninsula. J. Meteorol. Soc. Jpn. 83, 683-709.

Singh, M.S., O'Gorman, P.A., 2014. Influence of microphysics on the scaling of precipitation extremes with temperature. Geophys. Res. Lett. 41, 6037-6044.

Smith, E.A., Xiang, X., Mugnai, A., Tripoli, G.J., 1994a. Design of an inversion-based precipitation proflie retrieval algorithm using an explicit cloud model for initial guess microphysics. Meteorog. Atmos. Phys. 54, 53-78.

Smith, J.A., Bradley, A.A., Baeck, M.L., 1994b. The space-time structure of extreme storm rainfall in the Southern Plains. J. Appl. Meteorol. 33, 1402-1417.

Smith, J.A., Baeck, M.L., Steiner, M., Miller, A.J., 1996. Catastrophic rainfall from an upslope thunderstorm in the central Appalachians: the Rapidan Storm of June 27, 1995. Water Resour. Res. 32, 3099-3113.

Smith, J.A., Baeck, M.L., Morrison, J.E., Sturdevant-Rees, P., 2000. Catastrophic rainfall and flooding in Texas. J. Hydrometeorol. 1, 5-25.

Smith, J.A., Baeck, M.L., Zhang, Y., Doswell, C.A., 2001. Extreme rainfall and flooding from supercell thunderstorms. J. Hydrometeorol. 2, 469-489.

Smith, J.A., Sturdevant-Rees, P., Baeck, M.L., Larsen, M.C., 2005a. Tropical cyclones and the flood hydrology of Puerto Rico. Water Resources Research 41 n/a-n/a.

Smith, R.B., Barstad, I., Bonneau, L., 2005b. Orographic precipitation and Oregon's climate transition. J. Atmos. Sci. 62, 177-191.

Smith, R.B., Schafer, P., Kirshbaum, D.J., Regina, E., 2009. Orographic precipitation in the tropics: experiments in dominica. J. Atmos. Sci. 66, 1698-1716.

Smith, D.M., Eade, R., Dunstone, N.J., Fereday, D., Murphy, J.M., Pohlmann, H., Scaife, A.A., 2010. Skilful multi-year predictions of Atlantic hurricane frequency. Nat. Geosci. 3, 846 .

Smith, D.M., Scaife, A.A., Boer, G.J., Caian, M., Doblas-Reyes, F.J., Guemas, V., Hawkins, E., Hazeleger, W., Hermanson, L., Ho, C.K., Ishii, M., Kharin, V., Kimoto, M., Kirtman, B., Lean, J., Matei, D., Merryfield, W.J., Müller, W.A., Pohlmann, H., Rosati, A., Wouters, B., Wyser, K., 2013a. Real-time multi-model decadal climate predictions. Clim. Dyn. 41, 2875-2888.

Smith, J.A., Baeck, M.L., Villarini, G., Krajewski, W.F., 2010b. The hydrology and hydrometeorology of flooding in the Delaware River Basin. Journal of Hydrometeorology 11, 841-859.

Smith, J.A., Baeck, M.L., Villarini, G., Wright, D.B., Krajewski, W., 2013b. Extreme flood response: the June 2008 flooding in Iowa. J. Hydrometeorol. 14, 1810-1825.

Smith, B.K., Smith, J., Baeck, M.L., 2016. Flash flood-producing storm properties in a small urban watershed. J. Hydrometeorol. 17, 2631-2647.

Sodemann, H., Stohl, A., 2013. Moisture origin and meridional transport in atmospheric rivers and their association with multiple cyclones. Mon. Weather Rev. 141, $2850-2868$.

Sodemann, H., Wernli, H., Schwierz, C., 2009. Sources of water vapour contributing to the Elbe flood in August 2002 - a tagging study in a mesoscale model. Q. J. R. Meteorol. Soc. 135, 205-223.

Sohn, B.J., Ryu, G.-H., Song, H.-J., Ou, M.-L., 2013. Characteristic features of warm-type rain producing heavy rainfall over the Korean Peninsula inferred from TRMM measurements. Mon. Weather Rev. 141, 3873-3888.

Sow, K.S., Juneng, L., Tangang, F.T., Hussin, A.G., Mahmud, M., 2011. Numerical simulation of a severe late afternoon thunderstorm over Peninsular Malaysia. Atmos. Res. 99, 248-262.

Speer, M.S., Leslie, L.M., 2000. A comparison of five flood rain events over the new south
Wales north coast and a case study. Int. J. Climatol. 20, 543-563.

Stevenson, S.N., Schumacher, R.S., 2014. A 10-year survey of extreme rainfall events in the Central and Eastern United States using gridded multisensor precipitation analyses. Mon. Weather Rev. 142, 3147-3162.

Sun, W., Li, J., Yu, R., Yuan, W., 2015. Two major circulation structures leading to heavy summer rainfall over central North China. J. Geophys. Res.-Atmos. 120, 4466-4482.

Tang, Y., Gan, J., Zhao, L., Gao, K., 2006. On the climatology of persistent heavy rainfall events in China. Adv. Atmos. Sci. 23, 678-692.

Terranova, O.G., Gariano, S.L., 2014. Rainstorms able to induce flash floods in a Mediterranean-climate region (Calabria, southern Italy). Nat. Hazards Earth Syst. Sci. $14,2423-2434$.

Terranova, O.G., Iaquinta, P., 2011. Temporal properties of rainfall events in Calabria (southern Italy). Natural Hazards and Earth System Sciences 11, 751-757.

Teufel, B., Diro, G.T., Whan, K., Milrad, S.M., Jeong, D.I., Ganji, A., Huziy, O., Winger, K., Gyakum, J.R., de Elia, R., Zwiers, F.W., Sushama, L., 2017. Investigation of the 2013 Alberta flood from weather and climate perspectives. Clim. Dyn. 48, 2881-2899.

Thorndahl, S., Smith, J.A., Baeck, M.L., Krajewski, W.F., 2014. Analyses of the temporal and spatial structures of heavy rainfall from a catalog of high-resolution radar rainfall fields. Atmos. Res. 144, 111-125.

Tokay, A., Short, D.A., 1996. Evidence from tropical raindrop spectra of the origin of rain from stratiform versus convective clouds. J. Appl. Meteorol. 35, 355-371.

Tompkins, A.M., 2001. Organization of tropical convection in low vertical wind shears: the role of Cold Pools Journal of the Atmospheric Sciences 2001 58: 1650-1672. J. Atmos. Sci. 58, 1650-1672.

Toreti, A., Giannakaki, P., Martius, O., 2016. Precipitation extremes in the Mediterranean region and associated upper-level synoptic-scale flow structures. Clim. Dyn. 47, 1925-1941.

Torri, G., Kuang, Z., Tian, Y., 2015. Mechanisms for convection triggering by cold pools. Geophys. Res. Lett. 42 1943-1650.

Tous, M., Romero, R., 2013. Meteorological environments associated with medicane development. Int. J. Climatol. 33, 1-14.

Tous, M., Romero, R., Ramis, C., 2013. Surface heat fluxes influence on medicane trajectories and intensification. Atmos. Res. 123, 400-411.

Trenberth, K.E., 1998. Atmospheric moisture residence times and cycling: implications for rainfall rates and climate change. Clim. Chang. 39, 667-694.

Trenberth, K.E., 1999. Conceptual framework for changes of extremes of the hydrological cycle with climate change. In: Karl, T.R., Nicholls, N., Ghazi, A. (Eds.), Weather and Climate Extremes: Changes, Variations and a Perspective from the Insurance Industry. Springer Netherlands, Dordrecht, pp. 327-339.

Trenberth, K.E., 2011. Changes in precipitation with climate change. Clim. Res. 47, 123-138.

Trenberth, K.E., Dai, A., Rasmussen, R.M., Parsons, D.B., 2003. The changing character of precipitation. Bull. Am. Meteorol. Soc. 84, 1205-1217.

Trier, S.B., Davis, C.A., Ahijevych, D.A., 2010. Environmental controls on the simulated diurnal cycle of warm-season precipitation in the continental United States. J. Atmos. Sci. 67, 1066-1090.

Tu, C.-C., Chen, Y.-L., Chen, C.-S., Lin, P.-L., Lin, P.-H., 2014. A comparison of two heavy rainfall events during the terrain-influenced monsoon rainfall experiment (TiMREX) 2008. Mon. Weather Rev. 142, 2436-2463.

Tu, C.-C., Chen, Y.-L., Chen, S.-Y., Kuo, Y.-H., Lin, P.-L., 2017. Impacts of including rainevaporative cooling in the initial conditions on the prediction of a coastal heavy rainfall event during TiMREX. Mon. Weather Rev. 145, 253-277.

Tudurí, E., Ramis, C., 1997. The environments of significant convective events in the Western Mediterranean. Weather Forecast. 12, 294-306.

Tuttle, J.D., Davis, C.A., 2006. Corridors of warm season precipitation in the Central United States. Mon. Weather Rev. 134, 2297-2317.

Uebel, M., Bott, A., 2015. Mesoscale air transport at a midlatitude squall line in Europe - a numerical analysis. Q. J. R. Meteorol. Soc. 141, 3297-3311.

Ulbrich, U., Brucher, T., Fink, A.H., Leckebusch, G.C., Kriger, A., Pinto, J.G., 2003. The central European floods of August 2002: Part 2 - Synoptic causes and considerations with respect to climatic change. Weather $58,434-442$.

Ullah, K., Shouting, G., 2013. A diagnostic study of convective environment leading to heavy rainfall during the summer monsoon 2010 over Pakistan. Atmos. Res. 120-121, 226-239.

Unuma, T., Takemi, T., 2016. Characteristics and environmental conditions of quasistationary convective clusters during the warm season in Japan. Q. J. R. Meteorol. Soc. $142,1232-1249$.

Utsumi, N., Seto, S., Kanae, S., Maeda, E.E., Oki, T., 2011. Does higher surface temperature intensify extreme precipitation? Geophys. Res. Lett. 38 n/a-n/a.

Vera, C.S., Vigliarolo, P.K., Berbery, E.H., 2002. Cold season synoptic-scale waves over subtropical South America. Mon. Weather Rev. 130, 684-699.

Vilar, E., Burgueño, A., 1995. Statistical properties of 49 years of rainfall rate events. Theor. Appl. Climatol. 50, 213-225.

Villarini, G., Smith, J.A., Baeck, M.L., Marchok, T., Vecchi, G.A., 2011. Characterization of rainfall distribution and flooding associated with U.S. landfalling tropical cyclones: Analyses of Hurricanes Frances, Ivan, and Jeanne (2004). J. Geophys. Res.-Atmos. $116 \mathrm{n} / \mathrm{a}-\mathrm{n} / \mathrm{a}$.

Villarini, G., Lavers, D.A., Scoccimarro, E., Zhao, M., Wehner, M.F., Vecchi, G.A., Knutson, T.R., Reed, K.A., 2014. Sensitivity of tropical cyclone rainfall to idealized global-scale forcings. J. Clim. 27, 4622-4641.

Wang, B., Chan, J.C., 2002. How strong ENSO events affect tropical storm activity over the Western North Pacific. J. Clim. 15, 1643-1658.

Wang, Gu, W., 2016. The Eastern China flood of June 2015 and its causes. Chin. Sci. Bull. 61, 178-184.

Wang, Y., Wang, Y., Fudeyasu, H., 2009. The role of Typhoon Songda (2004) in producing distantly located heavy rainfall in Japan*. Mon. Weather Rev. 137, 3699-3716. 
Wang, C.-C., Chen, G.T.-J., Huang, H.-L., Carbone, R.E., Chang, S.-W., 2012. Synoptic conditions associated with propagating and nonpropagating cloud/rainfall episodes during the warm season over the East Asian continent. Mon. Weather Rev. 140, $722-747$.

Wang, H., Luo, Y., Jou, B.J.-D., 2014c. Initiation, maintenance, and properties of convection in an extreme rainfall event during SCMREX: Observational analysis. J. Geophys. Res.-Atmos. 119, 13,206-213,232.

Wang, C.-C., Hsu, J.C.-S., Chen, G.T.-J., Lee, D.-I., 2014a. A study of two propagating heavy-rainfall episodes near Taiwan during SoWMEX/TiMREX IOP-8 in June 2008. Part I: Synoptic evolution, episode propagation, and model control simulation. Mon, Weather Rev. 142, 2619-2643.

Wang, C.-C., Hsu, J.C.-S., Chen, G.T.-J., Lee, D.-I., 2014b. A study of two propagating heavy-rainfall episodes near Taiwan during SoWMEX/TiMREX IOP-8 in June 2008 . Part II: sensitivity tests on the roles of synoptic conditions and topographic effects. Mon. Weather Rev. 142 26344-2664.

Wang, H., Luo, Y., Zhang, R., 2015a. Synoptic pattern and severe weather associated with the wide convection over Southeast China during the summer monsoon period. J. Meteorol. Res. 29, 41-58.

Wang, C.-C., Kuo, H.-C., Johnson, R.H., Huang, S.-Y., Chen, Y.-H., 2015b. A numerical study of convection in rainbands of Typhoon Morakot (2009) with extreme rainfall: roles of pressure perturbations with low-level wind maxima. Atmos. Chem. Phys. 15, 11097-11115.

Wang, G., Wang, D., Trenberth, K.E., Erfanian, A., Yu, M., Bosilovich, Michael G., Parr, D.T., 2017. The peak structure and future changes of the relationships between extreme precipitation and temperature. Nat. Clim. Chang. 7, 268.

Warner, M.D., Mass Jr., C.F., Salathé, E.P., 2012. Wintertime extreme precipitation events along the Pacific Northwest Coast: climatology and synoptic evolution. Monthly Weather Review 140, 2021-2043.

Warren, R.A., Kirshbaum, D.J., Plant, R.S., Lean, H.W., 2014. A 'Boscastle-type' quasistationary convective system over the UK Southwest Peninsula. Q. J. R. Meteorol. Soc. $140,240-257$.

Wasko, C., Sharma, A., Johnson, F., 2015. Does storm duration modulate the extreme precipitation-temperature scaling relationship? Geophys. Res. Lett. 42, 8783-8790.

Wasko, C., Sharma, A., Westra, S., 2016. Reduced spatial extent of extreme storms at higher temperatures. Geophys. Res. Lett. 43, 4026-4032.

Weisman, M.L., Rotunno, R., 2004. "A theory for strong long-lived squall lines" revisited. J. Atmos. Sci. 61, 361-382.

Weisman, M.L., Trapp, R.J., 2003. Low-level mesovortices within squall lines and bow echoes. Part I: Overview and dependence on environmental shear. Mon. Weather Rev. 131, 2779-2803.

Westra, S., Fowler, H.J., Evans, J.P., Alexander, L.V., Berg, P., Johnson, F., Kendon, E.J., Lenderink, G., Roberts, N.M., 2014. Future changes to the intensity and frequency of short-duration extreme rainfall. Rev. Geophys. 52, 522-555.

White, B.A., Blyth, A.M., Marsham, J.H., 2016. Simulations of an observed elevated mesoscale convective system over southern England during CSIP IOP 3. Q. J. R. Meteorol. Soc. 142, 1929-1947.

Winschall, A., Sodermann, H., Pfahl, S., Wernli, H., 2014. How important is intensified evaporation for Mediterranean precipitation extremes? J. Geophys. Res.-Atmos. 119, $5240-5256$.

Observation of present and past weather; state of the ground. Part1 1, Chapter 14, WMOno 8 In: WMO (Ed.), Guide to Meteorologiical Instruments and Methods of Observation, 7 ed. WMO.

Wu, D., Zhao, X., Liang, S., Zhou, T., Huang, K., Tang, B., Zhao, W., 2015a. Time-lag effects of global vegetation responses to climate change. Glob. Chang. Biol. 21, 3520-3531.

Wu, M., Lam, H., Li, K., 2015b. Characterization and indexing of heavy rainstorms in Hong Kong. Meteorol. Appl. 22, 25-36.

Xie, B., Zhang, F., 2012. Impacts of Typhoon Track and Island topography on the heavy rainfalls in Taiwan associated with Morakot (2009). Mon. Weather Rev. 140, 3379-3394.

Xing, R., Ding, Z., Jou, S., Xu, H., 2016. Relationship of tropical-cyclone-induced remote precipitation with tropical cyclones and the subtropical high. Front. Earth Sci. 10, 595-606.
Xu, X., Lu, C., Xu, H., Chen, L., 2011. A possible mechanism responsible for exceptional rainfall over Taiwan from Typhoon Morakot. Atmos. Sci. Lett. 12, 294-299.

Yamoto, M., 2012. Rapid merger and recyclogenesis of twin extratropical cyclones leading to heavy precipitation around Japan on 9-10 October 2001. Meteorol. Appl. 19, 36-53.

Yang, M., Braun, S.A., Chen, D., 2011. Water budget of Typhoon Nari (2001). Mon. Weather Rev. 139, 3809-3828.

Yang, L., Smith, J.A., Wright, D.B., Baeck, M.L., Villarini, G., Tian, F., Hu, H., 2013 Urbanization and climate change: an examination of nonstationarities in urban flooding. J. Hydrometeorol. 14, 1791-1809.

Yang, L., Liu, M., Smith, J.A., Tian, F., 2017a. Typhoon Nina and the August 1975 flood over Central China. J. Hydrometeorol. 18, 451-472.

Yang, L., Smith, J.A., Baeck, M.L., Bou-Zeid, E., Jessup, S.M., Tian, F., Hu, H., 2014a Impact of urbanization on heavy convective precipitation under strong large-scale forcing: a case study over the Milwaukee-Lake Michigan region. J. Hydrometeorol. 15, 261-278.

Yang, L., Tian, F., Smith, J.A., Hu, H., 2014b. Urban signatures in the spatial clustering of summer heavy rainfall events over the Beijing metropolitan region. J. Geophys. Res.Atmos. 119, 1203-1217.

Yang, L., Smith, J., Baeck, M.L., Morin, E., Goodrich, D.C., 2017b. Flash flooding in arid/ semi-arid regions: dissecting the hydrometeorology and hydrology of the 19 August 2014 storm and flood hydroclimatology in Arizona. J. Hydrometeorol. 18, 3103-3123.

Yang, L., Smith, J., Baeck, M.L., Smith, B., Tian, F., Niyogi, D., 2016. Structure and evolution of flash flood producing storms in a small urban watershed. J. Geophys. Res.-Atmos. 121, 3139-3152.

You, C.H., Lee, D.I., Jang, S.M., Jang, M., Uyeda, H., Shinoda, T., Kobayashi, F., 2010. Characteristics of rainfall systems accompanied with Changma front at Chujado in Korea. Asia-Pac. J. Atmos. Sci. 46, 41-51.

Yu, Z.-G., Leung, Y., Chen, Y.D., Zhang, Q., Anh, V., Zhou, Y., 2014. Multifractal analyses of daily rainfall time series in Pearl River basin of China. Physica A 405, 193-202.

Yu, W., Nakakita, E., Kim, S., Yamaguchi, K., 2015. Improvement of rainfall and flood forecasts by blending ensemble NWP rainfall with radar prediction considering orographic rainfall. J. Hydrol. 531, 494-507.

Zhang, Y., Smith, J.A., 2003. Space-time variability of rainfall and extreme flood response in the Menomonee River Basin, Wisconsin. J. Hydrometeorol. 4, 506-517.

Zhang, W., Villarini, G., 2017. Heavy precipitation is highly sensitive to the magnitude of future warming. Clim. Chang. 145, 249-257.

Zhang, X.B., Hogg, W.D., Mekis, E., 2001. Spatial and temporal characteristics of heavy precipitation events over Canada. J. Clim. 14, 1923-1936.

Zhang, Y., Smith, J.A., Ntelekos, A.A., Baeck, M.L., Krajewski, W.F., Moshary, F., 2009. Structure and evolution of precipitation along a cold front in the Northeastern United States. J. Hydrometeorol. 10, 1243-1256.

Zhang, Y., Cassardo, C., Ye, C., Galli, M., Vela, N., 2011. The role of the land surface processes in the rainfall generated by a landfall typhoon: a simulation of the typhoon Sepat (2007). Asia-Pac. J. Atmos. Sci. 47, 63-77.

Zhang, Q., Gu, X., Li, J., Shi, P., Singh, V.P., 2018. The impact of tropical cyclones on extreme precipitation over coastal and Inland Areas of China and its association to ENSO. J. Clim. 31, 1865-1880.

Zheng, L., Sun, J., Zhang, X., Liu, C., 2013. Organizational modes of mesoscale convective systems over Central East China. Weather Forecast. 28, 1081-1098.

Zhou, Y., Lau, W.K.M., Liu, C., 2013. Rain characteristics and large-scale environments of precipitation objects with extreme rain volumes from TRMM observations. J. Geophys. Res.-Atmos. 118, 9673-9689.

Zhu, Y., Newell, R.E., 1994. Atmospheric rivers and bombs. Geophys. Res. Lett. 21, 1999-2002.

Zhu, Y., Newell, R.E., 1998. A proposed algorithm for moisture fluxes from atmospheric rivers. Mon. Weather Rev. 126, 725-735.

Zolina, O., Simmer, C., Gulev, S.K., Kollet, S., 2010. Changing structure of European precipitation: longer wet periods leading to more abundant rainfalls. Geophys. Res. Lett. 37, 1-5.

Zolina, O., Simmer, C., Belyaev, K., Koltermann, P., 2013. Changes in the duration of European wet and dry spells during de last 60 years. J. Clim. 26, 2022-2047. 